Portland State University

PDXScholar

Winter 3-15-2013

\title{
Evaluating the Effects of Road Crossing Structures on Stream-Associated Amphibians in the Wilson River Watershed, Tillamook State Forest, Oregon
}

Sara Erin Twitchell

Portland State University

Follow this and additional works at: https://pdxscholar.library.pdx.edu/open_access_etds

Part of the Aquaculture and Fisheries Commons, Other Forestry and Forest Sciences Commons, and the Terrestrial and Aquatic Ecology Commons

Let us know how access to this document benefits you.

\section{Recommended Citation}

Twitchell, Sara Erin, "Evaluating the Effects of Road Crossing Structures on Stream-Associated Amphibians in the Wilson River Watershed, Tillamook State Forest, Oregon" (2013). Dissertations and Theses. Paper 678.

https://doi.org/10.15760/etd. 678

This Thesis is brought to you for free and open access. It has been accepted for inclusion in Dissertations and Theses by an authorized administrator of PDXScholar. Please contact us if we can make this document more accessible: pdxscholar@pdx.edu. 
Evaluating the Effects of Road Crossing Structures on Stream-Associated Amphibians in the Wilson River Watershed,

Tillamook State Forest, Oregon

by

Sara Erin Twitchell

A thesis submitted in partial fulfillment of the requirements for the degree of

\author{
Master of Science \\ in \\ Environmental Science and Management
}

Thesis Committee:

Joseph Maser, Chair

Catherine DeRivera

Alan Yeakely

Portland State University

2013 
(C) 2012 Sara Erin Twitchell 


\begin{abstract}
As replacement and removal of undersized culverts gains momentum as an effective technique for restoring natural stream flows and removing fish passage barriers, it is important to evaluate the benefits of these efforts on the in-stream and adjacent riparian habitat for other species of potential concern. This study compares stream-associated amphibian (SAA) occurrence in streams adjacent to different road crossing structures on unpaved forest roads in the Wilson River watershed located within the Tillamook State Forest, Oregon. Surveys were conducted at road crossing structures for three taxa of SAA; Pacific giant salamander (Dicamptodon tenebrosus), coastal tailed frog (Ascaphus truei), and Columbia torrent salamander (Rhyacotriton kezeri). Statistical models were created to analyze the effect of habitat variables on SAA occupancy, and determine whether those variables changed relative to road crossing structures.
\end{abstract}

Results showed that coastal tailed frog occupancy was positively associated with dissolved oxygen and crayfish presence, negatively associated with longitude, and had a slight quadratic relationship to channel confinement. Because all sites were highly saturated with oxygen, percent dissolved oxygen was likely a surrogate for one or more other covariates, such as in-stream habitat or substrate size. Detection rates of Pacific giant salamander were too high and detection rates of Columbia torrent salamander were too low to provide reliable models, but they did provide some insight into the factors affecting occupancy in the study area, including information about their interactions with road crossing structures. Occupancy rates of Pacific giant salamanders in the study area appear to be unaffected by road crossings, fish passable or otherwise. Conversely, torrent 
salamanders seemed to be mostly absent from the study sites altogether, but based on the one stream where they were detected, they are not excluded from occupying fish barrier culvert sites.

Top weighted habitat covariates, including dissolved oxygen, channel confinement, crayfish and fish presence, and flow constriction are all indicators of disturbance that can be linked to road crossings. Although the size and structure of road crossings did not prove to significantly influence SAA occupancy, indicators of stream disturbance that can be related to road crossings were included in the best models for predicting occupancy, demonstrating the importance of reducing disturbance related to road crossings on streams. 


\section{Acknowledgements}

I would like to thank my graduate advisor, Dr. Joseph Maser for his support and guidance throughout my project. His diligence and attention to detail have helped me to form every aspect of this project into something tangible and useful. I would also like to thank my committee members Dr. Catherine DeRivera and Dr. J. Alan Yeakley for the valuable advice they have provided along the way, as well as Dr. Yangdong Pan for his continued assistance with all things statistics.

This project would not have been possible without the field efforts of the following people: Molly and Hannah Brown, Andrew Dietrich, Jodi Gronborg, Melissa Howes, Jalene Littlejohn, Donna Rupp, Danny Warren, and my delightful cousin, Julie Twitchell. Their countless volunteer hours and amazing patience helped the idea of this project become a reality. An extra special thank you is in order for Sara Viernum, a passionate herpetologist, without whom I would either still be trying to survey streams by myself or lying horribly injured somewhere in the Wilson River area. Sara took it upon herself to accompany me on countless surveys, keeping me safe while taking a genuine interest in the success of my project.

Finally, I thank my friends and family for encouraging me when I needed it most, my coworkers for their flexibility while I bounced between work and school, and everyone who has listened to me prattle on about this project for the past several years. Your perspective and counsel will continue to influence my everyday experiences. 


\section{Table of Contents}

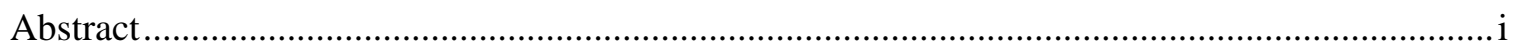

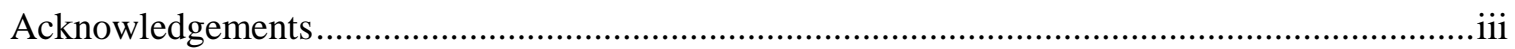

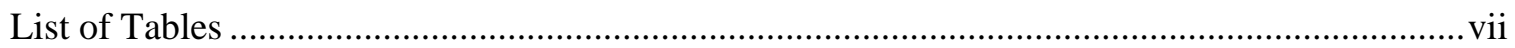

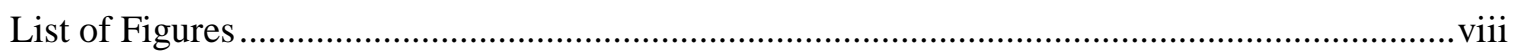

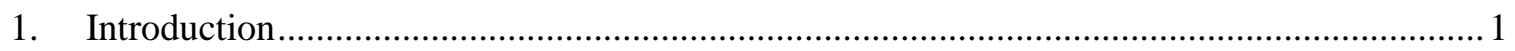

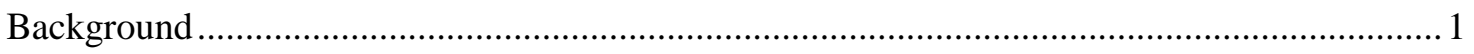

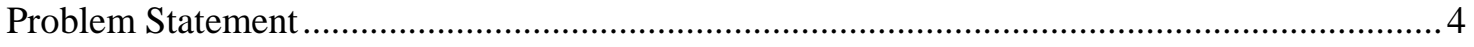

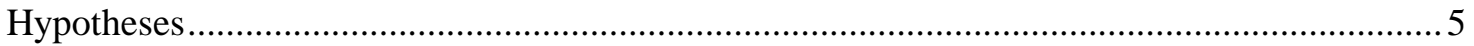

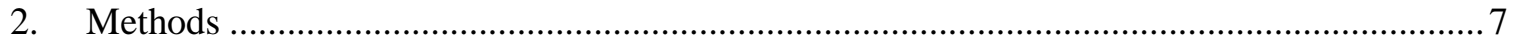

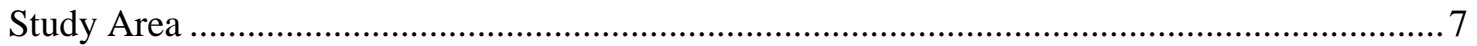

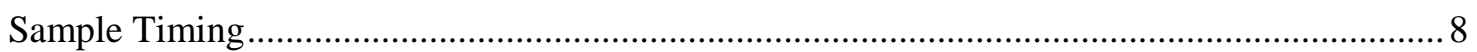

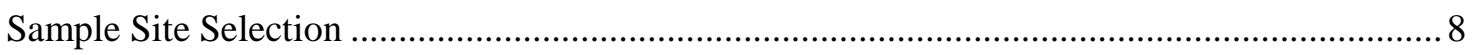

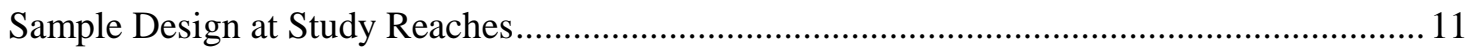

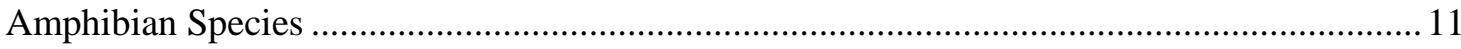

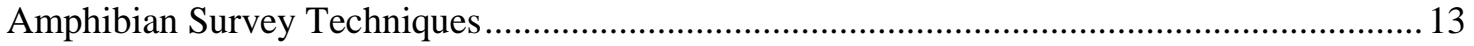

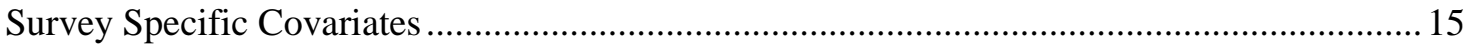

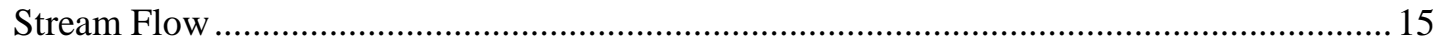

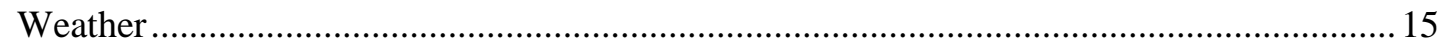

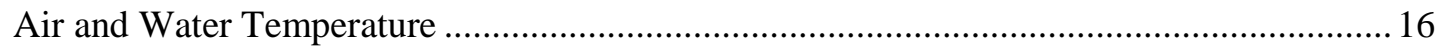

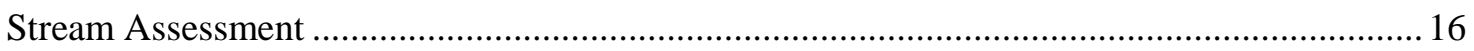

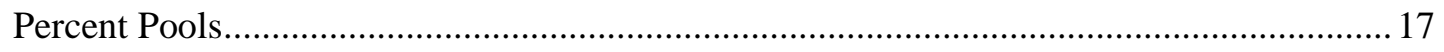

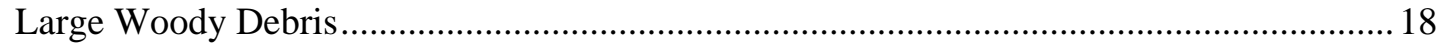

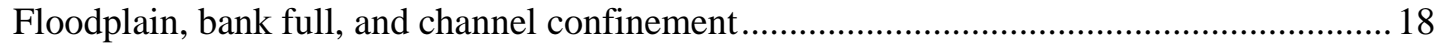

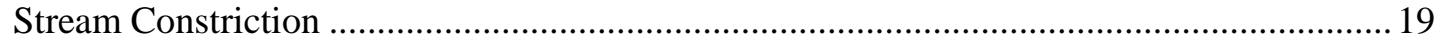

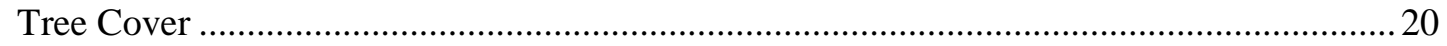

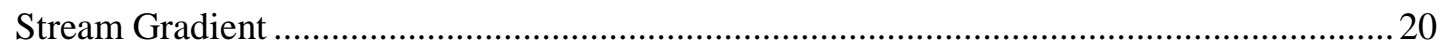

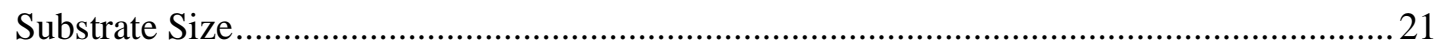

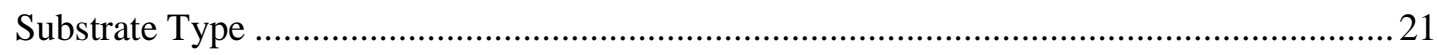

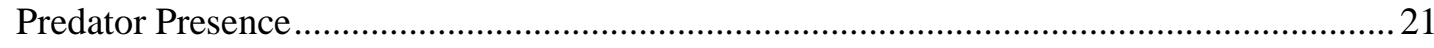

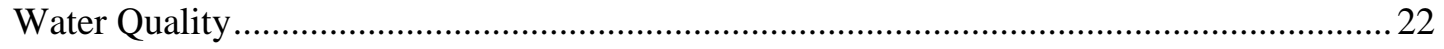

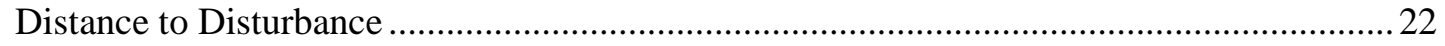


Analysis

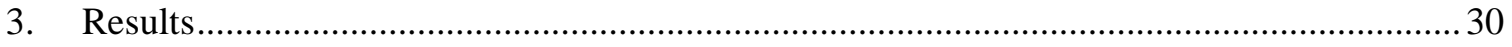

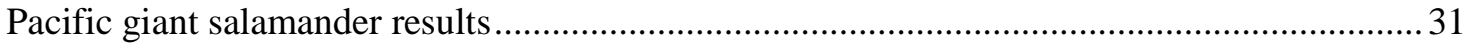

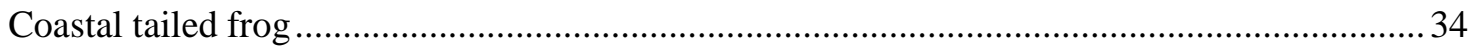

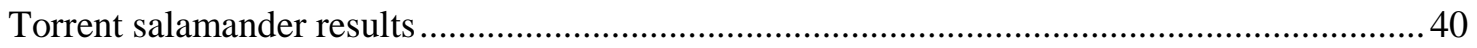

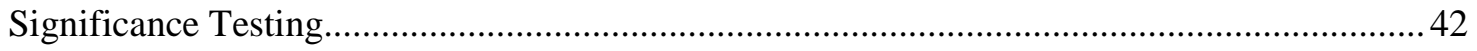

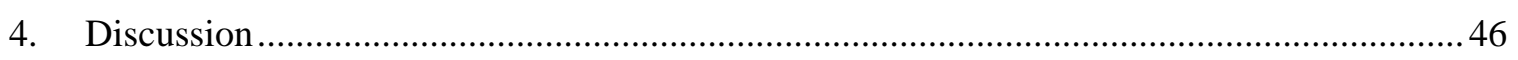

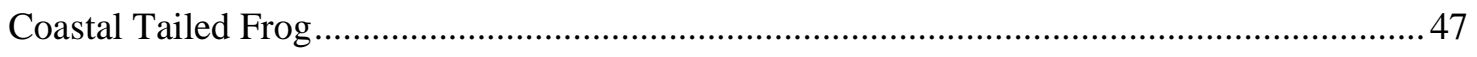

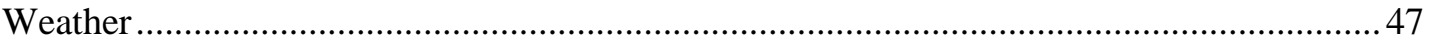

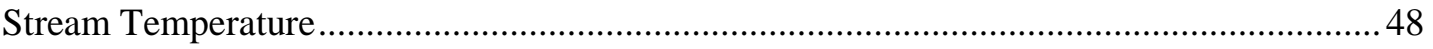

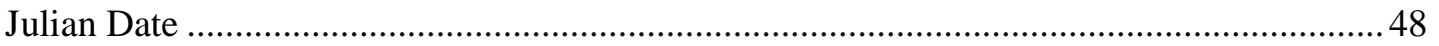

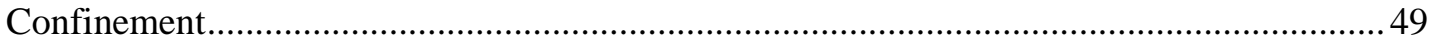

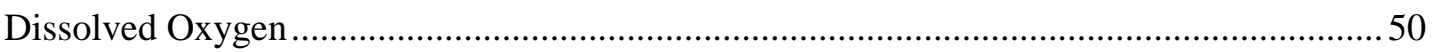

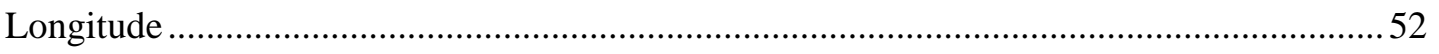

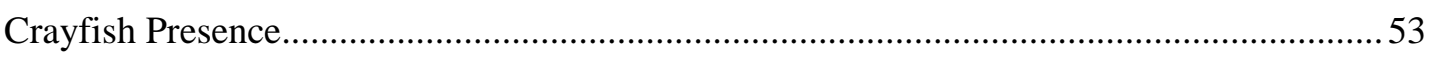

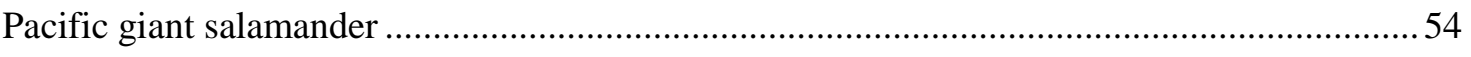

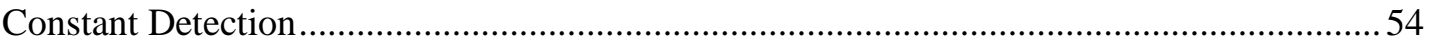

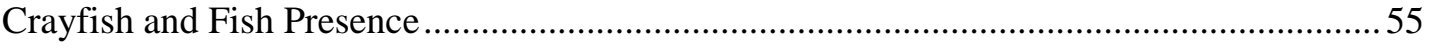

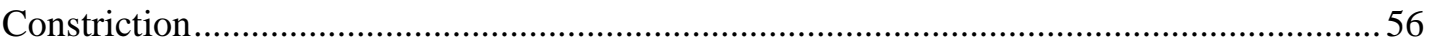

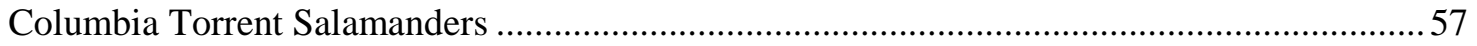

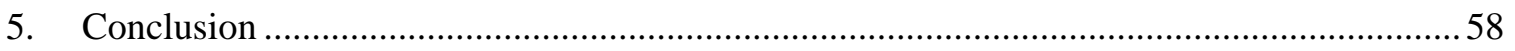

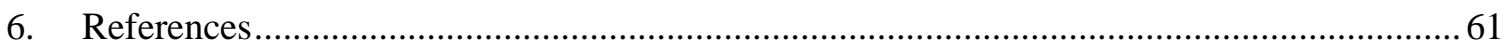

Appendix A. Representative photos of SAA found in the Wilson River watershed, Tillamook

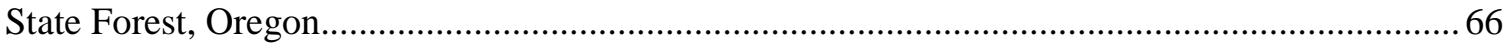

Appendix B. Descriptions and representative photos of stream reaches assessed during surveys including habitat covariates evaluated for their influence on each species' occupancy.

Appendix C. Detection results for each study species at sample reaches in the study area including abundance of individuals detected during each survey ...............................................98

Appendix D: Covariance Matrices for habitat and sampling parameters. Covariance was determined to be positive when values were greater than 0.5 and negative when values were less than -0.5. Values of all non-binomial covariates have been transformed using z-scores prior to

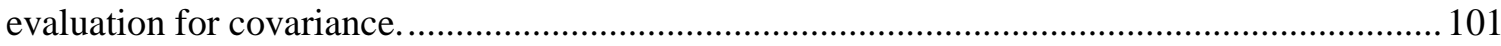

Appendix E. Highest weighted models for the Pacific giant salamander 2011 dataset. .............. 104

Appendix F. Highest weighted models for the coastal tailed frog 2010/2011 dataset................. 105 
Appendix G. Highest weighted models for the coastal tailed frog 2011 dataset. ....................... 106

Appendix H. Highest weighted models for the Columbia torrent salamander 2010/2011 dataset.

Appendix I. Linear regression analysis results for habitat covariates presumably linked to percent

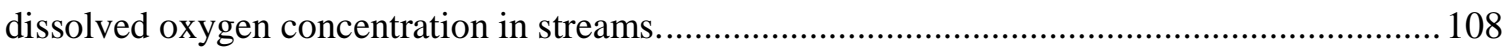




\section{List of Tables}

Table 1. Definitions of covariates used to estimate stream occupancy probabilities for Pacific giant salamander, Columbia torrent salamander, and coastal tailed frogs and the frequency with which they were measured at each study reach.

Table 2. Definition of key terms used throughout the analysis of SAA occupancy in this study.

Table 3. One way ANOVA test results comparing confinement, percent dissolved oxygen, and Longitude at upstream and downstream reaches. Longitude measurements did not vary between upstream and downstream reaches, and a comparison between stream reaches was not included in the table.

Table 4. Linear regression analysis results evaluating confinement and percent dissolved oxygen relative to different diameters and lengths of road crossing structures. 43

Table 5. ANOVA results evaluating the relationship between crayfish presence, fish presence, and flow constriction to diameter and length of crossing

Table 6. Chi-squared test results evaluating the relationship between crayfish and fish presence to upstream vs. downstream study reaches and study reaches with and without constricted flow. 


\section{List of Figures}

Figure 1. Road crossing stream sites evaluated in this study within the Wilson River System Tillamook State Forest, Oregon. Sites $1-10$ were evaluated in both 2010 and 2011, and Sites $11-14$ were only evaluated in 2011.

Figure 2. Naïve occupancy rate and estimated proportions of occupancy $(\psi)$ and detection (p) when detection and occupancy are held constant $[\psi(),.(\mathrm{p})]$ with standard error bars for species modeled using data collected at the 20 study reaches for 2010/2011 data and 28 study reaches for 2011 data.

Figure 3. Comparison of model averaged estimates of Pacific giant salamander occupancy at each study reach to null model estimates, demonstrating the difference between estimated occupancy rates that take crayfish presence and upstream/downstream study reaches into consideration and estimated occupancy rates when the influence of habitat covariates is considered constant............... 32

Figure 4. Relationship between average occupancy probability, crayfish presence (a), fish presence (b), and flow constriction (c) for Pacific giant salamanders during the 2011 sampling season. Occupancy probabilities were estimated by model averaging the top three models' estimated occupancy of individual study reaches.

Figure 5. Comparison of estimated coastal tailed frog detection rates at each study reach based on the top model for detection $[\psi(),. \mathrm{p}($ Weather $)]$ to the detection rates estimated by the null model $[\psi(),. \mathrm{p}()$.$] for each sampling occasion,$ demonstrating how detection rates vary between sampling occasions when the effect of weather is taken into account compared to the null model which assumes that detection rates were constant for all samples.

Figure 6. Comparison of model averaged estimates of coastal tailed frog occupancy at each study reach to null model estimates, demonstrating the difference between estimated occupancy rates that take dissolved oxygen, gradient, and confinement into consideration and estimated occupancy rates when the influence of habitat covariates is considered constant.

Figure 7. Relationship between occupancy probability, channel confinement, $\%$ dissolved oxygen concentration, and longitude for coastal tailed frogs during the 2010 and 2011 sampling seasons. Occupancy probabilities were estimated by model averaging the top three models' estimated occupancy of individual study reaches. Values of channel confinement and dissolved oxygen have been transformed using z-scores. 
Figure 8. Relationship between detection probability, weather conditions and stream temperature for coastal tailed frogs during the 2010 and 2011 sampling seasons. Detection probabilities were estimated for the individual study reaches using the top model for detection. Weather conditions were assigned a numerical value and both weather conditions and stream temperature were transformed using $\mathrm{z}$ scores

Figure 9. Comparison of estimated coastal tailed frog detection rates at each site based on the top model for detection $[\psi(),. \mathrm{p}($ StreamTemp)] to the detection rates estimated by the null model $[\psi(),. p()$.$] for each sampling occasion,$ demonstrating how detection rates vary between sampling occasions when the affect of stream temperature is taken into account compared to the null model which assumes that detection rates were constant for all samples.

Figure 10. Comparison of model averaged estimates of coastal tailed frog occupancy at each study reach to null model estimates, demonstrating the difference between estimated occupancy rates that take crayfish presence, dissolved oxygen, and gradient into consideration and estimated occupancy rates when the influence of habitat covariates is considered constant. ................................................. 38

Figure 11. Relationship between occupancy probability, crayfish presence and \% dissolved oxygen concentration for coastal tailed frogs during the 2011 sampling season. Occupancy probabilities were estimated by model averaging the top three models' estimated occupancy of individual study reaches. Dissolved oxygen values have been transformed using z-scores.

Figure 12. Relationship between detection rate, Julian date and stream flow for coastal tailed frogs during the 2011 sampling season. Detection rates were estimated using the model $[\psi(.) \mathrm{p}($ JDate, StreamTemp)], where occupancy was held constant. Julian date and stream flow values have been transformed using zscores

Figure 13. Comparison of estimated coastal tailed frog detection rates at each study reach based on the top model for detection $[\psi(),. \mathrm{p}($ JDate $)]$ to the detection rates estimated by the null model $[\psi(),. \mathrm{p}()$.$] for each sampling occasion,$ demonstrating how detection rates vary between sampling occasions when the affect of Julian date is taken into account compared to the null model which assumes that detection rates were constant for all samples.

Figure 14. Comparison of model averaged estimates of Columbia torrent salamander occupancy at each study reach to null model estimates, demonstrating the difference between estimated occupancy rates that take crayfish presence, fish 
presence, and fish passage into consideration and estimated occupancy rates when the influence of habitat covariates is considered constant. ..................... 41 


\section{Introduction}

The goal of this study was to contribute to the understanding of stream associated amphibians (SAA) habitat requirements, and to determine what effect, if any, different road crossing structures have on that habitat and the species that occupy it. To accomplish this, habitat conditions were evaluated in a number of similarly sized streams adjacent to road crossing structures in the Wilson River Watershed. Streams were then surveyed to determine SAA occupancy and analyzed to determine whether that occupancy was related to habitat conditions potentially impacted by road crossing structures.

\section{Background}

Amphibians are an important indicator of the overall health of an ecosystem due to their dual life histories, specialized physical adaptations, and specific habitat requirements (Welsh and Ollivier, 1998) and will often make use of the riparian corridor for habitat and/or breeding purposes (Dickerson, 2001). Amphibians span aquatic and terrestrial habitats throughout the stream system and are linked across food webs as both predator and prey (Oregon Forest Resources Institute, 2009). SAA, or stream breeding amphibians, are particularly sensitive to environmental change and may be negatively impacted by habitat changes resulting from human disturbance (Wilkins and Peterson, 2000). Many SAA larvae are highly specialized in their use of lotic habitats for both foraging and cover, making them susceptible to minor environmental changes (Welsh and Ollivier, 1998). Because SAA have partially or fully terrestrial life stages, disturbance of the adjacent riparian habitat may influence occupancy and distribution through impacts 
on reproduction, foraging, dispersal, and overwintering habitat (Stoddard and Hayes, 2005). Information obtained from observing local SAA can offer insight into how human infrastructure is affecting amphibians in general, which are rapidly declining.

One quarter of the 47 species of amphibians native to the Pacific Northwest depend on streams and the riparian environment for breeding habitat, cover, food, or all three (Oregon Forest Resources Institute, 2009). Three taxa of Pacific Northwest SAA are known to reproduce and develop into adults in the coastal streams of Oregon; Pacific giant salamander (Dicamptodon tenebrosus), Columbia torrent salamander (Rhyacotriton kezeri), and coastal tailed frogs (Ascaphus truei). All species of SAA in coastal Oregon require permanent water for their multi-year larval stages (Adams and Bury, 2002). Representative photos of each species included in this study are provided in Appendix A. Variations in stream habitat, naturally occurring or otherwise, are known to influence the populations of SAA that occupy specific stream reaches. For example, torrent salamanders are typically associated with higher gradient streams that will tend to have more cascading water with adjacent splash zones due to life history traits associated with this type of habitat (National Audubon Society, 1979). Additional factors including elevation, latitude and longitude, tree cover, and the presence or absence of potential predators such as fish and crayfish may have a less direct link to the life history of individual species, but an equally powerful influence on where they occur (Stoddard and Hayes, 2005). Range restrictions can be exacerbated by the additional influence of manmade structures or practices, further limiting the area available for SAA habitat (Bury and Corn, 1991). 
Due to its wet climate, the Pacific Northwest is crisscrossed by hundreds of thousands of streams and waterways. Freshwater streams sculpt the landscape and support aquatic and terrestrial life, including SAA. To make it possible for roads to cross the vast number of streams, culverts and bridges have become a key component of the transportation network. Because road crossings can alter the flow of streams, the size and shape of the crossing can play an important role in the overall health of the stream ecosystem.

Historically, road crossing design has focused on merely allowing water to pass, which has resulted in installation of the smallest possible pipes to minimize costs (Castro, 2003). Culverts that are too small can have negative impacts on both ecology and human safety, making them a popular target of stream restoration efforts. Culverts that are smaller than the stream width can result in problems such as plugging, sediment deposition at the inlet, and high velocity flows which can cause channel scour (Castro, 2003). Deposition of sediment upstream of a culvert can result in an unbalanced movement of sediment downstream (Wolman, 1967), limiting the formation of floodplains and restricting the flow of nutrients through the stream system. Bank erosion and plunge pools can develop at the downstream end of small culverts when flow is constricted within the barrel of the culvert, causing a turbulent jet of water at the outlet (Castro, 2003). The small barrel of the culvert paired with the deep plunge pool can effectively block fish passage in the stream, inhibiting upstream and downstream migration of salmonids (Benton et al., 2008). Bank erosion can eventually lead to stream incision and bank failure, altering the substrate, submerged and emergent vegetation, and flow patterns in the stream. 
Emergent vegetation, size of substrate, presence of large woody debris, and in-stream flow patterns such as pools and riffles are important elements of habitat suitability for SAA (Corn and Bury, 1989), all of which can be influenced by road crossing structures. In addition to the negative effects of bank erosion, restrictive road crossing structures can prevent the natural movement of large woody debris and larger substrate such as cobbles and boulders through stream systems, reducing available refugia (Lassettre and Kondolf, 2003; Wellman et al., 2000). Lower stream flows caused by banks that have been broadened by sediment can increase water temperatures and decrease water quality in streams, creating pockets of unsuitable habitat in otherwise suitable stream segments (Poff et al., 1997). Because road crossings can significantly modify stream elements, all of the factors that influence habitat must be evaluated when considering the potential impacts of road crossing structures on streams and SAA habitat.

\section{Problem Statement}

With the widespread recognition of the worldwide decline of anadromous fish, the removal of fish passage barriers, such as undersized culverts, has become a priority in stream restoration efforts (O’Hanley and Tomberlin, 2005). To address the most predominant issues leading to fish barriers, key elements are implemented in the design of replacement culverts or bridges to restore streambeds to their more natural state (Caltrans, 2007). Undersized stream crossings, lack of adequate substrate, and a high stream gradient can all contribute to increased flow velocities at culvert outlets. Due to the potential impacts on anadromous fish migration, fish passable road culvert designs emphasize shorter, larger diameter pipes that are partially embedded in the stream channel, mimicking the more-natural state of the stream. While it is generally accepted 
that returning rivers and streams to more natural and unrestricted flows will eventually mitigate the impacts of culverts on stream flow at the road crossing (Poff et al., 1997), little is understood about the degree to which these efforts will help to maintain stream habitats and the sensitive species that occupy them (Shafroth et al., 2002).

Several studies have investigated the impacts of forest practices on SAA and determined that increased water temperatures and sedimentation in streams is reducing the abundance of SAA in streams, especially torrent salamanders and tailed frogs (Corn and Bury, 1989; Oregon Forest Resources Institute, 2009). These studies have focused on evaluating timber harvest practices, but have not thoroughly investigated the more subtle effects of infrastructure, such as roads, on SAA habitat. An evaluation of the impact of various types and sizes of forest road crossing structures on SAA occupancy, including the habitat conditions that directly affect occupancy, will help to identify the value in replacing undersized culverts.

\section{Hypotheses}

Road crossings have the potential to impact SAA in two ways; 1) by directly reducing occupancy adjacent to the undersized road crossing, and 2) by altering habitat in adjacent stream segments and creating conditions unfavorable to SAA occupancy. If undersized road crossings are directly reducing occupancy, SAA will disproportionately occupy sites adjacent to road crossings that do not restrict stream flow. Structural variables such as type, length, and diameter of the crossing relative to the stream width will influence occupancy for one or more species of SAA. If undersized road crossings are reducing occupancy by altering habitat covariates, stream conditions that are known to be 
positively associated with SAA occupancy will be negatively influenced by road crossings that restrict flow. Food sources, water quality, refugia, and favorable flow conditions will influence occupancy and be significantly different at stream crossings with and without restricted flows. If road crossing size and structure have no influence on SAA in adjacent stream reaches, SAA species will occupy sites adjacent to undersized road crossings in the same frequency as they occupy sites with unrestricted flows. 


\section{Methods}

To determine if road crossing structures impact SAA occupancy, habitat conditions were evaluated in a number of similarly sized streams in the Wilson River Watershed adjacent to different types of dirt or gravel forest road crossings within the Tillamook State Forest. Streams were then surveyed to determine SAA occupancy and analyzed to determine whether that occupancy was related to the structure of the crossing or habitat conditions potentially impacted by the road crossing. For each survey, time discreet variables, or parameters that could vary between sampling dates, were measured to determine their potential impact on the ability to detect SAA during the survey.

\section{Study Area}

The Tillamook State Forest is an approximately 364,000 acre forest located in the North Coast Basin of Oregon. The forest is actively managed by the Oregon Department of Forestry (ODF) in accordance with the Northwest Oregon State Forests Management Plan (NW FMP) (ODF, 2001). Tillamook State Forest was established after a series of wildfires burned much of the area between 1931 and 1951. Following a massive reforestation and rehabilitation program, the forest is now densely forested with trees averaging $50-60$ years in age, and contains a minimal network of roads and trails (ODF, 2001). The Tillamook State Forest was chosen as the location for this study under the assumption that the fairly uniform land use and stand age would help to reduce the number of potential confounding factors in the study that could be caused by variations in land use, impervious surface, and population found in more urban areas. Additionally, the use of public land eliminated potential limitations associated with requesting access from private land owners. 
To minimize potential variation between stream segments, sampling was limited to the Wilson River watershed, Hydrologic Unit Code (HUC) 1710020305. The Wilson River watershed is one of the five main river systems in the Tillamook Bay Watershed. Comprising nearly 123,000 acres of the Tillamook State Forest, the Wilson River drainage is approximately 30 miles long with forested uplands utilized primarily for timber production and recreation (ODF, 2008a). According to Fishing Oregon: an Angler's Guide to Oregon (Yuskavitch, 2008), the Wilson River is “one of the state's best steelhead and Chinook salmon fisheries."

\section{Sample Timing}

The most effective time to perform in-water sampling is while stream flows are at their lowest, which in Western Oregon falls between July and September (Hayes, 2010). All SAA in coastal Oregon streams hatch between July and late September and have multiyear larval stages (Californiaherps.com, 2012), increasing the chance of detection due to higher densities during the summer months. Sampling occurred over two summers in 2010 and 2011 to maximize the chance of detecting SAA under conditions that could vary between years. Tillamook County had above average precipitation in July, August, and September of both years (CoCoRaHS, 2012).

\section{Sample Site Selection}

Sample sites were selected based on a random sampling of road crossings found across perennial "small" streams, as designated by the Forest Practices Act (FPA) (streams with less than 2 cubic yards of average annual flow) located in the Tillamook State Forest (ODF, 1994). Small streams were chosen because all three study species predominantly 
occur in headwater streams (Nussbaum et al., 1983) and SAA survey techniques are less effective in larger streams (Barr and Babbitt, 2001; Corn and Bury 1989). GIS data supplied by ODF showed that there were 83 road crossings that serve as fish barriers and 31 road crossings passable to fish known to cross perennial FPA-designated small streams in the Wilson River watershed. To select each site, the Wilson River watershed was separated into 4 quadrants and an equal number of fish passage barrier and fish passable road crossings were randomly selected from each quadrant. Following random selection, reconnaissance was performed to determine which culverts were accessible for surveys. Reconnaissance ruled out many of the road crossings in higher altitude areas, as streams frequently flowed in extremely steep ravines, making them inaccessible from the road above. Fish passable sites were restricted to sites that have been designed in compliance with the Oregon Department of Fish and Wildlife's Fish Passage Criteria (ODFW, 2004). Due to road conditions and steep gradients, most sites were located within $4 \mathrm{~km}$ of the Wilson River and Highway 6 or along one of the main roads within the Tillamook State Forest (Figure 1). All sites consisted of road crossing structures on dirt or gravel forest roads used for recreation and logging purposes. Descriptions of each of the study sites and a table of each of the habitat covariates are provided in Appendix B. 


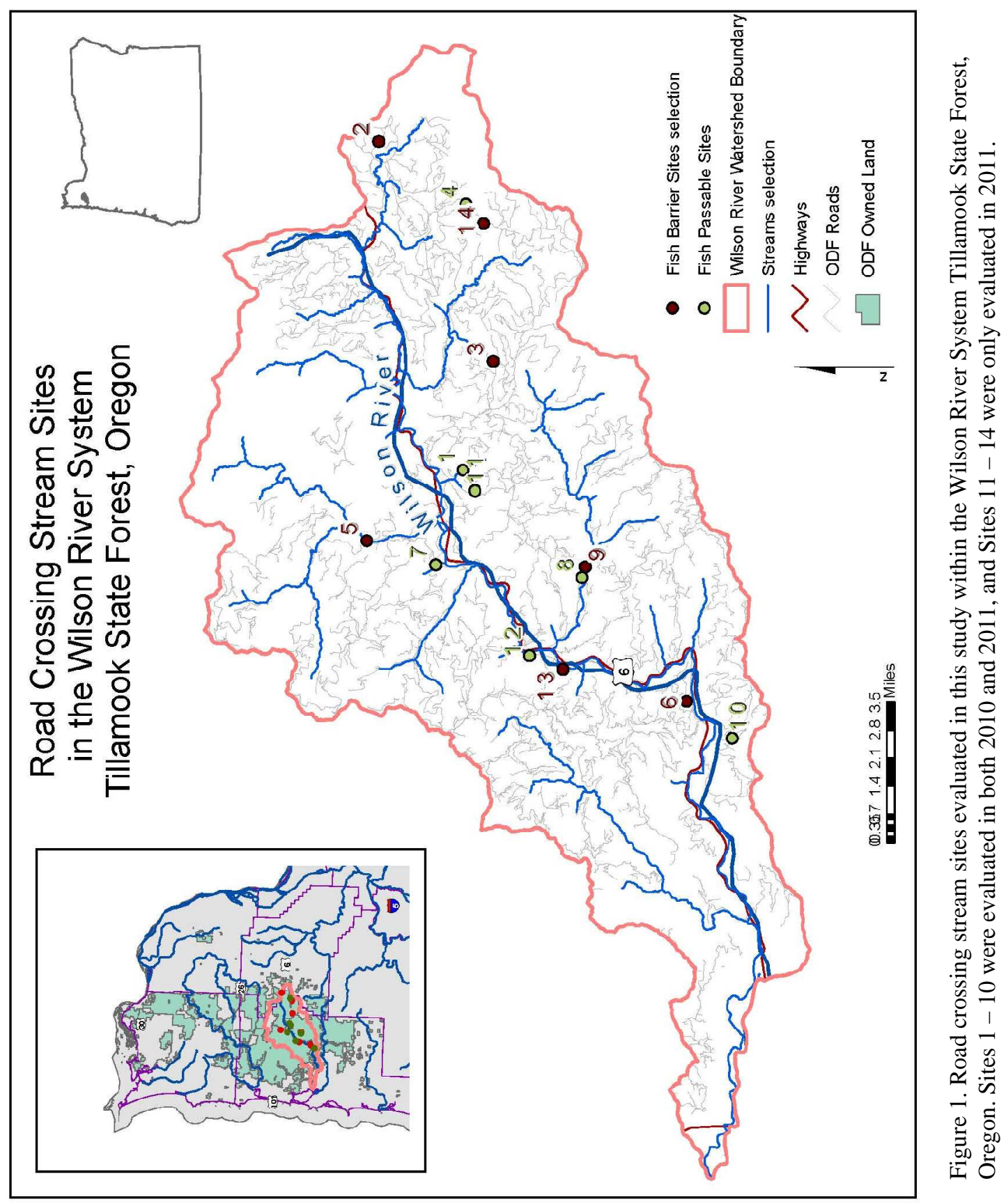




\section{Sample Design at Study Reaches}

Ten road crossing sites were selected in 2010 and 4 more were added in 2011. Each site consisted of two 100 meter long stream segments that were evaluated for habitat variables, one upstream and one downstream of the road crossing. Culvert installation guidelines indicate that stream bank stabilization should be implemented for at least 100 meters above and below installation of a new culvert (Wild Salmon Center, 2002), making a 100 meter stream segment appropriate for assessing the habitat area potentially impacted by road crossings. Within each 100 meter long study reach, amphibian sampling occurred within a 10 meter long sampling reach. The sampling reaches were centered 50 meters above and below the road crossing structure, or as close as possible when the 50 meter mark was not accessible.

\section{Amphibian Species}

Pacific giant salamanders occur in or near cold, clear streams, rivers, mountain lakes, or ponds. Adult Pacific giant salamanders can range in length from 7 - 13", and are the largest species of salamander in North America (Californiaherps.com, 2012). Terrestrial adults breed in headwater streams in early spring, laying single eggs underneath objects in running water. Larvae will emerge in June or July of the following year and will take up to three years to transform into adults, inhabiting the edgewater of streams or hiding beneath rocks. Neoteny, or the retention of juvenile traits into adulthood, is common with giant salamanders and gilled adults often outnumber transformed adults (Californiaherps.com, 2012). Larvae are particularly voracious and will cannibalize smaller larvae and prey on tailed frog larvae, invertebrates, and small fish, making them one of the top predators in the stream system (National Audubon Society, 1979). 
Terrestrial adults often remain in underground burrows, are typically found within 50 meters of streams, and will emerge at night or during dark rainy conditions (Californiaherps.com, 2012).

Columbia torrent salamanders typically occur in shallow, cold, clear, well-shaded streams in mature old growth forests (National Audubon Society, 1979). Torrent salamanders are extremely moisture dependent and are usually found in direct contact with streams. Relatively little is known about Columbia torrent salamanders, but descriptions of other species of Rhyacotriton indicate that they will remain small $(45 \mathrm{~mm})$ at sexual maturity, and are suspected to deposit unattached eggs in the interstices of the coarse substrate in low velocity streams (AmphibiaWeb, 2012). Larval torrent salamanders will remain in slow moving parts of streams for three to four years, and will then inhabit areas close to slow-moving aquatic environments for the remainder of their lives (AmphibiaWeb, 2012). Recent studies have shown that some species of larval torrent salamanders may be unpalatable to giant salamanders, which could limit the impact that this predator has on the torrent salamander in its habitat (Rundio and Olson, 2001). Relationships with other predators, such as fish or crayfish, are currently unknown. Columbia torrent salamanders likely feed on invertebrates occurring in semi-aquatic or aquatic habitats (Bury and Martin, 1967) and may compete with coastal tailed frogs for food sources (Bury, 1970). Coastal tailed frogs are a small frog with rough skin, reaching $1-2$ inches at maturity, that inhabit clear, cold, rocky streams in wet forests (Californiaherps.com, 2012). Adult tailed frogs will breed in the fall and females will deposit eggs in strings under large rocks the following spring or summer. Eggs hatch into tadpoles in $3-6$ weeks and larvae 
will spend between $1-4$ years developing in coastal streams. Tadpoles vary in size based on age and attach themselves to rocks with their large sucker-like mouth. Adults remain mostly aquatic, occasionally venturing upland during damp conditions (AmphibiaWeb, 2012). Tadpoles feed on diatoms, algae and desmids while adults will eat a wide variety of invertebrates (National Audubon Society, 1979).

\section{Amphibian Survey Techniques}

Amphibian sampling surveys were conducted in 2010 and 2011. The upstream and downstream segments of 10 sites consisting of 5 fish passable and 5 fish barrier sites were sampled in 2010 (Sites 1 - 10), and 4 more consisting of 2 of each type of site were sampled in 2011 (Sites 11 - 14). Each study reach was 100 meters long, in accordance with culvert installation guidelines (Wild Salmon Center, 2002). For each stream segment selected, 10 meter long surveys were conducted from 45 meters to 55 meters above and below culverts (or as close as possible when the 50 meter mark was not accessible). Sampling at these locations was intended to capture variation in amphibian occupancy due to habitats affected by stream crossing size, while minimizing any immediate effects of vehicles utilizing the road crossing. Single 10 meter long surveys are appropriate for describing SAA occupancy variation among broad categories of streams, such as streams with and without fish barriers (Bury and Corn, 1991). Surveys used the rubble-rousing technique for in-stream SAA sampling described by Bury and Corn (1991).

The 10 meter sampling reach was barricaded with seine nets at each end to ensure that the stream segment was a closed system, and no organisms could enter or depart during the survey. Surveys began at the downstream end of the sampling reach and proceeded 
upstream in 1 meter increments, beginning with a visual survey of each segment, looking beneath all rocks and debris that could reasonably be moved by one person. All amphibian species were caught using hand nets and placed in buckets, so that no one individual was counted twice. Following the visual survey, the substrate was systematically disturbed by surveyors, catching SAA in hand nets or flushing them downstream into the barricading seine nets.

Rubble rousing has been shown to have the highest rate of detection for the most life stages of SAA species of interest in this study (Quinn et al, 2007). Rubble rousing surveys detected larval and neotenic Pacific giant salamanders; first and second year larval, metamorph, and post-metamorph tailed frogs; and larval and post-metamorph Columbia torrent salamanders. Adult Pacific giant salamanders and coastal tailed frogs were occasionally encountered in the riparian corridor adjacent to the sampling segment. Individuals detected during sampling were classified by lifestage and species, and were removed from the stream and added to the buckets until all sampling at the sampling reach had been completed for the day to avoid possible recapture. Once rubble rousing was complete for the entire 10 meter sampling reach, SAA were released as closely as possible to their point of capture in the stream.

All sampling occurred between mid-July and mid-October to coincide with lower stream flows and increase the effectiveness of in-water sampling (Hayes, 2010). Because it was not possible to sample all sites in one day, one site was randomly selected for each sampling day and several sites within a drivable distance were also surveyed in a random order for the remainder of the day. This process was repeated until 3 rounds of sampling 
without replacement had occurred at each site or until all three species had been detected, as was the case for one site in 2011. A typical sampling day consisted of sampling 3 or 4 sites, both upstream and downstream. Completely random site selection was not possible due to travel time restrictions, but randomly selecting a sampling area reduced the amount of bias introduced due to uncontrollable conditions, such as date, weather, and time of day.

\section{Survey Specific Covariates}

For each survey, parameters that could vary between sampling dates were measured to determine their potential impact on the ability to detect SAA during the survey. Stream flow, weather conditions, air and water temperature, and Julian date were all recorded during each survey. Julian date, which included the fraction of the day since noon, was calculated as the time at the beginning of the survey.

\section{$\underline{\text { Stream Flow }}$}

Stream flow was estimated by timing how long it took a small flotation device (ping pong ball) to travel a pre-measured straight portion of the stream (1 to 5 meters, depending on the stream). Average depth and stream width were measured along that segment and used to calculate the cross sectional area of the stream (stream width multiplied by average water depth). Stream flow rate was calculated by multiplying the cross sectional area by the average surface velocity (distance/float time).

\section{$\underline{\text { Weather }}$}

Weather was qualitatively described using 4 categories; clear and sunny, raining, overcast, and partly cloudy. For analysis purposes, each of the weather categories was 
assigned a numerical value from 1 to 4 . If weather changed during the survey, for example from partly cloudy to clear and sunny, the type of weather that was present for more than 50 percent of the survey time was recorded.

\section{Air and Water Temperature}

Temperature measurements were taken with a digital thermometer with \pm 0.5 degrees of precision. Measurements were taken to the 10th of a degree in Celsius degrees. Air temperature was taken while standing on the banks of the stream, out of direct sunlight. Water temperature was taken towards the middle of the stream in a run or riffle area (not a pool), approximately 12 inches $(30.5 \mathrm{~cm})$ deep. Temperature measurements were taken directly prior to beginning the survey for that segment.

\section{Stream Assessment}

Both water quality and habitat destruction have been observed to be key factors contributing to the worldwide decline of amphibians (Boyer and Grue, 1995). To evaluate the impact of habitat quality on this study, each stream segment was evaluated for variables known to influence amphibian occurrence and detection (Table 1). Some habitat indicators can be directly connected to the size of the road crossing structure, while others are simply characteristic of the stream geography. When multiple measurements of a habitat covariate were taken on different sampling occasions, all stream measurements were averaged for each study reach. If extreme changes in the stream conditions were observed between sampling seasons, measurements were not averaged and evaluated independently. The results of the stream assessments are included in Appendix B. 
For each study reach, standard measurements and observations were taken including elevation, latitude, longitude, substrate, and crossing type (culvert or bridge), material, diameter, and length. Variation between study reaches was evaluated to determine if there was a relationship with SAA occupancy.

Table 1. Definitions of covariates used to estimate stream occupancy probabilities for Pacific giant salamander, Columbia torrent salamander, and coastal tailed frogs and the frequency with which they were measured at each study reach.

\begin{tabular}{|l|l|l|}
\hline \multicolumn{1}{|c|}{ Covariate } & \multicolumn{1}{|c|}{ Definition and Values } & \multicolumn{1}{c|}{$\begin{array}{c}\text { Frequency of } \\
\text { Measurement }\end{array}$} \\
\hline Percent Pools & $\begin{array}{l}\text { The percent of stream reach comprised of pool } \\
\text { habitat }\end{array}$ & Once per sampling season \\
\hline Large Woody Debris & $\begin{array}{l}\text { Percentage of stream reach covered by large, } \\
\text { medium, and small pieces of fallen wood } \\
\text { greater than 2 m long and } 10 \text { cm in diameter }\end{array}$ & Once per sampling season \\
\hline Floodplain width & $\begin{array}{l}\text { Area inundated during unusually high flow } \\
\text { events, receives water most years (m) }\end{array}$ & Once per sampling season \\
\hline Bank full width & Wetted width of stream segment (m) & Once per sampling season \\
\hline Confinement & $\begin{array}{l}\text { Channel width relative to wetted width of } \\
\text { stream }\end{array}$ & Once per sampling season \\
\hline Stream constriction & $\begin{array}{l}\text { Width of the bank full width relative to the } \\
\text { road crossing diameter; constricted (bank full > } \\
\text { diameter), not constricted (bank full < } \\
\text { diameter) }\end{array}$ & Once per sampling season \\
\hline Tree cover & $\begin{array}{l}\text { Percentage of stream reach covered by tree } \\
\text { foliage. }\end{array}$ & Once per sampling season \\
\hline Stream gradient & Channel gradient (degrees) & Once per sampling season \\
\hline Substrate size & $\begin{array}{l}\text { Median particle size of sediment, pebbles, } \\
\text { cobbles, and boulders (mm) }\end{array}$ & Once per sampling season \\
\hline Substrate type & $\begin{array}{l}\text { Consolidated or unconsolidated basalt, glacial, } \\
\text { marine, organic }\end{array}$ & Once per sampling season \\
\hline Crayfish and fish & Present or absent & Noted during each survey \\
\hline Water quality & $\begin{array}{l}\text { Salinity, total dissolved solids (TDS), pH, } \\
\text { percent dissolved oxygen }\end{array}$ & Once in 2011 \\
\hline $\begin{array}{l}\text { Distance to } \\
\text { disturbance }\end{array}$ & $\begin{array}{l}\text { Distance to cleared roads, camp sites, or logged } \\
\text { areas (m). }\end{array}$ & 2009 and November 2011 \\
\hline
\end{tabular}

\section{$\underline{\text { Percent Pools }}$}

The percentage of pool habitat was estimated for each 100 meter study reach, up and downstream from the road crossing. The percent of the study reach comprised of pool habitat was estimated by summing the lengths of each pool and dividing by the 100 meter 
stream reach length (Roper et al., 2002). Pool length was approximated using visual estimation.

\section{$\underline{\text { Large Woody Debris }}$}

Large woody debris (LWD) was defined as logs with a minimum diameter of 10 centimeters and a minimum length of 2 meters that protrude or lay within the stream layer, and was quantified based on visual observation over each 100 meter stream reach, up and downstream from the road crossing. Once defined as LWD, the wood was separated into three size categories; small, medium, and large. Small LWD was defined as those pieces measuring between 2 and 3 meters long, medium LWD was defined as those pieces measuring between 3.1 and 5 meters long, and large LWD was defined as those pieces measuring 5.1 meters long and longer (Beechie and Sibley, 2011). Because diameter could vary greatly between different pieces of debris, length was used as the criterion for categorizing LWD, although most of those pieces placed into the large category exceeded 40 centimeters in diameter. Measurements were taken in terms of percent stream cover by size class and were based on visual estimation (Watson and Hillman, 2011; Beechie and Sibley, 2011).

\section{Floodplain, bank full, and channel confinement}

Bank full width is defined as the width of the channel that has formed as a result of standard flow events (WDNR, 2002). The floodplain is the area that will be inundated during unusually high flow events, receiving water in most years, but generally vegetated by perennial trees and plants. The edge of the bank full channel typically corresponds to the beginning of the floodplain, which consists of a break in slope from the channel 
becoming a valley, terrace, or bench (WDNR, 2002). Both the bank full and the floodplain boundaries were determined following established protocols based on a change in vegetation, topography, and/or sediment texture (WDNR, 2002). Bank full and floodplain widths were measured in centimeters using a tape measure stretched across the stream at the 50 meter point of each 100 meter long stream segment.

Channel confinement is defined as the width between the channel's valley walls relative to the active channel, and is a measure of how incised the channel is (WDNR, 2002). Following measurement of bank full and floodplain width, channel confinement was calculated by dividing the bank full by the floodplain, based on standard stream assessment practices (OWEB, 1999). Measurements of floodplain and bank full width were completed during each study season, converted to channel confinement, and then averaged for each stream segment unless major discrepancies were noted between seasonal measurements.

\section{$\underline{\text { Stream Constriction }}$}

The diameter of the road crossing by itself tells us very little about its impact on the stream habitat, as the size of the stream may vary proportionally. To determine if a road crossing is impacting stream habitat, it is necessary to compare the width of the stream channel to the diameter of the road crossing structure. Each study reach was evaluated to determine if the stream was constricted by the road crossing structure by comparing the bank full width to the diameter of the crossing. For study reaches where the bank full width was larger than the diameter of the crossing, it was assumed that stream flow was constricted by the road crossing. 


\section{$\underline{\text { Tree Cover }}$}

Tree cover at each study reach was estimated using a spherical densiometer, using the methods supplied with the instrument. The squares on the mirrored grid of the densiometer were used to count the number of canopy openings, visually assuming four equi-spaced dots in each square of the grid and counting the number of dots that reflected canopy openings (sky image or unfilled squares). The total count of canopy openings was then multiplied by 1.04 to obtain the percent overhead area not occupied by canopy. The resultant number was subtracted from 100 to obtain the overstory density in percent. Four readings were taken at each location, facing North, East, South, and West. Tree cover readings were taken at three locations for each study reach; approximately 25,50 , and 75 meters upstream and downstream of the culvert, or as close as possible to these values. The average of the three overstory density calculations was the value used as the percent canopy cover value for the analysis of each 100 meter long study reach.

\section{$\underline{\text { Stream Gradient }}$}

The gradient of each 100 meter stream reach was estimated using a Suunto optical reading clinometer PM-5, using the methods supplied with the clinometer. A flag was tied at eye level near the downstream endpoint of the stream reach and then the gradient reading was taken at the furthest possible point upstream where the flag was still visible. Readings were taken by looking at the flag with the clinometers held to the right eye while both eyes were kept open. The measurement was taken in degrees from the horizontal plane at eye level. 


\section{$\underline{\text { Substrate Size }}$}

Substrate size was estimated using the Wolman pebble count method (Wolman, 1954), a standard method for evaluating size of streambed material. One hundred pebbles or rocks were selected with eyes averted along random transects in each 100 meter stream segment. The intermediate axis, or width, of the pebble was measured using a gravelometer, a tool that measures the axis of a pebble by dropping it through different sized cutout squares. For boulders and embedded cobbles, the smallest visible axis was measured and recorded. Following data collection, the result of each study reach was plotted by size class and frequency. The median particle size, or the particle size with 50 percent of the samples equal to or smaller $\left(D_{50}\right)$, was used as an overall estimate of particle size for each study reach.

\section{Substrate Type}

Substrate was qualitatively described based on the type of parent material and whether or not it was consolidated. Material was placed into one of four categories; basalt, marine, glacial or organic (Kroll et al., 2008). When more than one type of material was present, the values of all types were listed in order of predominance.

\section{Predator Presence}

If fish or crayfish were detected during any of the surveys, it was assumed that they were present in the stream reach at all times. Presence or absence for each type of predator was noted for each study reach, with all types of fish being noted regardless of size or species. Crayfish were not identified to the species level during surveys, but most crayfish in the study area are the Oregon native signal crayfish (Pacifastacus leniusculus). The majority 
of fish in the study reaches were minnows or other fish that were too small to identify, with the occasional scuplin present.

\section{$\underline{\text { Water Quality }}$}

Water quality was sampled at the 50 meter point of each 100 meter stream segment, upstream and downstream of the road crossing, suspending the probe of a YSI 556 Handheld Multiparameter Instrument in the center of the stream without touching the substrate. Water quality measurements of total dissolved solids (TDS), salinity, percent dissolved oxygen, and $\mathrm{pH}$ were taken for each study reach. All water quality measurements were taken over the course of two days in 2011; October 22 and 23. Weather conditions were similar (rainy) on both days of water quality testing, and Tillamook County received approximately 0.5 inches of rain on both October 22 and 23 (CoCoRaHS, 2012). While one measurement is not sufficient to detect the overall water quality or any seasonal trends at streams, it did enable a direct comparison between streams and the ability to identify any extreme outlying water quality conditions. Prior to each day of water quality sampling, the equipment was calibrated for each parameter according to the instructions provided in the YSI 556 operations manual.

\section{$\underline{\text { Distance to Disturbance }}$}

Disturbances to the riparian corridor, such as adjacent roads (other than those crossing the stream), logged areas, and campsites, were evaluated using aerial photographs available from Google Earth. The distance from the 50 meter mark of the stream segment to the nearest disturbance area was measured in meters for each site. New disturbances between 
the sample years were noted in the measurements, using aerial photographs updated in 2009 and November 2011.

\section{Analysis}

Estimating the proportion of study reaches that are occupied by a species of interest (occupancy rate) can be useful in relating species presence or absence to habitat characteristics of the study reach (MacKenzie and Bailey, 2004). Occupancy can be used as a state variable in metapopulation models, expressing the probability of occurrence at a site as a function of habitat characteristics (MacKenzie et al., 2002). Methods used for collecting presence/absence data are more cost effective in terms of time and effort than those required for abundance estimates, making occupancy estimations preferable when resources are limited (MacKenzie et al., 2002). However, a species may not be detected at a study reach, even when present, due to unfavorable survey conditions. Failing to account for imperfect detection will lead to an underestimate of the true probability of occupancy (MacKenzie and Bailey, 2004). MacKenzie et al. (2002) developed a model to estimate the probability that a study reach is occupied by a species, despite imperfect detection. Throughout this study, a model refers to a mathematical equation that describes the relationship between two or more variables. Additional key terms used throughout the analysis are identified in Table 2. 
Table 2. Definition of key terms used throughout the analysis of SAA occupancy in this study.

\begin{tabular}{|l|l|}
\hline \multicolumn{2}{|c|}{ Analysis Key Terms } \\
\hline \multicolumn{1}{|c|}{ Term } & \multicolumn{1}{c|}{ Definition } \\
\hline Occupancy $(\psi)$ & $\begin{array}{l}\text { The proportion of study reaches occupied by a species of interest. } \\
\text { Factor of habitat specific covariates. }\end{array}$ \\
\hline Detection Rate $(p)$ & $\begin{array}{l}\text { The probability that a species was detected at a study reach during a } \\
\text { survey. Factor of survey specific covariates. }\end{array}$ \\
\hline Naïve Occupancy Rate & $\begin{array}{l}\text { The proportion of study reaches where a species was detected in the } \\
\text { field. }\end{array}$ \\
\hline Null Model $[\psi(),. p()]$. & $\begin{array}{l}\text { Occupancy model that assumes that detection and occupancy were } \\
\text { constant across surveys and study reaches. Does not fluctuate. }\end{array}$ \\
\hline
\end{tabular}

Methods developed by MacKenzie et al. (2002, 2005) were used to estimate occupancy probability of stream segments by SAA as a function of the independent covariates measured. Habitat covariates, or those that are constant but vary between study reaches, can influence the probability that a study reach will be occupied by a species; where survey specific covariates, or those that are time specific and vary between sampling occasions, can influence the probability that a species will be detected at a study reach.

To model which habitat covariates were associated with SAA occupancy $(\psi)$ and which survey specific covariates were associated with the probability of detection $(p)$, a single season, single species, custom occupancy estimation analysis was performed for each of the three study species using the PRESENCE statistical software package (version 4.4). PRESENCE evaluates the influence of habitat covariates on species occupancy by ranking individual models that incorporate both the habitat covariates and the detection rate based on survey specific covariates. Single season, single species occupancy estimates assess each species independently and assume that the species did not newly occupy or become extinct at a study reach between surveys. 
Model analyses were run for each species individually for the 10 road crossing sites that were surveyed in both 2010 and 2011, and then for the 14 road crossing sites surveyed only in 2011. Upstream and downstream study reaches were analyzed separately, resulting in 20 study reaches in the 2010/2011 datasets and 28 study reaches in the 2011 datasets. Upstream and downstream study reaches were assumed to be independent because undersized culverts affect stream reaches differently, typically resulting in ponding upstream and incision downstream. For the 2010/2011 dataset, it was assumed that no new colonizations or extinctions occurred at study reaches between sampling seasons. For example, if a species was detected at Study Reach A only once in 2011, it was assumed that the species had always occupied Study Reach A and was not detected during other surveys. Similarly, if a species was detected in 2010 but not again in 2011, it was assumed that it was still present but not detected by the later surveys. While new colonizations or extinctions can occur between years, multi-year models are more useful for predicting the probability of extinctions than determining which habitat covariates affect occupancy (MacKenzie, 2003).

Numerical data, or that data that were measured directly (e.g., temperature and distance), and data that were placed into more than 2 categories and numerically coded (e.g., weather and crossing type) were standardized by determining the z-score of each measurement, or standard deviation from the mean. Z-scores are calculated by subtracting the mean of the data from the individual measurement and then dividing the result by the standard deviation. Standardizing data ensures that all data points are on a comparable scale, so that models are weighted appropriately. Following data 
transformation, covariance was evaluated to determine possible interdependence among variables. Covariance analysis was performed using the program R 2.11.1.

Once covariance was evaluated, analysis was performed using a three step process; 1) analysis of the null model which holds detection and occupancy constant, 2) determination of the factors influencing detection, and 3) determination of the factors influencing occupancy. The three step process made it possible to systematically narrow down the number of covariates impacting detection and occupancy and determine those with the most influence.

Analysis of the models that best fit the data began with the most basic null model, $[\psi($.$) ,$ $p()$.$] where "." denotes a constant. The null model holds both occupancy and detection$ constant, assuming that they do not vary between study reaches or surveys. The null models provide a good baseline for comparison to models incorporating survey specific and habitat covariates, by showing what we would expect to see across study reaches if occupancy and detection were uniform. If a model that incorporates habitat or site covariates is weighted higher, or more closely fits the data, than the null model, it implies that those covariates are influencing occupancy.

Next, factors influencing detection were evaluated by holding occupancy constant and evaluating each of the survey specific variables independently, using an approach selected a priori based on accepted literature for each species. The models that most accurately predicted detection rates were chosen based on a comparison of their Akaike's Information Criteria (AIC) values with a small sample size correction (AICc) (Burnham and Anderson, 2002). AIC is a measure of the relative goodness of fit of statistical 
models, measuring the amount of information lost when a given model is used to describe reality. Those models of survey variables that had the highest AICc model weights were assumed to be the best fitting, most parsimonious models for detection probability and were included in the third step; models evaluating habitat covariates affecting occupancy rates.

Once the best model for detection was determined for each dataset, models incorporating the top weighted survey specific covariate for detection were run for each habitat covariate to determine which parameters were most important in modeling occupancy. A global model, incorporating all of the covariates that were potentially relevant to occupancy, was developed and assessed for fit using a parametric bootstrap test $(\mathrm{n}=$ 1000), as described by MacKenzie and Bailey (2004), to estimate overdispersion and a potential lack of fit within the dataset. Models with 3 or fewer habitat parameters were then derived from the global model, focusing on additive models to avoid the error that can be introduced by over fitting a model (i.e., including too many variables) (Burnham and Anderson, 2002). Datasets tended to have 3 or fewer covariates that made up the top ranked models $\left(\Delta_{\mathrm{i}}<2\right)$, making it appropriate to exclude additional covariates in the combined models. Similar to detection models, those models with the highest AICc weight were assumed to be the best fitting, most parsimonious model for occupancy probability. If overdispersion was detected in the global model $(\hat{c}>1)$ for a dataset, a variance inflation factor was estimated based on the $\hat{c}$ value and used to adjust the AICc for each of the derivative models to a Quasi AICc (QAICc), which was then used for model selection in place of the AICc (Burnham and Anderson, 2002). 
Beta coefficients, the standardized estimates of how a dependent variable will change as a result of a predictor variable, were used to determine how occupancy estimates vary relative to a given covariate. The beta coefficient estimates of the detection and occupancy rates for each study reach from the top ranked models $\left(\Delta_{\mathrm{i}}<2\right)$ were model averaged using the Akaike weights $\left(w_{i}\right)$ to account for uncertainty in the model selection process (Burnham and Anderson, 2002). Model estimated occupancy rates were multiplied by each model's Akaike weight and then combined to calculate a model averaged estimate of occupancy for each study reach. Averaging the top models stabilizes the inference when those models are closely related and, therefore, highly variable between data sets (Burnham and Anderson, 2002). Model averaged occupancy and detection rate estimates were then used to evaluate the relationship of the top weighted covariates to the individual species.

Following identification of the top weighted habitat covariates influencing each species of SAA, those covariates were evaluated to determine if they were significantly related to the structure of road crossings. Linking SAA occupancy to the covariates used for approximating disturbance (e.g., confinement, tree cover, and large woody debris), does not necessarily indicate that the disturbance is caused by the road crossing structure. To assess the effect of stream crossings on disturbance, a one way ANOVA was performed for each of the top weighted numerical covariates to determine if they were significantly different between structural binomial covariates, (upstream/downstream and constricted/not constricted study reaches) (Johnson and Kuby, 2000). Similarly, a linear regression analysis was performed on the top weighted numeric covariates to determine if there was a significant relationship between disturbance and road crossing structure 
dimensions (diameter and length) (Johnson and Kuby, 2000). For each of the top weighted categorical parameters (such as crayfish presence, fish presence, and material), a one way ANOVA was performed to evaluate the relationship between the habitat covariates and diameter and length, and a chi-squared test was performed to evaluate the relationship between upstream/downstream and constricted/not constricted study reaches (Keating and Cherry, 2004). In all cases, analysis was performed using the program $\mathrm{R}$ 2.11.1, and p-values were evaluated at a $95 \%$ confidence level to determine if there was a significant relationship between variables. 


\section{Results}

At least one species of SAA was detected at every study reach during the course of the study. Abundance of individual species detected at each study reach is shown in Appendix C. Pacific giant salamanders were detected at 20 of the 20 study reaches in the 2010/2011 dataset and at 25 of the 28 study reaches in the 2011 dataset. Tailed frogs were detected at 12 of the 20 study reaches in the 2010/2011 dataset and at 18 out of the 28 study reaches in the 2011 dataset. Columbia torrent salamanders were detected at 2 of the 20 study reaches in the 2010/2011 dataset and at 2 of the 28 study reaches in the 2011 dataset. The proportion of study reaches where species were detected in the field, or the naïve occupancy rate, can vary significantly from the modeled occupancy rates (Figure 2).

In situations where the naïve occupancy rate, is either too high or too low ( $>80 \%$ or $<15 \%$ ), effectively modeling the effects of habitat covariates on occupancy can be difficult to impossible (Woods, 2007; Balas, 2008). Inferences about the effects of habitat covariates on SAA occupancy cannot be made when a species is found at all habitats reviewed in the study, or when a species is found at only one study reach. Based on the naïve occupancy rates, models for the 2010/2011 Pacific giant salamander and the 2011 torrent salamander datasets were not evaluated (naïve occupancy rates $=100$ and $7 \%$, respectively). The 2011 Pacific giant salamander dataset had a naïve occupancy rate greater than the typical upper limit (89\%) and the 2010/2011 Columbia torrent salamander naïve occupancy rate was less than the lower limit (10\%), but they were both considered close enough to the upper and lower limits to carry through the modeling 
process, in case they provided information pertinent to this or future studies, acknowledging the limitations of those models.

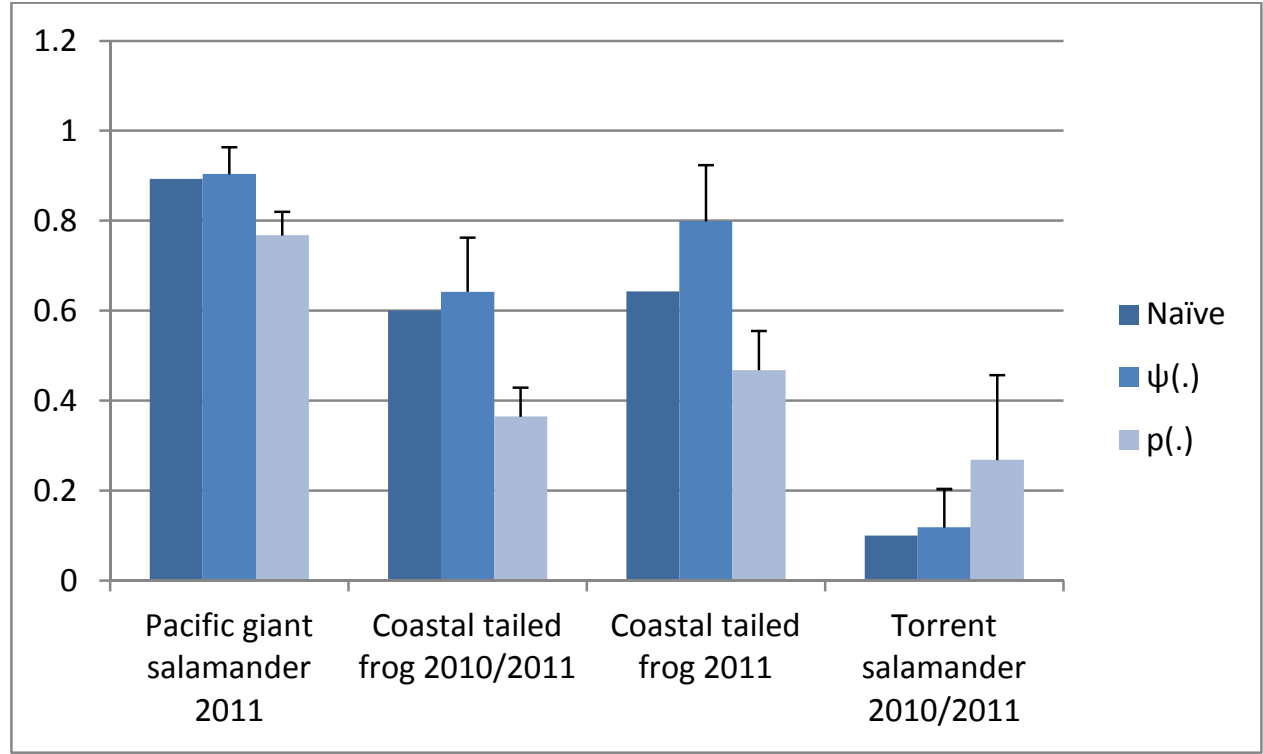

Figure 2. Naïve occupancy rate and estimated proportions of occupancy $(\psi)$ and detection $(p)$ when detection and occupancy are held constant $[\psi(),.(p)]$ with standard error bars for species modeled using data collected at the 20 study reaches for 2010/2011 data and 28 study reaches for 2011 data.

Evaluation of covariance between parameters showed that in several cases strong evidence of interdependence existed (covariance $>0.5$ or $<-0.5$ ). The results of the covariance analysis are presented in Appendix D. When interdependence between two parameters was confirmed by the analysis, those parameters were not included in the same model in order to avoid over parameterization of the model.

\section{Pacific giant salamander results}

Bootstrap analysis of the global model for the 2011 Pacific giant salamander dataset showed evidence of overdispersion, with a $\hat{c}$ value of 1.5435 . To account for overdispersion in the global model, each AICc value and delta AICc value were modified 
using a variance inflation factor to achieve QAICc and delta QAICc values. Comparison of QAICc values resulted in no change to the ranking of the first and second models, but did reverse the order of the third and fourth top models.

The top model for detection of Pacific giant salamanders did not include any survey specific variables, indicating that detection remained constant across each survey. The top models for Pacific giant salamander occupancy (Appendix E) included crayfish presence, fish presence, and stream constriction as the highest weighted covariates [ $\psi($ CFPres $), p(.) ; \psi($ CFPres, FPres $), p(.) ; \psi($ CFPres, FPres, Constriction $) p(.) ; \psi($ CFPres, Constriction), $p()$.$] . The top four models accounted for 94 \%$ of the Akaike weight, indicating that they have a $94 \%$ chance of including the best models to explain the variation in occupancy. The first four models were averaged to estimate occupancy probabilities at all study reaches to evaluate the effects of individual habitat covariates (Figure 3).

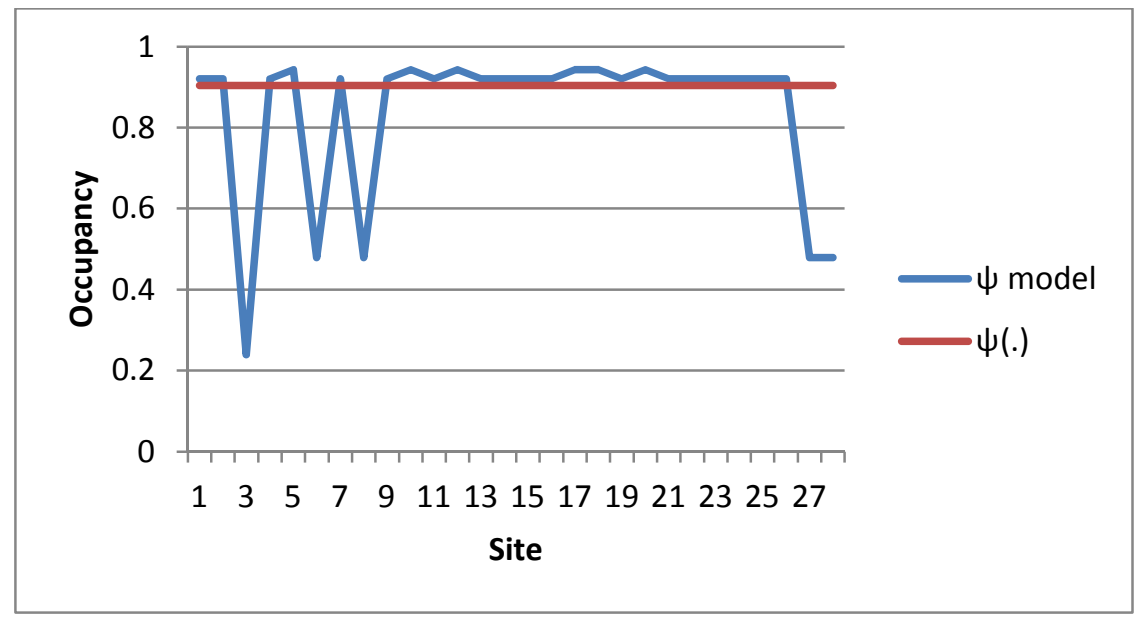

Figure 3. Comparison of model averaged estimates of Pacific giant salamander occupancy at each study reach to null model estimates, demonstrating the difference between estimated occupancy rates that take crayfish presence and upstream/downstream study reaches into consideration and estimated occupancy rates when the influence of habitat covariates is considered constant. 
Pacific giant salamander occupancy rates increased with crayfish presence and fish presence, with salamanders tending to occupy streams where crayfish and fish were also detected. Pacific giant salamander occupancy rates were also higher at study reaches without flow constriction, or where the diameter of the road crossing structure was not smaller than the bank full width of the stream (Figure 4).
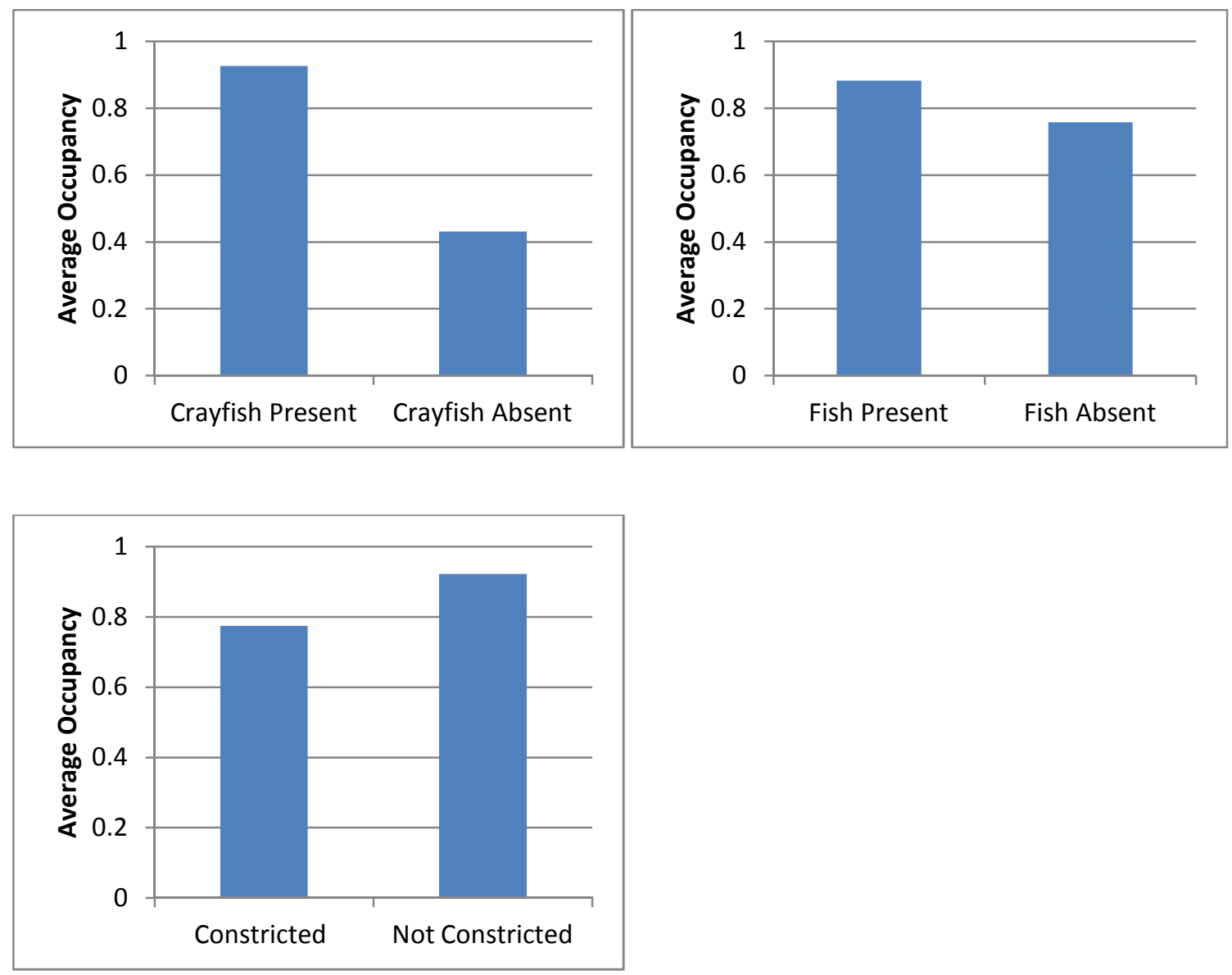

Figure 4. Relationship between average occupancy probability, crayfish presence (a), fish presence (b), and flow constriction (c) for Pacific giant salamanders during the 2011 sampling season. Occupancy probabilities were estimated by model averaging the top three models' estimated occupancy of individual study reaches. 


\section{Coastal tailed frog}

The top models for detection of coastal tailed frogs for the 2010/2011 dataset included a combination of weather and stream temperature as the highest weighted survey covariates (Figure 5). The top models for tailed frog occupancy in 2010/2011 (Appendix F) included stream confinement, dissolved oxygen, and longitude as the highest weighted covariates [ $\psi(\mathrm{DO}), \mathrm{p}($ Weather, StreamTemp); $\psi($ Confinement), $\mathrm{p}$ (Weather, StreamTemp); $\psi($ Long, Confinement), p(Weather, StreamTemp); $\psi($ Long, DO), p(Weather, StreamTemp)]. The combined Akaike weights of the top models equaled 62\% indicating that they have a $62 \%$ chance of including the best models for explaining the variation in occupancy. The first four models were averaged to estimate occupancy probabilities at all study reaches and evaluate the effects of individual habitat covariates (Figure 6).

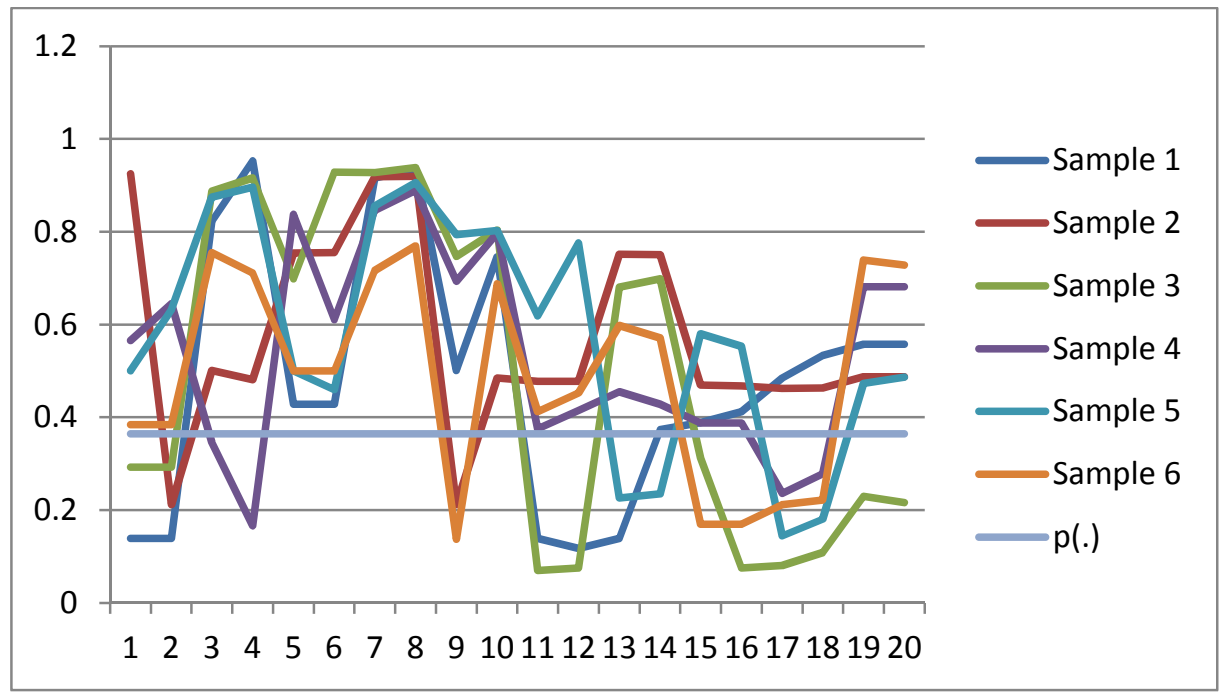

Figure 5. Comparison of estimated coastal tailed frog detection rates at each study reach based on the top model for detection $[\psi(),$.$p (Weather)] to the detection rates estimated by the null model [\psi(),. p()$.$] for each$ sampling occasion, demonstrating how detection rates vary between sampling occasions when the effect of weather is taken into account compared to the null model which assumes that detection rates were constant for all samples. 


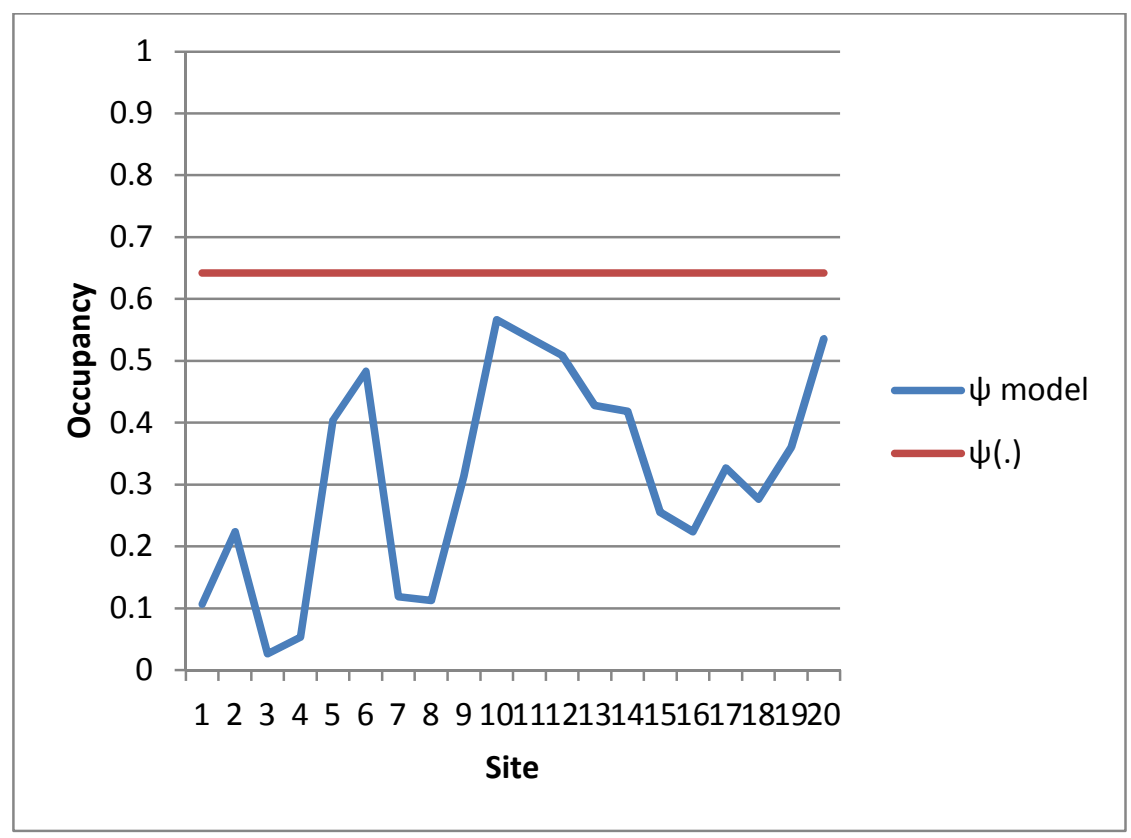

Figure 6. Comparison of model averaged estimates of coastal tailed frog occupancy at each study reach to null model estimates, demonstrating the difference between estimated occupancy rates that take dissolved oxygen, gradient, and confinement into consideration and estimated occupancy rates when the influence of habitat covariates is considered constant.

Coastal tailed frog occupancy was positively correlated with percent dissolved oxygen concentration, had a negative relationship with increasing longitude, and had a positive to slightly quadratic relationship with channel confinement (Figure 7). A combination of weather and stream temperature had the highest Akaike weight for detection models, with partly cloudy conditions having the highest detection rate (72\%) and detection decreasing as stream temperatures increased (Figure 8). 

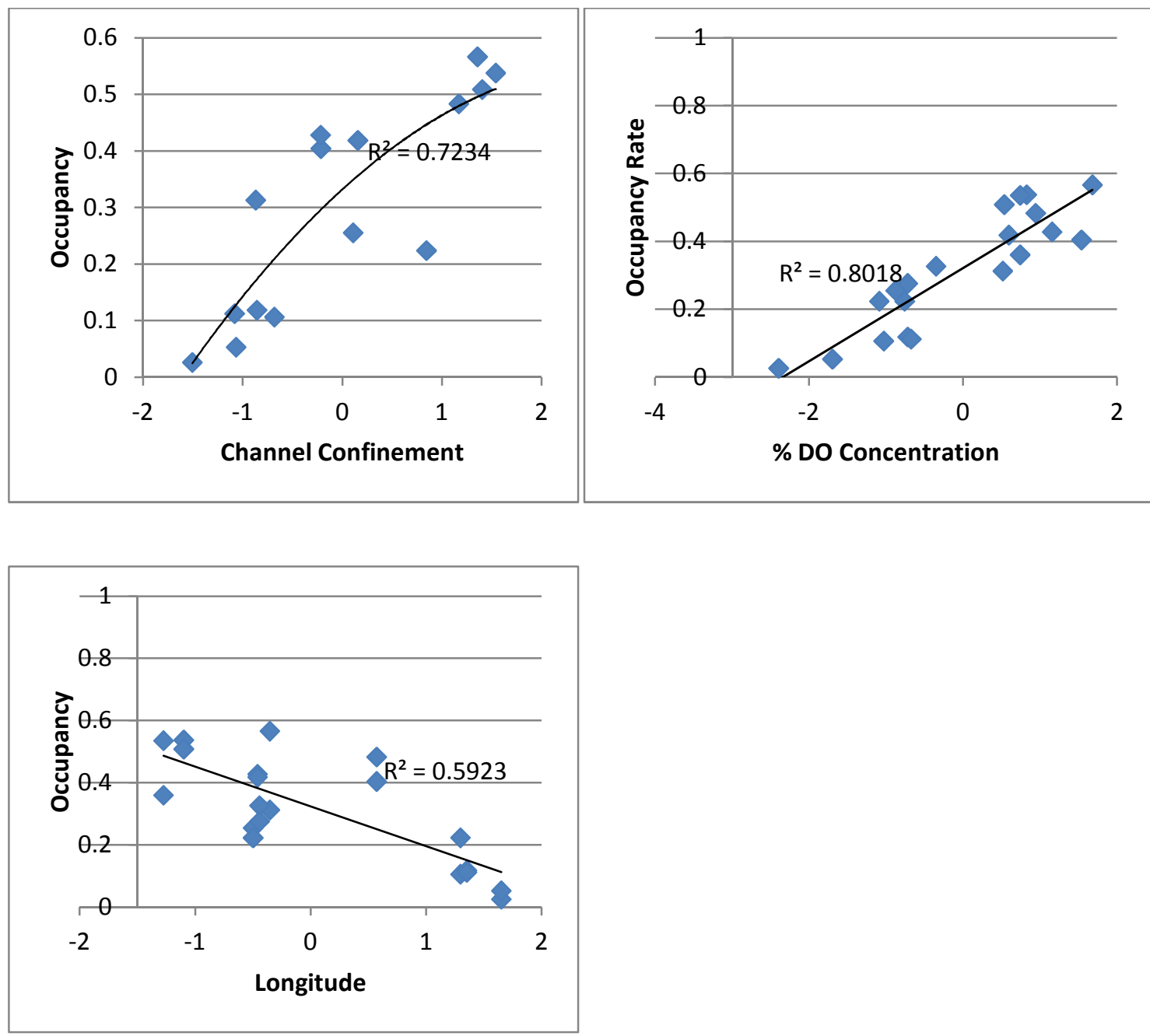

Figure 7. Relationship between occupancy probability, channel confinement, \% dissolved oxygen concentration, and longitude for coastal tailed frogs during the 2010 and 2011 sampling seasons. Occupancy probabilities were estimated by model averaging the top three models' estimated occupancy of individual study reaches. Values of channel confinement and dissolved oxygen have been transformed using z-scores. 

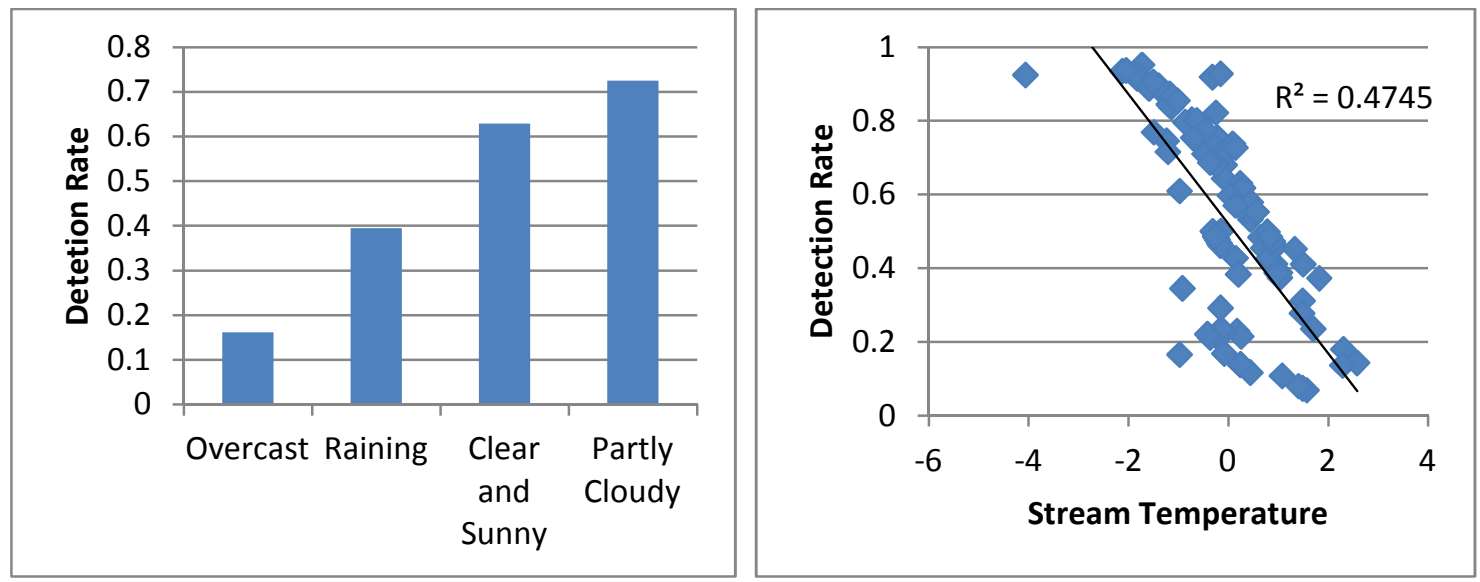

Figure 8. Relationship between detection probability, weather conditions and stream temperature for coastal tailed frogs during the 2010 and 2011 sampling seasons. Detection probabilities were estimated for the individual study reaches using the top model for detection. Weather conditions were assigned a numerical value and both weather conditions and stream temperature were transformed using $\mathrm{z}$-scores.

The top models for detection of coastal tailed frogs for the 2011 dataset consisted of a combination of Julian date and stream temperature (Figure 9). The top models for tailed frog occupancy in 2011(Appendix G) included crayfish presence and dissolved oxygen [ $\psi($ CFPres, DO), p(JDate); $\psi($ CFPres, DO), p(StreamTemp); $\psi($ CFPres $), p(J D a t e$, StreamTemp)] (Figure 10). The top three models accounted for $73 \%$ of the Akaike weight, and were used to estimate occupancy probabilities at all study reaches and evaluate the effects of individual habitat covariates. 


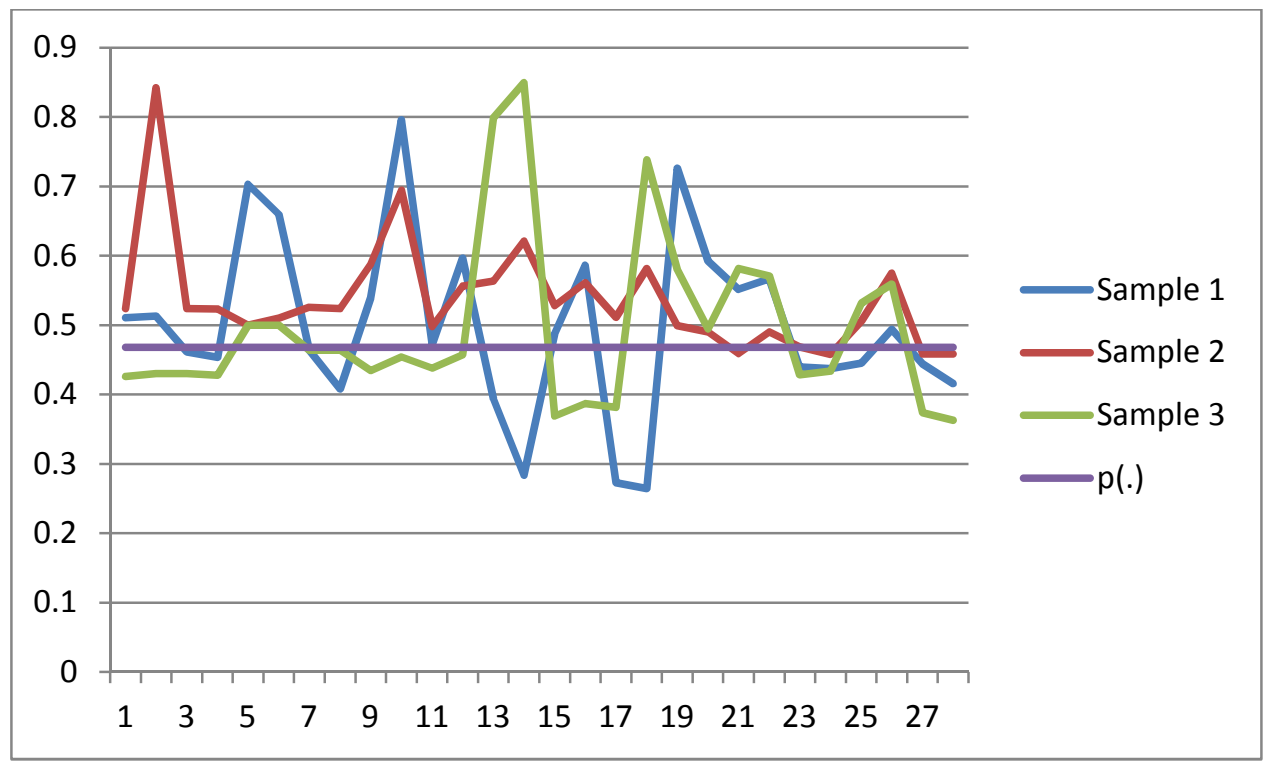

Figure 9. Comparison of estimated coastal tailed frog detection rates at each site based on the top model for detection $[\psi(),. p($ StreamTemp) $]$ to the detection rates estimated by the null model $[\psi(),. p()$.$] for each$ sampling occasion, demonstrating how detection rates vary between sampling occasions when the affect of stream temperature is taken into account compared to the null model which assumes that detection rates were constant for all samples.

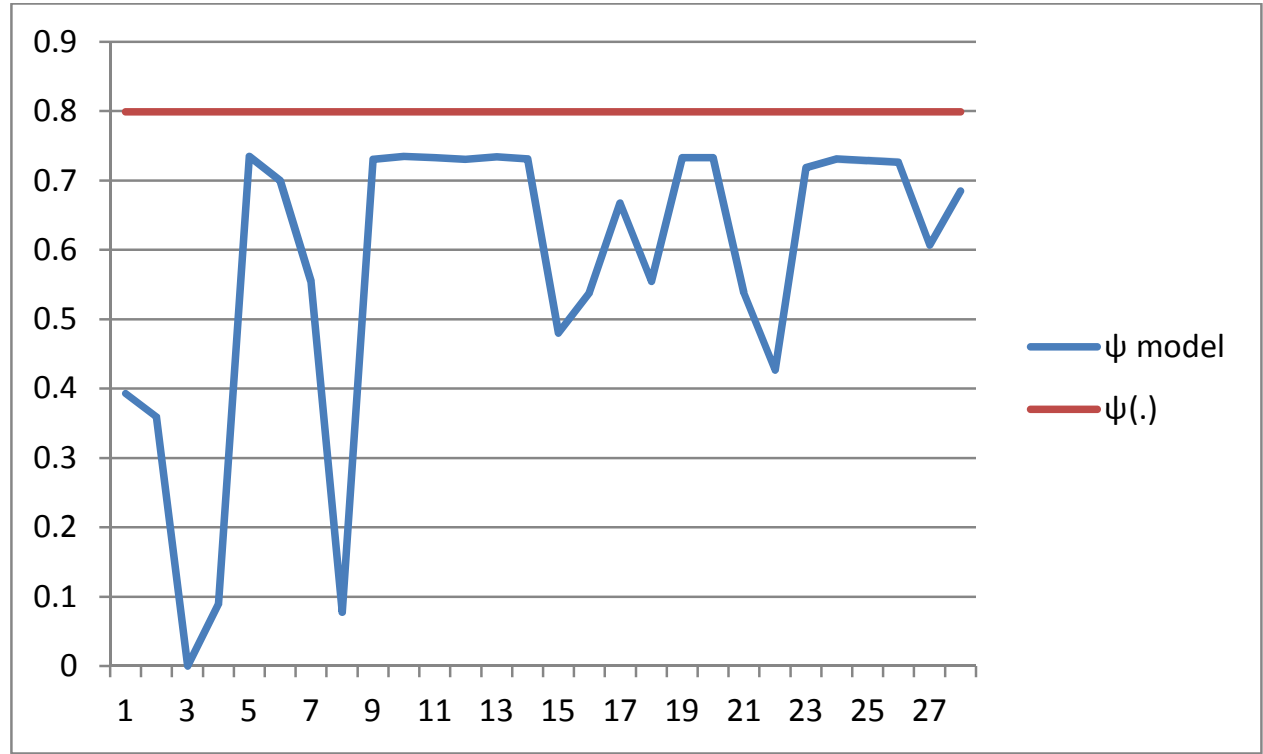

Figure 10. Comparison of model averaged estimates of coastal tailed frog occupancy at each study reach to null model estimates, demonstrating the difference between estimated occupancy rates that take crayfish presence, dissolved oxygen, and gradient into consideration and estimated occupancy rates when the influence of habitat covariates is considered constant. 
In the 2011 dataset, tailed frog occupancy increased with crayfish presence indicating that tailed frogs tended to occupy streams where crayfish were also detected. Coastal tailed frog occupancy was also positively correlated with dissolved oxygen (Figure 11). Tailed frog detection was negatively correlated with later Julian dates and positively associated with increased stream flow (Figure 12).
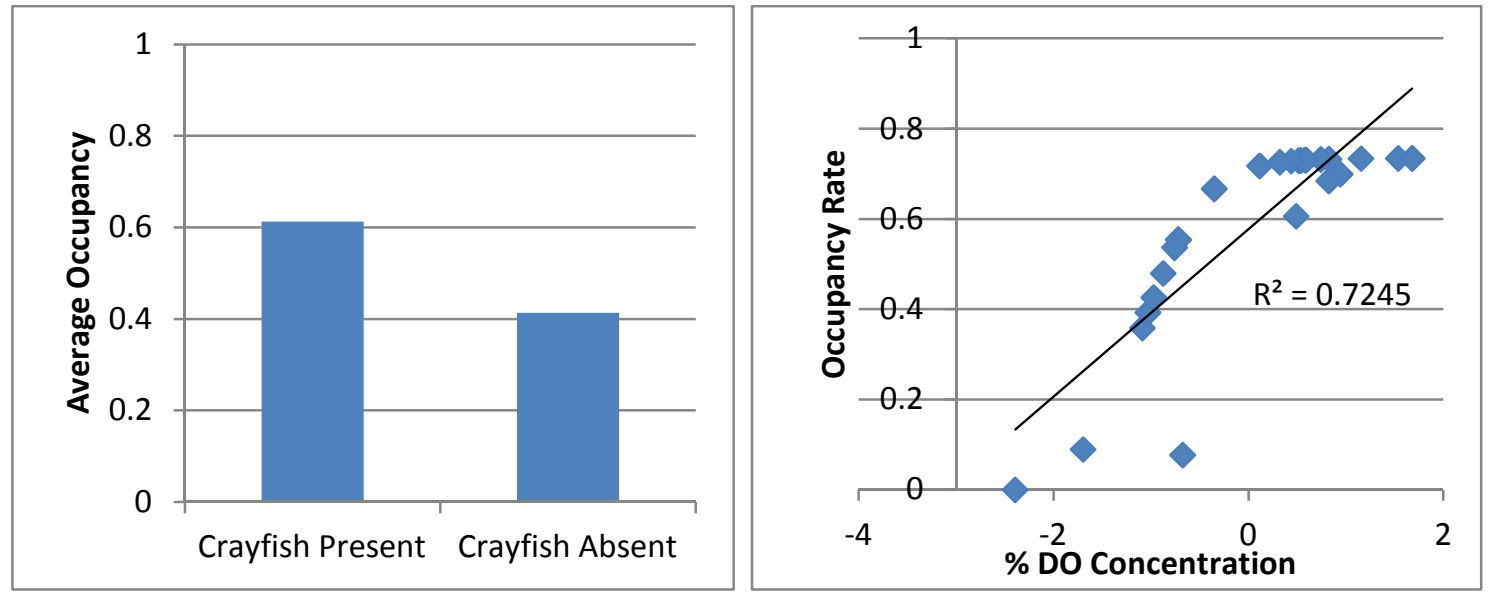

Figure 11. Relationship between occupancy probability, crayfish presence and \% dissolved oxygen concentration for coastal tailed frogs during the 2011 sampling season. Occupancy probabilities were estimated by model averaging the top three models' estimated occupancy of individual study reaches. Dissolved oxygen values have been transformed using z-scores. 

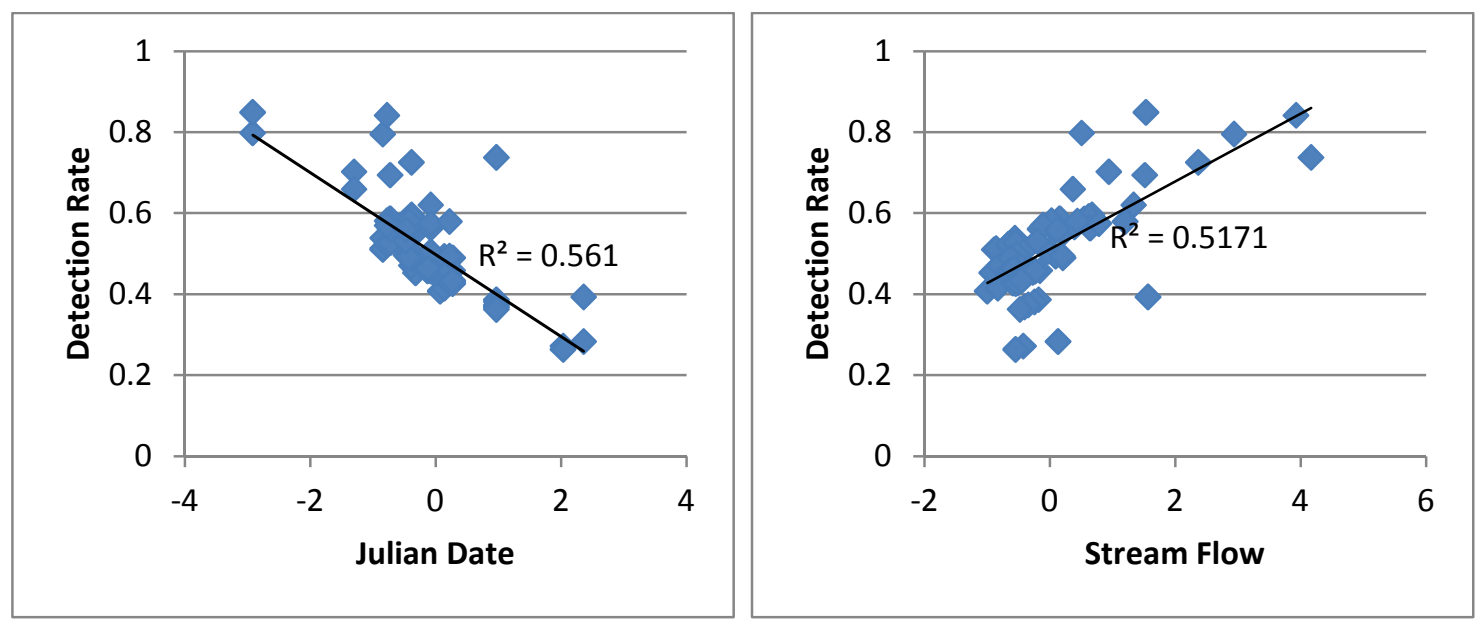

Figure 12. Relationship between detection rate, Julian date and stream flow for coastal tailed frogs during the 2011 sampling season. Detection rates were estimated using the model [ $\psi(.) \mathrm{p}(\mathrm{JDate}$, StreamTemp)], where occupancy was held constant. Julian date and stream flow values have been transformed using zscores.

\section{Torrent salamander results}

The top model for detection of torrent salamanders for the 2010/2011 dataset included Julian date as the highest weighted survey covariate (Figure 13). The top models for torrent salamanders (Appendix $\mathrm{H}$ ) included fish presence, fish passage and crayfish presence [ $\psi($ FPres, FishPass), p(JDate); $\psi($ CFPres, FPres), p(JDate); $\psi($ CFPres, FishPass), p(JDate); $\psi($ CFPres), p(JDate); $\psi($ CFPres, FPres, FishPass), p(JDate)]. Combined, these models accounted for $68 \%$ of the Akaike weight. The top five models were averaged to estimate occupancy probabilities at all study reaches and evaluate the effects of individual habitat covariates (Figure 14 ). 


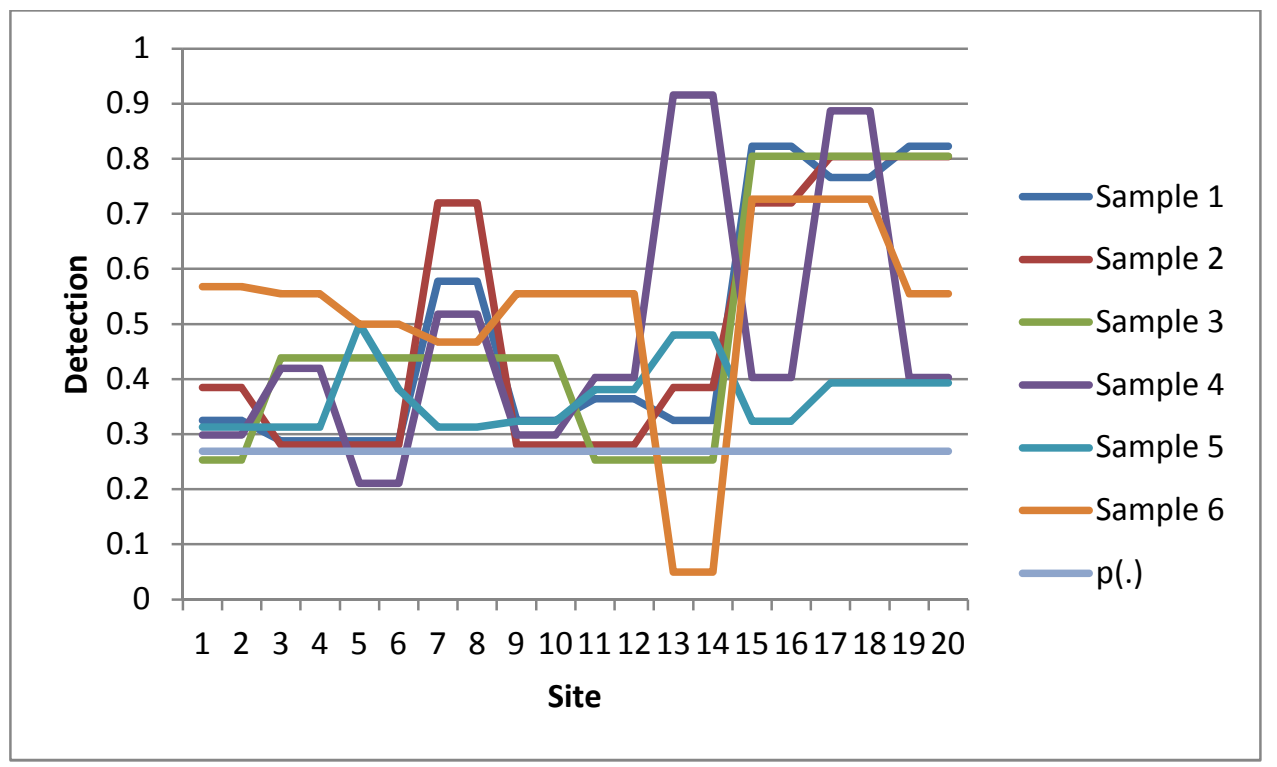

Figure 13. Comparison of estimated coastal tailed frog detection rates at each study reach based on the top model for detection $[\psi(),. p(\mathrm{JDate})]$ to the detection rates estimated by the null model $[\psi(),. p()$.$] for each$ sampling occasion, demonstrating how detection rates vary between sampling occasions when the affect of Julian date is taken into account compared to the null model which assumes that detection rates were constant for all samples.

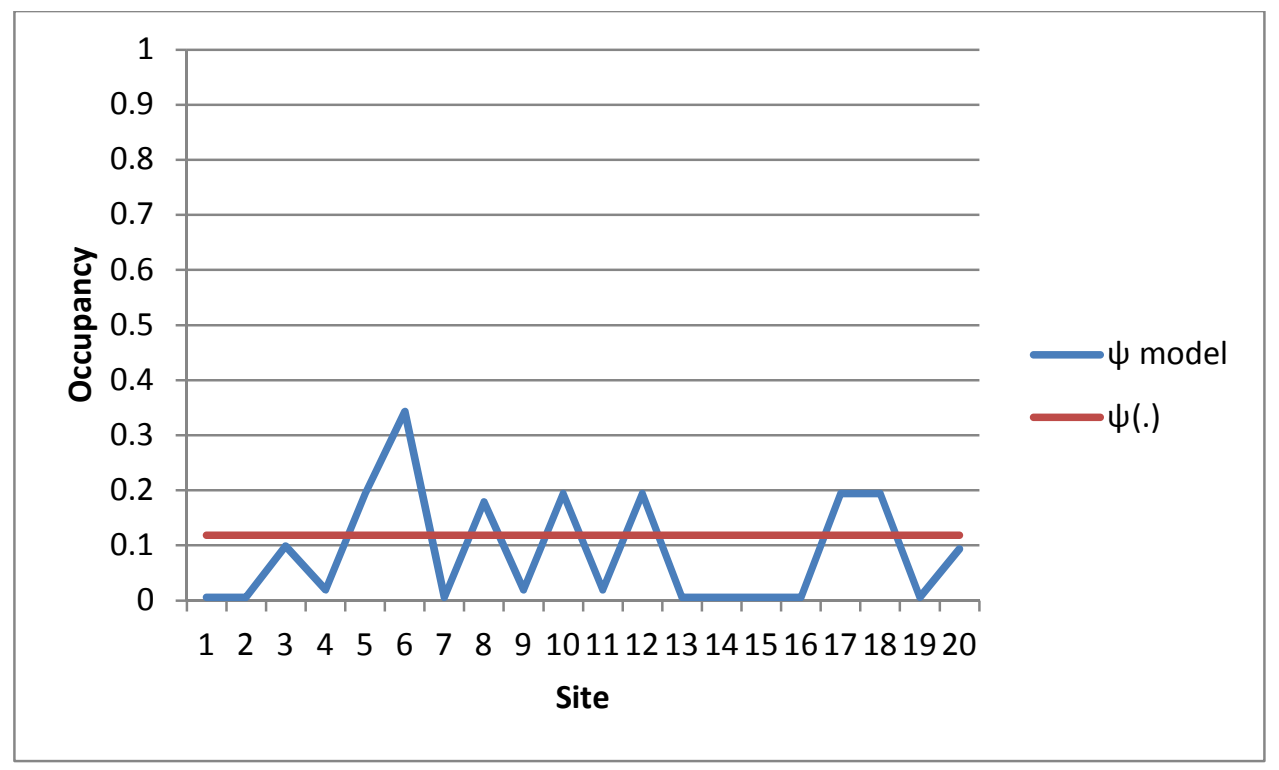

Figure 14. Comparison of model averaged estimates of Columbia torrent salamander occupancy at each study reach to null model estimates, demonstrating the difference between estimated occupancy rates that take crayfish presence, fish presence, and fish passage into consideration and estimated occupancy rates when the influence of habitat covariates is considered constant. 
Because only 3 Columbia torrent salamanders were detected throughout the 2010/2011 sampling season, no inference about occupancy can be made from the top weighted models. The only information gained from this data is based on direct observation of the study reach. Two of the three Columbia torrent salamanders were detected in September, in a stream with no fish or crayfish present, adjacent to a culvert that is considered a fish barrier.

\section{Significance Testing}

A one way ANOVA test for significance was run to determine if there was a significant difference in the top weighted numerical covariates (confinement, dissolved oxygen, and longitude) at study reaches upstream and downstream of road crossing structures and study reaches with and without constricted flow. Confinement and dissolved oxygen were compared to both of the structural binomial covariates, but longitude measurements were taken at the stream crossing, and did not vary between upstream and downstream reaches. The results of the ANOVA test for the highest weighted covariates for influencing SAA are shown in Table 3. Each of the p-values is higher than the p-value corresponding to the 95\% significance level, and thus does not provide enough evidence to reject the null hypothesis that the variables are independent of each other. 
Table 3. One way ANOVA test results comparing confinement, percent dissolved oxygen, and Longitude at upstream and downstream reaches. Longitude measurements did not vary between upstream and downstream reaches, and a comparison between stream reaches was not included in the table.

\begin{tabular}{|l|l|l|l|l|}
\hline & $\begin{array}{c}\text { Sum of } \\
\text { Squares }\end{array}$ & $\begin{array}{c}\text { Mean } \\
\text { Squares }\end{array}$ & F-Value & p-value \\
\hline Upstream/Downstream \\
\hline Confinement & 0.008 & 0.008 & 0.196 & $\mathbf{0 . 6 6 1 8}$ \\
\hline \%DO & 0.0001 & 0.0001 & 0.0551 & $\mathbf{0 . 8 1 6 2}$ \\
\hline Constriction & \multicolumn{5}{|l}{} \\
\hline Confinement & 2.665 & 2.665 & 2.8479 & $\mathbf{0 . 1 0 3 5}$ \\
\hline \%DO & 1.269 & 1.269 & 1.2823 & $\mathbf{0 . 2 6 7 8}$ \\
\hline Longitude & 1.473 & 1.473 & 1.5002 & $\mathbf{0 . 2 3 1 6}$ \\
\hline
\end{tabular}

Linear regression models were created to evaluate the relationship between road crossing structure dimensions and the top weighted numerical habitat parameters. The results of the linear regression analysis for the highest weighted habitat parameters versus diameter and length are shown in Table 4. Each of the p-values is higher than the p-value corresponding to the $95 \%$ significance level, and thus does not provide enough evidence to reject the null hypothesis that the variables are independent of each other.

Table 4. Linear regression analysis results evaluating confinement and percent dissolved oxygen relative to different diameters and lengths of road crossing structures.

\begin{tabular}{|l|l|l|l|}
\hline & $\begin{array}{l}\text { Multiple } \\
\text { R-squared }\end{array}$ & $\begin{array}{l}\text { Adjusted } \\
\text { R-squared }\end{array}$ & p-value \\
\hline Diameter & \multicolumn{5}{|l|}{} \\
\hline Confinement & 0.092 & 0.057 & $\mathbf{0 . 1 1 5 9}$ \\
\hline \%DO & 0.017 & -0.021 & $\mathbf{0 . 5 1 4 0}$ \\
\hline Longitude & 0.018 & -0.019 & $\mathbf{0 . 4 9 1 4}$ \\
\hline Length \\
\hline Confinement & 0.056 & 0.019 & $\mathbf{0 . 2 2 5 2}$ \\
\hline \%DO & 0.001 & -0.037 & $\mathbf{0 . 8 7 0 2}$ \\
\hline Longitude & 0.044 & 0.007 & $\mathbf{0 . 2 8 4}$ \\
\hline
\end{tabular}


One way ANOVA tests for significance were run to determine if there was a significant difference in diameter or length at study reaches with or without crayfish present, with or without fish present, and with or without flow constriction. The results of the ANOVA test between the road crossing structural covariates in stream segments are shown in Table 5. The p-values associated with the relationship between fish presence, constriction, and road crossing diameter are both higher than that corresponding to the 95\% significance level, and thus provides enough evidence to reject the null hypothesis that the variables are independent of each other.

Table 5. ANOVA results evaluating the relationship between crayfish presence, fish presence, and flow constriction to diameter and length of crossing

\begin{tabular}{|l|l|l|l|l|}
\hline & \multicolumn{1}{|c|}{ Sum of Squares } & Mean Squares & F-Value & p-value \\
\hline Crayfish Presence & 1.849 & 1.849 & 1.9114 & $\mathbf{0 . 1 7 8 6}$ \\
\hline Diameter & 0.719 & 0.719 & 0.7118 & $\mathbf{0 . 4 0 6 6}$ \\
\hline Length & 4.768 & 4.768 & 5.5764 & $\mathbf{0 . 0 2 5 9 *}$ \\
\hline Fish Presence & 0.1324 & 0.1282 & $\mathbf{0 . 7 2 3 2}$ \\
\hline Diameter & 0.132 & 13.205 & 24.888 & $\mathbf{4 . 4 6 2 e - 0 5 * * *}$ \\
\hline Length & 1.227 & 1.238 & $\mathbf{0 . 2 7 6 0}$ \\
\hline Constriction & 13.205 & 1.227 &
\end{tabular}

Pearson's chi-squared tests were run for crayfish presence and fish presence at upstream versus downstream study reaches at study reaches with and without constriction. The results of the chi-squared test between upstream/downstream segments and flow constricted/not constricted study reaches with or without crayfish and with or without fish are shown in Table 6 . The p-values associated with the relationship between crayfish presence and upstream/downstream segments is higher than that corresponding to the 
95\% significance level, and thus provides enough evidence to reject the null hypothesis

that the variables are independent of each other.

Table 6. Chi-squared test results evaluating the relationship between crayfish and fish presence to upstream vs. downstream study reaches and study reaches with and without constricted flow.

\begin{tabular}{|c|c|c|}
\hline & $\mathrm{X}$-squared & p-value \\
\hline \multicolumn{3}{|c|}{ Upstream/Downstream } \\
\hline Crayfish Presence & 4.2667 & $0.03887 *$ \\
\hline Fish Presence & 0.5 & 0.4795 \\
\hline \multicolumn{3}{|l|}{ Constriction } \\
\hline Crayfish Presence & 2.1176 & 0.1456 \\
\hline Fish Presence & 0.05 & 0.823 \\
\hline
\end{tabular}




\section{Discussion}

In all datasets, model averaged occupancy estimates accounted for at least $68 \%$ of the Akaike's weight, indicating that they had at least that chance of including the best models for predicting occupancy of the given species. Naïve occupancy rates for Pacific giant salamanders and Columbia torrent salamanders limited the reliability of occupancy models created using those species, restricting inferences about stream associated amphibians to the coastal tailed frog datasets. Model averaged estimates for the coastal tailed frog datasets were relatively consistent between datasets and provided good insight into the covariates effecting detection and occupancy. Despite their limitations, the Pacific giant salamander and torrent salamander models provided some information about the factors influencing detection and the effect of road crossings on occupancy, and may be useful in structuring future studies. Evaluation of each of the top models provides insight into the impact of road crossing structures on each species' occurrence, even when occupancy models were not reliable.

For data outside of the ideal naïve occupancy range (giant and torrent salamanders) all of the top models included only binary covariates (crayfish presence, fish presence, constriction, upstream/downstream). This bias in the models is likely because the binary covariates had the most distinct difference within the covariate ( 0 and 1$)$, rather than the gradation of values found in other covariates. Bias towards binary covariates further limits the reliability of those models in detecting occupancy and the habitat covariates that may influence it. 


\section{Coastal Tailed Frog}

Coastal tailed frogs provided the best data for determining the effects of road crossing structures on SAA occupancy, because they occurred at slightly over half of the study reaches in both datasets. Dissolved oxygen was a common covariate between datasets, reinforcing the importance of its influence on coastal tailed frog occupancy. For this study, dissolved oxygen was likely a surrogate for other habitat covariates that are indirectly related to dissolved oxygen, such as in-stream habitat (pools and riffles), substrate, or stream flow. While dissolved oxygen is not necessarily linked to road crossing structures, is has been linked to overall stream disturbance (Corn and Bury, 1989). Detection rates were linked to weather, stream temperature, and Julian date, providing important context for future studies. Perhaps most informatively were the covariates that were not included in the highest weighted models, specifically road crossing diameter, length, type of crossing, and flow constriction.

\section{Weather}

The best model for predicting detection rates in 2010/2011 consisted of weather, with partly cloudy conditions having the highest detection rate, followed by clear and sunny conditions. Changes in detection due to weather are likely caused by one or both of the following interactions: 1) coastal tailed frogs are less active in streams during overcast or rainy conditions, and/or 2) visibility of tailed frogs in the stream was reduced do to unfavorable conditions. While terrestrial adult tailed frogs are known to be more active during rainy conditions (Noble and Putnam, 1931), aquatic tailed frog larvae may hide during wet weather due to turbulent stream conditions caused by wind or rain. Turbulent 
stream conditions would also limit visibility, making it more difficult to detect tailed frogs if they were present.

\section{$\underline{\text { Stream Temperature }}$}

The best models for predicting coastal tailed frog detection rates in 2011 included stream temperature, with a negative correlation between higher temperatures and tailed frog detection. Stream temperature was used in this study as a survey covariate to predict detection rates because it can fluctuate from day to day, but the overall temperature trends of a stream can also be used as a habitat covariate to model occupancy. Diller and Wallace (1999) showed an inverse relationship between stream temperature and tailed frog occupancy. Higher occupancy would increase detection rates, corresponding to the results of this analysis. Additionally, stream temperature is known to increase near road crossings due to reduced canopy cover (Vaughan, 2002), potentially linking tailed frog occupancy to road crossing disturbance. Lower water temperatures are also directly related to higher dissolved oxygen content (Diller and Wallace, 1999), corresponding to the top weighted occupancy models for both the 2010/2011 and 2011 datasets.

\section{$\underline{\text { Julian Date }}$}

The best models for coastal tailed frog detection in 2011 included Julian date, with a negative correlation between increased Julian date and the likelihood of detecting a species at an occupied study reach. Because Julian date can be linked to other variables, it is difficult to draw conclusions about what specific influence it would have on detection. In the 2010/2011 dataset, the highest weighted survey covariate was weather, indicating that detection rates may be driven by seasonal changes linked to Julian date. 
Weather conditions were more likely to be rainy at later (increased) Julian dates during the 2011 sampling season, and Coastal tailed frog detection rates were lower (0.4) during rainy conditions compared to other conditions.

Tailed frog breeding cycles, which were not quantified as a part of this study, are also tied to Julian dates (Bury and Adams, 1999), and could affect detection. Coastal tailed frog larvae will metamorphose into adults in September/October, leaving the stream and avoiding detection by rubble rousing sampling techniques. While Brown (1990) showed that 5 age classes of tailed frogs can be present in stream systems in September, age classes present in the same stream reach will typically be limited to two or fewer (Bury and Adams, 1999). If late-stage tadpoles were detected in the earlier part of the summer they would not be detected following metamorphosis, reducing overall abundance and detection rates in stream reaches.

\section{$\underline{\text { Confinement }}$}

Preliminary evaluation using a linear regression trend line showed that coastal tailed frogs were positively associated with channel confinement, which is counterintuitive because confinement is a measure of disturbance in streams. Applying a polynomial regression trend line (Figure 7) showed that coastal tailed frog occupancy had a slightly quadratic relationship with increasing channel confinement. Removing outliers, or those streams in the study area with confinement greater than 0.6 , further emphasized the quadratic relationship. It is likely that including more streams with higher degrees of stream confinement would result in a more pronounced quadratic relationship. 
Kroll et al. (2008) determined that bank full width had a quadratic, rather than a linear relationship, to coastal tailed frog occupancy. Assuming that bank full width is a surrogate for basin area, a quadratic relationship exists because smaller basins may not be able to provide perennial flows required by tailed frog tadpoles and larger basins may have too high of flow rates that push tadpoles downstream (Hayes et al, 2006; Kroll et al., 2008). As discussed in the Methods section, confinement is calculated by dividing bank full width by floodplain width, directly relating confinement to bank full width and thus, to basin area. A quadratic relationship between confinement and tailed frog occupancy coincides with the results reported by Kroll et al. (2008) and also emphasizes the effect of under sized road crossings on SAA populations.

While streams with minimal bank full widths do not provide adequate habitat for tailed frogs, streams with high degrees of confinement minimize habitat variation in stream segments, increasing flows and pushing tadpoles downstream. None of the streams in this study had flows that were high enough to exclude tailed frogs, but the combination of high flows and high confinement could limit occupancy by homogenizing stream habitat in a way that is unfavorable to tailed frog life history traits. Linear regression did not show a significant relationship between confinement and pools or substrate size, but confinement could be linked to riffle-type habitat that was not quantified as a part of this study.

\section{Dissolved Oxygen}

The highest weighted models for both the 2010/2011 and the 2011 dataset included dissolved oxygen as an influential covariate. Occupancy had a positive correlation with 
percent dissolved oxygen, where coastal tailed frogs more frequently occupied stream reaches with higher dissolved oxygen concentrations. Previous studies have shown that tailed frogs require cold, well oxygenated streams throughout the year (Bury and Adams, 1999). Larval tailed frogs never develop external gills, so they have to absorb all required oxygen through the surrounding environment (Noble and Putnam, 1931). Because each of the study reaches was supersaturated with oxygen ( $96 \%$ or greater), dissolved oxygen is not a limiting factor for tailed frogs in the study area, even in the streams with the lowest concentrations.

For this study, dissolved oxygen was likely a surrogate for other habitat covariates that are directly or indirectly related to dissolved oxygen, such as in-stream habitat (pools and riffles), substrate, or stream flow. The amount of oxygen dissolved in streams is directly related to temperature and streamflow, which are both tied to gradient and sedimentation (Diller and Wallace, 1999). Any stream element that churns water will increase air-water oxygen exchange, so streams with a higher percentage of high gradient riffles or large cobbles and boulders will be more saturated with oxygen (EPA, 2012). Results of the linear regression analysis did not show that dissolved oxygen was associated with either percent pools or pebble size, but approximations of the percentage of riffles or the larger substrate that can create a riffle were not quantified as a part of this study and could differ substantially from percent pools and the overall substrate size. Results of the linear regressions comparing dissolved oxygen concentrations to different habitat covariates are provided in Appendix I. The covariance matrix and linear regression did show a positive association between channel confinement and dissolved oxygen. Channel confinement, 
which can be linked to undersized road crossings, alters stream habitat and flows, modifying dissolved oxygen values (Shields et al., 1994).

The positive correlation between dissolved oxygen and tailed frog occupancy in this and other studies may support the hypothesis that disturbance caused by road crossings impact tailed frog occupancy. Mulholland et al. (2005) showed that dissolved oxygen levels, a good indicator of reach-scale rates of stream metabolism, declined with disturbance levels. Additionally, studies have shown that water quality decreases immediately downstream of road crossings following rain events (Lane and Sheridan, 2002). The significance tests did not show a relationship between dissolved oxygen levels and road crossing diameter, length, or upstream versus downstream study reaches, but did show an association with channel confinement, indicating that the impacts of the road crossing and not necessarily the type of crossing structure may influence dissolved oxygen concentrations.

\section{$\underline{\text { Longitude }}$}

Several of the top models from the 2010/2011 dataset included longitude as one of the top weighted habitat covariates. Occupancy rates generally decreased as longitude increased. In the study area, increases in longitude corresponded to sites moving from West to East, with higher rates of occupancy at western sites. The covariance analysis showed that longitude was negatively associated with crayfish presence and positively associated with both elevation and latitude. Bury and Adams (1999) determined that larval tailed frog development was correlated to both latitude and elevation, with total length at one year decreasing at higher latitudes and higher elevations. Increases in 
longitude and elevation in the study area corresponded to sites moving further into the coastal range, where the climate is generally cooler year round. Environmental factors influenced by colder climates associated with increased longitude and elevation in the study area, and associated with increased latitude (distance from the equator) in Bury and Adams' study, could reduce habitat suitability for tailed frog larvae and reduce occupancy. While tailed frogs generally prefer colder stream temperatures, an overall colder climate could change vegetation types, substrate, and other habitat factors potentially influencing tailed frog occupancy.

\section{Crayfish Presence}

Kroll et al. (2008) determined that crayfish presence was negatively associated with tailed frog occupancy, which is contrary to the results of this model. Previous studies have found either no effect or were not able to detect an effect of crayfish occupancy on tailed frog larvae (Hunter, 1998). One explanation for the discrepancy between this study's model and that of Kroll et al. (2008) is that crayfish were present at 23 of the 28 sample study reaches (82\%). Similar to the problems with creating a reliable model when the naïve occupancy rate of amphibians is too high (Woods, 2007; Balas, 2008), high crayfish occupancy could similarly distort the model results. Regardless of the relationship, this study demonstrates that crayfish do not completely exclude tailed frogs from streams, with crayfish present in 16 of the 19 streams where tailed frogs were detected. 


\section{Pacific giant salamander}

Pacific giant salamanders were detected at a majority of the study reaches, demonstrating that they are capable of spanning a variety of habitat types and stream conditions in the study area. In order to effectively determine which habitat parameters impact Pacific giant salamander occupancy, a wider, more diverse, study area may be required. Each of the top weighted occupancy models demonstrated a strong bias towards binary habitat covariates, further limiting the reliability of the models in determining influential habitat covariates. While this study may not have been able to reliably predict which habitat covariates affect Pacific giant salamanders, it is clear that the presence of road crossing structures is not negatively influencing occupancy within the study area. Further investigation is needed to determine if abundance estimates of Pacific giant salamanders are the same at study reaches with and without road crossing structures.

\section{$\underline{\text { Constant Detection }}$}

The top weighted model for detecting Pacific giant salamanders consisted of the null model, or a constant rate of detection across all surveys. Constant detection likely resulted from the high naïve occupancy rate at all study reaches, demonstrating a very high rate of detection under all survey conditions. For surveys where salamanders were not detected, other survey covariates were too variable to assert a distinct influence on detection. For example, if weather was equally distributed between all four categories on days when giant salamanders were not detected, no individual weather type would emerge as influential on detection. Evaluation of abundance estimates at different surveys could potentially result in identification of an influential survey covariate, but that 
covariate might not have been included in this study. Abundance of individuals detected at each study reach during each survey is provided in Appendix C.

\section{$\underline{\text { Crayfish and Fish Presence }}$}

While the naïve occupancy rate of Pacific giant salamanders was considered too high to produce a dependable model, the best fitting models for Pacific giant salamanders showed that occupancy was positively associated with crayfish and fish presence. Both crayfish and small fish are a common prey item for larval giant salamanders (Esselstyn and Wildman, 1997), explaining their coexistence in streams. Most of the fish observed during the study were small minnows or other fish that were too young to identify, providing a valuable food source for developing salamanders (Californiaherps.com, 2012). Adult Pacific giant salamanders likely select stream segments with an adequate food supply for larval salamanders when depositing eggs. Additionally, female Pacific giant salamanders will move from upland areas to lay their eggs in streams and then guard their eggs for approximately 275 days before they hatch (Nussbaum, 1969), making it important for the females to have an adequate food source as well.

While all crayfish in the study were not identified to species level, the signal crayfish is the only species native to Oregon streams and was persistent throughout the study. Evaluations of the signal crayfish as an invasive species in California have shown that human reduction of the natural disturbance flow regime in streams can facilitate the invasion of this species by promoting dispersion (Light, 2003). Similarly, signal crayfish may be able to spread to Oregon streams outside of their natural range where flow patterns have been altered by small impoundments, such as undersized road crossings. 
Results of the chi-squared test shows that crayfish presence was significantly associated with downstream study reaches, and the covariance analysis and chi-squared test showed that fish presence was significantly associated with stream constriction. Crayfish were present at $86 \%$ of downstream study reaches compared to $79 \%$ of upstream study reaches, and fish were present at $92 \%$ of the unconstricted study reaches compared to $44 \%$ of the constricted study reaches. Because both crayfish and fish are a main food source for larval Pacific giant salamanders, reduced habitat for these prey species caused by movement barriers and restricted flows could negatively impact salamander occupancy. Further studies at areas where Pacific giant salamander occupancy is limited would provide additional insight into the degree to which fish presence impacts occupancy.

\section{Constriction}

Two of the highest weighted models for Pacific giant salamanders included constriction, or whether or not a road crossing was wider than the stream channel, as a habitat covariate influencing occupancy. Giant salamander occupancy was higher at stream reaches that were not constricted by road crossings. Road crossing structures that are not as wide as the stream channel can alter the transport of sediment and bedload material, change flow patterns, and change the composition of substrate and large woody debris. Each of the habitat covariates that can change due to constriction have been evaluated individually as a part of this study but inclusion of constriction in the top weighted models signifies that the overall effect of constriction could be influencing Pacific giant salamander occupancy. 
The covariance matrix shows that constriction was negatively linked to crossing material and diameter, total dissolved solids, and salinity. Because constriction was not associated with any of the habitat covariates known to be affected by undersized road crossings, the influence on Pacific giant salamander occupancy is likely the due to changes in flow and habitat or the cumulative result of one or more covariate acting in combination. Again, because naïve occupancy rates were too high to give reliable occupancy models, which habitat covariate linked to both constriction and giant salamander occupancy could not be determined.

\section{Columbia Torrent Salamanders}

Columbia torrent salamanders were only detected at one site in the study area, making it nearly impossible to draw real conclusions from the top weighted models. Analysis showed that detection rates were related to Julian date and occupancy rates were related to crayfish presence, fish presence, and whether the road crossing was fish passable. All of these relationships are based on finding three salamanders, later in the sample period, in a stream without crayfish or fish, adjacent to a culvert that is considered a fish barrier. Because the naïve occupancy rate was so low, the only conclusions that can be drawn from this data is that torrent salamanders are not completely excluded from sites with fish barrier culverts.

Given the low detection of torrent salamanders in the study area, it is reasonable to conclude that occupancy in the study area was also particularly low. Torrent salamander occupancy has been shown to increase as stream gradient increases and basin size

decreases, generally increasing occupancy rates moving towards headwater streams 
(Wilkins and Peterson, 2000). Site 3, where the torrent salamanders were found, is one of the lowest order streams with the highest gradients included in the study, suggesting that it might be on the very edge of the habitat range for torrent salamanders in the area. A wider sample including more high-gradient headwater streams would be useful for evaluating occupancy rates. Unfortunately, road crossings at high-gradient headwater streams are particularly difficult to access in the Wilson River watershed, as the downstream end of the site is typically located at the bottom of a very steep (high gradient) drop from the roadway.

\section{Conclusion}

The main objective of this study was to determine if different sizes and types of road crossings had different effects on SAA occupancy in adjacent stream reaches. Although the structure of road crossings did not prove to directly influence SAA occupancy significantly, several indicators of stream disturbance that can be related to the presence of road crossings were included in the best models for predicting occupancy. While Pacific giant salamander and Columbia torrent salamander naïve occupancy rates made the analysis results for those species unreliable, the coastal tailed frog datasets provided insight into the factors effecting occupancy, and more importantly, the factors that do not.

Dissolved oxygen, confinement, longitude, and crayfish presence are all habitat covariates that have been evaluated in earlier studies of coastal tailed frog occupancy. With the exception of crayfish presence, which is known to be particularly irresolute (Kroll et al., 2004), the relationship between SAA presence and the top weighted covariates coincided with existing literature. Results that agree with other studies imply 
that the study and methods were, for the most part, valid in determining factors influencing coastal tailed frog occupancy. Presumably, the study also validly determined the factors that do not influence SAA occupancy, such as road crossing diameter, length, type and whether those crossings restrict flows. None of the covariates directly related to road crossing structures ranked high enough to be considered significant indicators of occupancy, demonstrating that there is no direct relationship between the type of road crossing structure and coastal tailed frog occupancy in adjacent stream reaches. The type of road crossing could have a more variable effect on populations further downstream of the crossing, with the effect of larger crossings such as bridges dissipating more quickly than the effects of undersized culverts, but further studies are required to make that determination.

Despite not being able to contribute measurably to the results of the modeling analysis, the Pacific giant salamander and Columbia torrent salamander data did provide valuable information about their interactions with road crossing structures. Occupancy rates of Pacific giant salamanders in the study area appear to be unaffected by road crossings, fish passable or otherwise. Abundance estimates could vary, but Pacific giant salamanders do not discriminate between streams when it comes to occupancy in the study area. Conversely, torrent salamanders seemed to be mostly absent from the study sites altogether, but based on the one stream where they were detected, they are not excluded from occupying fish barrier culvert sites. It is clear that there is not enough evidence to determine that either species selects streams based on road crossing structure. 
Further studies encompassing multiple watersheds and land uses are needed to investigate the true impact that road crossing related disturbance has on SAA. Because confinement does affect coastal tailed frog occupancy, further research should evaluate the relationship between stream crossing structure and channel confinement and how occupancy changes as a result of extreme confinement in otherwise appropriately sized stream channels. A study emphasizing streams that show the severe effects of undersized road crossings could provide additional information about SAA occupancy. Additionally, studies centered either on the margins of Pacific giant salamander habitat or closer to the core of Columbia torrent salamander habitat would help determine if and how those species are limited by road crossings, and specifically whether flow constriction is significantly limiting giant salamander occupancy.

Beyond road crossing structures, the occupancy models made it possible to investigate how SAA react to stream disturbances known to upset life history patterns. Because stream disturbance can be closely tied to undersized road crossings (Castro, 2003), models that reflect how disturbance affects SAA occupancy demonstrates the importance of reducing road crossing related impacts on streams. Amphibians are an excellent indicator of the overall health of a stream system, and evaluating their response to environmental parameters should guide future management decisions. While road crossing size and structure were not shown to directly impact SAA in this study, factors related to overall disturbance do influence stream communities and should be taken into consideration when designing a road crossing. 


\section{References}

Adams, Michael and R. Bruce Bury. 2002. The endemic headwater stream amphibians of the American Northwest: association with environmental gradients in a large forested preserve. Global Ecology and Biogeography 11: 169-178.

AmphibiaWeb.com. 2010. Species Accounts. http://amphibiaweb.org/. Accessed May 2010.

Balas, Caleb J. 2008. The effects of conservation programs on amphibians of the prairie pothole region's glaciated plain. Master's thesis. Humboldt State University, Department of Natural Resources: Wildlife. June, 2008.

Barr, Garrett E. and Kimberly J. Babbitt. 2001. A comparison of 2 techniques to sample larval stream salamanders. Wildlife Society Bulletin 29(4): 1238-1242.

Beechie, Timothy J. and Thomas H. Sibley. 2011. Relationships between channel characteristics, woody debris, and fish habitat in northwestern Washington streams. Fisheries Research Institute, University of Washington, Seattle, WA. January 9, 2011.

Benton, Paul D., William E. Ensign, and Byron J. Freeman. 2008. The Effect of Road Crossings on Fish Movements in Small Etowah Basin Streams. Southeastern Naturalist 7: 301-310.

Boyer, Robin and Christian E. Grue. 1995. The Need for Water Quality Criteria for Frogs. Environmental Health Perspectives 103(4): 352-357.

Burnham, K. P., and Anderson, D.R. 2002. Model Selection and Multimodel Inference: A Practical Information-Theoretic Approach, 2nd ed. Springer-Verlag. ISBN 0-38795364-7.

Bury, R. Bruce. 1970. Food similarties in thetailed frog, Ascaphus truei, and the Olympic salamander, Rhyacotriton olympicus. Copeia 1970: 170-171.

Bury, Bruce and Michael J. Adams. 1999. Variation in age at metamorphosis across a latitudinal gradient for the tailed frog, Ascaphus truei. Herpetologica 55:283-291.

Bury, R. Bruce and Paul Stephen Corn. 1991. Sampling Methods for Amphibians in Streams in the Pacific Northwest. United States Department of Agriculture, Forest Service. Pacific Northwest Research Station. General Technical Report PNW-GTR275, November 1991.

Bury, R.B. and M. Martin. 1967. The food of the salamander Rhyaotriton olympicus. Copeia 1967:487.

Californiaherps.com. 2010. Dicamptodon tenobrasus - Coastal Giant Salamander. http://www.californiaherps.com/salamanders/pages/d.tenebrosus.html. Accessed May 2010. 
Caltrans. 2007. Fish Passage Design for Road Crossings: An Engineering Document Providing Fish Passage Design Guidance for Caltrans Projects. May 2007.

Castro, Janine. 2003. Geomorphologic Impacts of Culvert Replacement and Removal: Avoiding Channel Incision. U.S. Fish and Wildlife Service, Portland, OR.

Corn, Paul Stephen and R. Bruce Bury. 1989. Logging in western Oregon: responses of headwater habitats and stream amphibians. Forest Ecology and Management 29: 3957.

Community Collaborative Rain, Hail, and Snow Network (CoCoRaHS). 2012. http://www.cocorahs.org/ViewData/StationPrecipSummary.aspx. Accessed September 25, 2012.

Dickerson, Dena D. 2001. Riparian Habitat Management for Reptiles and Amphibians on Corps of Engineers Projects. ERDC TN-EMRRP-SI-22.

Diller, Lowell V. and Richard L. Wallace. 1999. Distribution and habitat of Ascaphus truei in streams on managed young growth forests in North Coastal California. Journal of Herpetology 33: 71-79.

Environmental Protection Agency (EPA). 2012. Water: Monitoring and Assessment, Section 5.2 Dissolved Oxygen and Biochemical Oxygen Demand. http://water.epa.gov/type/rsl/monitoring/vms52.cfm. Accessed November 18, 2012, Updated: March 6, 2012.

Esselstyn, Jacob A. and Randall C. Wildman. 1997. Observations of Juga in the diet of larval Pacific giant salamanders (Dicamptodon tenebrosus). Northwestern Naturalist 78:79-73.

Hayes, Marc. 2010. Personal Communication with Sara Twitchell. February 8, 2010.

Hayes, Marc P., Timothy Quinn, Daniel J. Dugger, Tiffany L. Hicks, M. Anthony Mechiors, and Douglas E. Runde. 2006. Dispersion of coastal tailed frog (Ascaphus truei): An hypothesis relating occurrence of frogs in non-fish bearing headwater basins to their seasonal movements. Journal of Herpetology 40: 531-543.

Hunter, Matthew G. 1998. Watershed-level Patterns among stream amphibians in the Blue River Watershed, West-Central Cascades of Oregon. Master's thesis. Oregon State University, Forest Sciences Department.

Johnson, Robert R. and Patricia J. Kuby. 2000. Elementary Statistics. Duxbury Press. ISBN 0534356761, 9780534356767

Keating, Kim and Steve Cherry. 2004. Use and interpretation of logistic regression in habitat-selection studies. The Wildlife Society 68: 774-789.

Kroll, Andrew J., Ken Risenhoover, Tim McBride, Eric Beach, Brian J. Kernohan, Jeff Light, and Janette Bach. 2008. Factors influencing stream occupancy and detection 
probability parameters of stream-associate amphibians in commercial forests of Oregon and Washington, USA. Forest Ecology and Management 255: 3726-3735.

Lassettre, Neil S. and G. Mathias Kondolf. 2003. Process based management of large woody debris at the basin scale, Soquel Creek, California. Report presented to California Department of Forestry and Fire Protection by the Department of Landscape Architecture and Environmental Planning, University of California, Berkeley.

Light, Theo. 2003. Success and failure in a lotic crayfish invasion: the roles of hydrologic variability and habitat alteration. Freshwater Biology 48: 1886-1897.

MacKenzie, Darryl I. and Larissa Bailey. 2004. Assessing the Fit of Site-Occupancy Models. Journal of Agricultural, Biological, and Environmental Statistics. 9(3): 300318.

MacKenzie, Darryl I. et. Al. 2002. Estimating site occupancy rates when detection probabilities are Less than one. Ecology. 83: 2248-2255.

MacKenzie, Darryle i., James D. Nichols, James E. Hines, Melinda G. Knutson, and Alan B. Franklin. Estimating site occupancy, colonization and local extinction when a species is detected imperfectly. Ecology 84: 2200-2207.

MacKenzie, Darryl I. and Andrew Royle. 2005. Designing Occupancy studies: general advice and allocating survey effort. Journal of Applied Ecology 42: 1105 - 1114.

Mulholland, Patrick J, Jeffrey Houser, and Kelly Maloney. 2005. Stream diurnal dissolved oxygen profiles as indicators of in-stream metabolism and disturbance effects: Fort Benning as a case study. Ecoloical Indicators 5:243-252.

National Audubon Society, 1979. Field Guide to Reptiles and Amphibians. Chanticleer Press, Inc. New York, New York. December 1979 (26th printing February 2011). Page 301.

Noble, G. K. and Phillips G. Putnam. 1931. Observations on the Life History of Ascaphus truei Stejneger. Copeia 1931: 97-101.

Nussbaum, R. A., E. Brodie, and R.M. Storm. 1983. Amphibians and Reptile dos the Pacific Northwest. University Press Idaho, Moscow, Idaho. 332 pp.

Nystrom, P. and K. Abjornsson. 2000. Effects of fish chemical cues on the interactions between tadpoles and crayfish. Oikos 88:181-190.

ODF (Oregon Department of Forestry). 1994. The Oregon Forest Practices Act Water Protection Rules: Scientific and policy considerations. Prepared by the Forest Practices Policy Unit. December 1994.

ODF. 2001. Northwest Oregon State Forests Management Plan. http://www.oregon.gov/ODF/STATE_FORESTS/nwfmp.shtml 
ODF. 2008a. Wilson River Watershed Assessment: Tillamook State Forest. March 2008. http://www.oregon.gov/ODF/STATE_FORESTS/watershed.shtml.

Oregon Department of Fish and Wildlife (ODFW). 2001. Wilson River Watershed Assessment. Prepared by E\&S Environmental Chemistry, Inc. for ODFW. October, 2001.

O'Hanley, Jesse Rush and David Tomberlin. 2005. Optimizing the Removal of Small Fish Passage Barriers. Environmental Modeling and Assessment 10: 85-98.

Oregon Forest Resources Institute, 2009. Wildlife in Managed Forests: Stream Associated Amphibians. Prepared for the Oregon Forest Resources Institute by Gail Wells, Gail Wells Communication, Corvallis, Oregon. 2009.

Oregon Watershed Enhancement Board (OWEB). 1999. Oregon watershed assessment manual, component III, channel habitat type classification.

Poff, N. Leroy, J. David Allen, Mark B. Bain, James R. Karr, Karen L. Prestegaard, Brian D. Richter, Richard E. Sparks, and Julie C. Stromberg. 1997. The Natural Flow Regime. Bioscience 47: 769-784.

Quinn, Timothy, Marc P. Hayes, Daniel J. Dugger, Tiffany L. Hicks, and Annette Hoffman. 2006. Comparison of two techniques for surveying headwater stream amphibians. Journal of Wildlife Management 7(1): 282-288.

Roper, Brett, Jeffrey Kershner, Eric Archer, Richard Henderson, and Nicolaas Bouwes. 2002. An Evaluation of Physical Stream Habitat Attributes used to Monitor Streams. Journal of the American Water Resources Association 38(6):1637-1646.

Rundio, David E. and Deanna H. Olson. 2001. Palatability of southern torrent salamanders (Rhyacotriton variegates) larvae to Pacific giant salamanders (Dicamptodon tenebrosus) larvae. Journal of Herpetology 35(1): 133-136.

Russell, Kevin R., Todd J. Mabee, Michael B. Cole, and Michael J. Rochelle. 2005. Evaluating the biotic and abiotic influences on torrent salamanders in managed forests in western Oregon. Wildlife Society Bulletin 33: 1413-1424.

Sagar, Gina. Movement and Demography of Larval Coastal Giant Salamanders (Dicamptodon tenebrosus) in Streams with Culvers in the Oregon Coast Range. Master's thesis. Oregon State University, Wildlife Science.

Shafroth, Patrick B., Jonathan M. Friedman, Gregor T. Auble, Michael L. Scott, and Jeffrey H. Braatne. 2002. Potential Response of Riparian Vegetation to Dam Removal. Bioscience 52: 703-712.

Shields, F.D., S.S. Knight, and C.M. Cooper. 1994. Effects of Channel Incision on Base Flow Stream Habitats and Fishes. Environmental Management 18(1): 43-57. 
Stoddard, Margo A. and John P. Hayes. 2005. The Influence of Forest Management on Headwater Stream Amphibians at Multiple Spatial Scales. Ecological Applications 15(3): 811-823.

Watson, Greg and T.W. Hillman. 2011. Factors affecting the distribution and abundance of bull trout: an investigation at hierarchical scales. North American Journal of Fisheries Management 17(2): 237-252.

Washington Department of Natural Resources (WDNR). 2002. Channel migration zones and bankfull channel features. Forest Practices Board Manual. November 2004.

Wellman, Jennifer C., Daniel L. Combs, and S. Bradford Cook. 2000. Long-term impacts of bridge and culvert construction or replacement on fish communities and sediment characteristic of stream. Journal of Freshwater Ecology 15(3): 317-328.

Welsh, Hartwell H. and Lisa M. Ollivier. 1998. Stream amphibians as indicators of ecosystem stress: a case study from California's redwoods. Ecological Applications 8(4): 1118-1132.

Wild Salmon Center. 2002. Culvert Installation in Salmon Streams. White Paper.

Wilkins, Neal and Phil Peterson. 2000. Factors related to amphibian occurrence and abundance in headwater streams draining second-growth Douglas-fir forests in southwestern Washington. Forest Ecology an Management 139: 79-91.

Wolman, M. Gordon. 1954. A method of sampling coarse river-bed material. Transactions, American Geophysical Union. Volume 35, Number 6.

Wolman, Gordon M. 1967. A Cycle of Sedimentation and Erosion in Urban River Channels. Geografiska Annaler. Series A, Physical Geography 49: 385-395.

Woods, Eric M. 2007. Occupancy models of focal bird species in central Sierra Nevada foothill Woodlands, California. Master's thesis. Humboldt State University, Department of Wildlife.

Yuskavitch, Jim. 2008. Fishing Oregon: An Angler's Guide to Oregon (2nd edition). Guilford, Connecticut: The Lyons Press. Pg. 44-45. 
Appendix A. Representative photos of SAA found in the Wilson River watershed, Tillamook State Forest, Oregon.

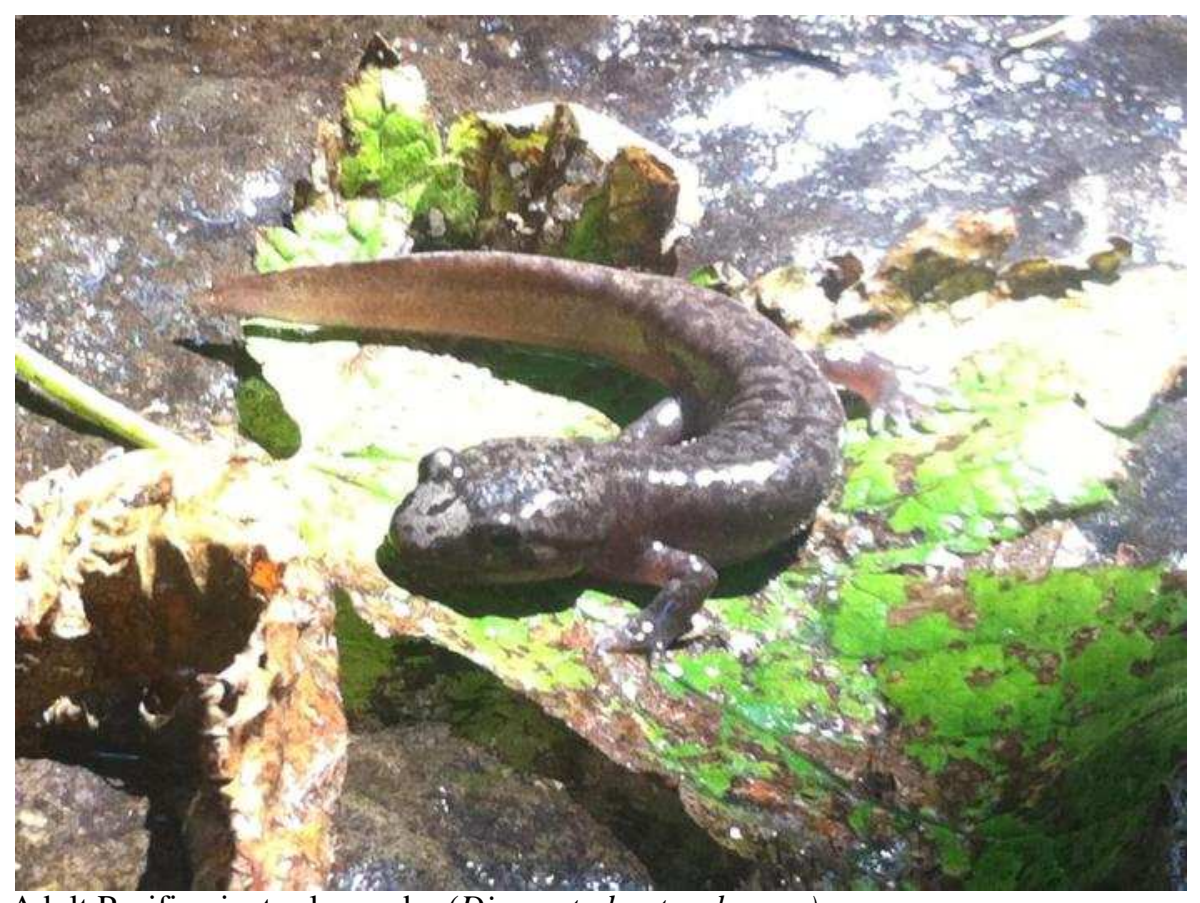

Adult Pacific giant salamander (Dicamptodon tenebrosus)

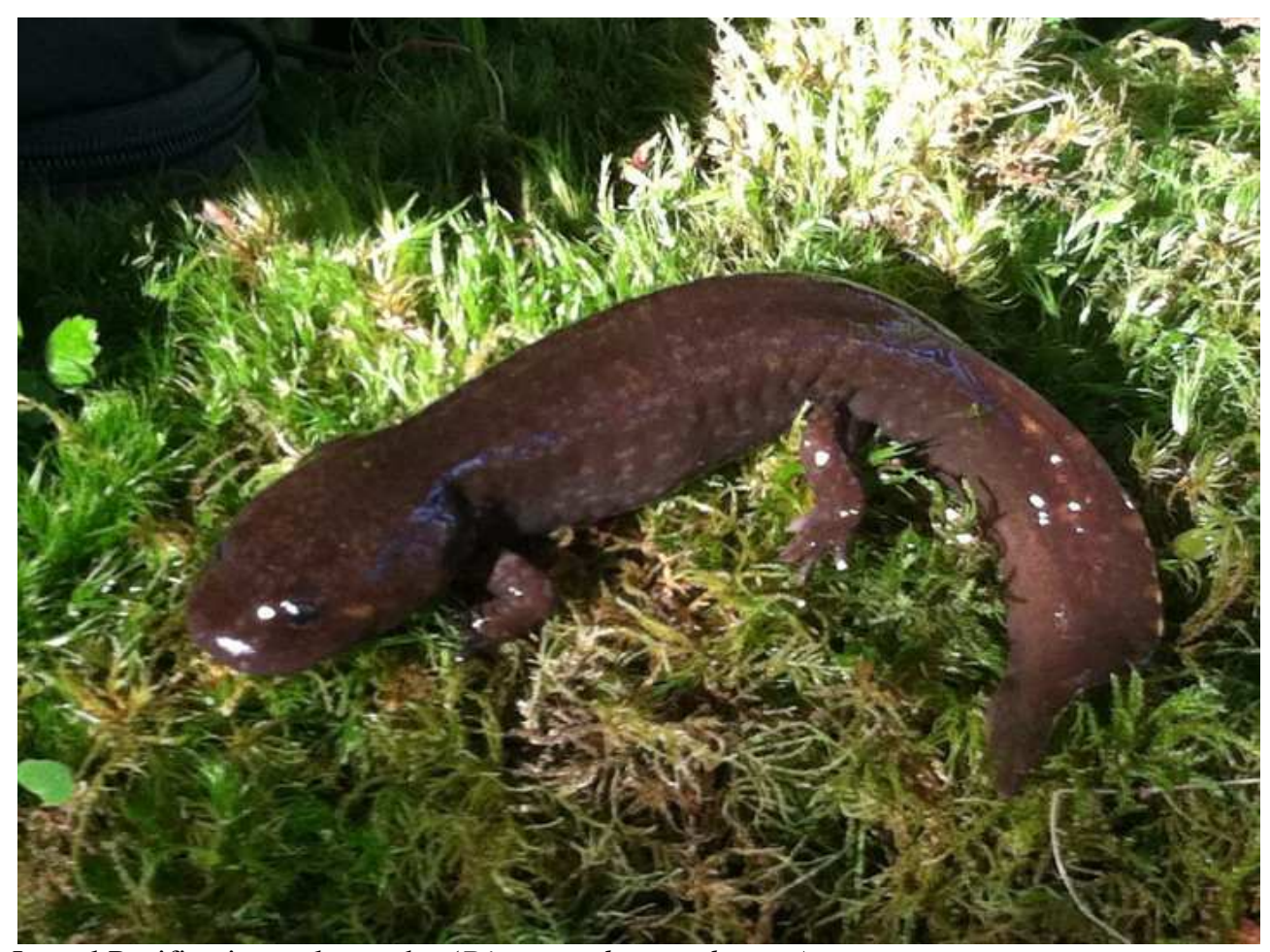

Larval Pacific giant salamander (Dicamptodon tenebrosus) 

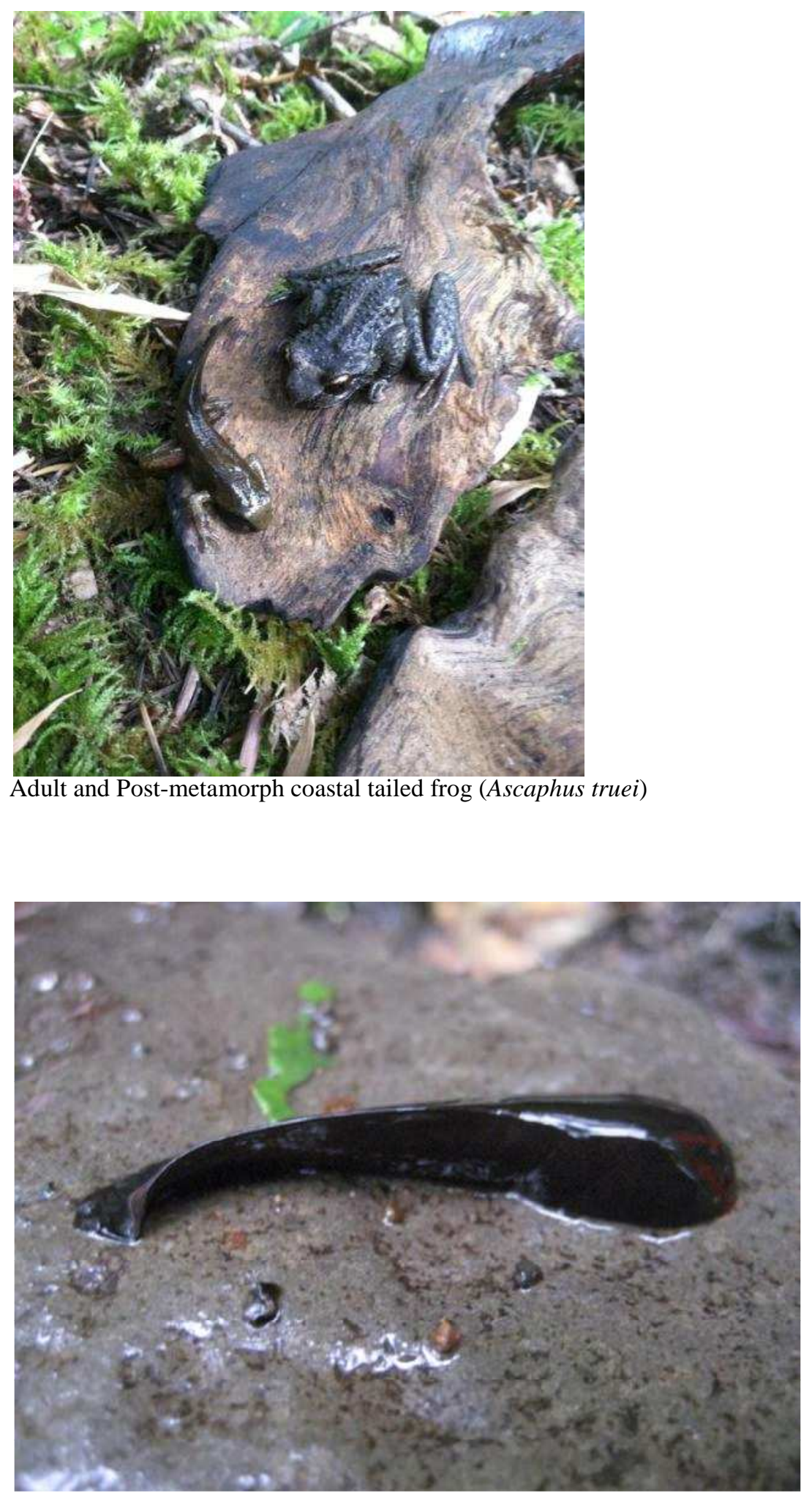

Larval coastal tailed frog (Ascaphus truei) 


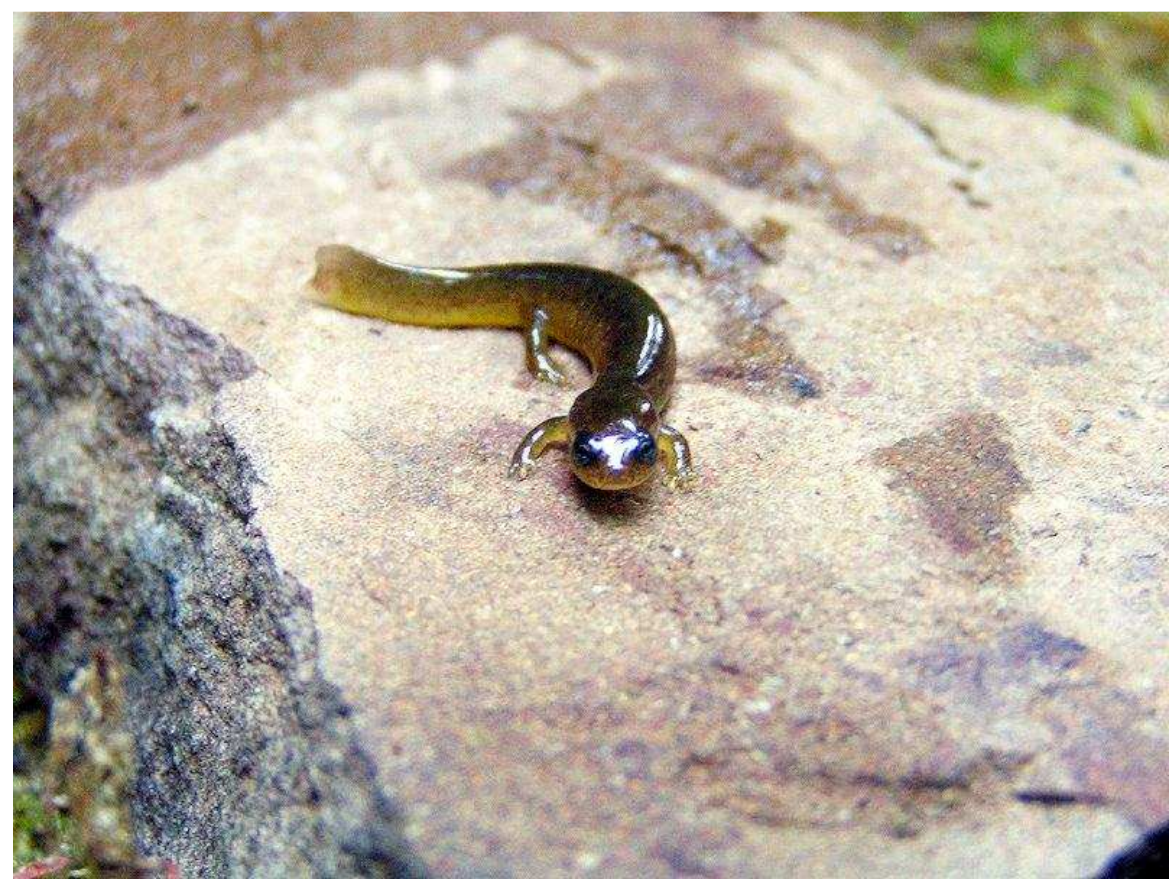

Larval Columbia torrent salamander (Rhyacotriton kezeri)

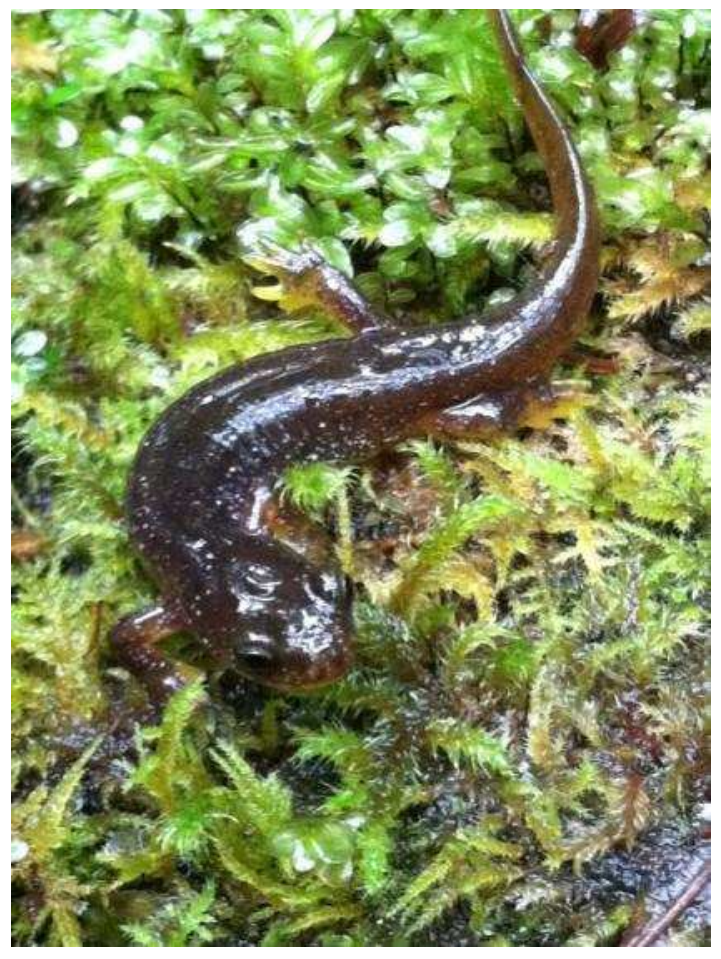

Subadult Columbia torrent salamander (Rhyacotriton kezeri) 


\section{Appendix B. Descriptions and representative photos of stream reaches assessed during surveys including habitat covariates evaluated for their influence on each species' occupancy.}

Each road crossing site was evaluated for habitat features that may affect amphibian occupancy. A summary of each of the upstream and downstream segments is provided in Table B-1. Elevation of stream crossings ranged from 404 to 1,975 feet $(123-602$ meters) above mean sea level, with overstories dominated by alder, Douglas fir, or a combination of alder and maple. Stream incision varied from 13 to 92 percent with gradients spread between 2 and 21 degrees. Stream substrates were mostly dominated by either consolidated or unconsolidated basalt with pebble size ranging from fine sediment to large cobbles. Water quality was fairly uniform between sites for all parameters measured. Large woody debris was fairly uniformly distributed amongst sizes, with percent cover ranging between 0 and 40 percent, and most sites falling between 5 and 20 percent. Culverts ranged in size from 39 to 89 inches $(99-226 \mathrm{~cm})$ in diameter and 420 to 852 inches $(1067-2,164 \mathrm{~cm})$ long. Bridges ranged from 204 to 696 inches $(518-$ $1,768 \mathrm{~cm}$ ) wide (from bank to bank) and 168 to 672 inches $(427-1707 \mathrm{~cm}$ ) across, with all but one footbridge being more than 200 inches across. A description and representative photos of each site are provided below. 
Table B-1. Summary of habitat characteristics expected to affect amphibian occupancy by sample reaches.

\begin{tabular}{|c|c|c|c|c|c|c|c|c|c|c|c|c|c|}
\hline $\begin{array}{c}\text { Sample } \\
\text { Reach }\end{array}$ & $\begin{array}{c}\text { Riparia } \\
\text { n Type }\end{array}$ & $\begin{array}{l}\text { Tree } \\
\text { Cover } \\
(\%)\end{array}$ & $\begin{array}{l}\text { Gradient } \\
\text { (degrees) }\end{array}$ & $\begin{array}{l}\text { Bank full } \\
\text { Width } \\
\text { (cm) }\end{array}$ & $\begin{array}{l}\text { Floodplain } \\
\text { Width } \\
\text { (cm) }\end{array}$ & $\begin{array}{l}\text { Pools } \\
(\%)\end{array}$ & Substrate & $\begin{array}{c}\text { Substrate } \\
\text { Size } \mathbf{D}_{\mathbf{5 0}} \\
(\mathbf{m m})\end{array}$ & $\begin{array}{c}\text { Small } \\
\text { LWD } \\
\text { Cover } \\
(\%)\end{array}$ & $\begin{array}{c}\text { Med } \\
\text { LWD } \\
\text { Cover } \\
(\%) \\
\end{array}$ & $\begin{array}{c}\text { Lrg } \\
\text { LWD } \\
\text { Cover } \\
(\%) \\
\end{array}$ & $\begin{array}{c}\text { Cray } \\
\text {-fish }\end{array}$ & Fish \\
\hline $1 \mathrm{~A}$ & Alder & 23 & 9 & 224 & 841 & 40 & $\begin{array}{l}\text { U-basalt, } \\
\text { U-organic }\end{array}$ & 4 & 3 & 7 & 2 & $X$ & $X$ \\
\hline 1B & Alder & 21 & 6 & 193 & 323 & 15 & $\begin{array}{l}\text { U-basalt, } \\
\text { U-organic }\end{array}$ & 6 & 5 & 15 & 20 & $X$ & $X$ \\
\hline $2 \mathrm{~A}$ & Alder & 19 & 4 & 71 & 823 & 30 & $\begin{array}{l}\text { C-basalt, } \\
\text { U-organic }\end{array}$ & 8 & 3 & 15 & 1 & & $\mathrm{X}$ \\
\hline $3 \mathrm{~A}$ & Alder & 14 & 7 & 318 & 864 & 25 & $\begin{array}{l}\text { C-basalt, } \\
\text { U-basalt, } \\
\text { U-glacial }\end{array}$ & 45 & 2 & 5 & 10 & $\mathrm{X}$ & \\
\hline $3 \mathrm{~B}$ & Alder & 23 & 18 & 437 & 653 & 15 & $\begin{array}{l}\text { C-basalt, } \\
\text { U-basalt, } \\
\text { U-organic }\end{array}$ & 64 & 1 & 5 & 5 & & \\
\hline $4 \mathrm{~A}$ & Doug Fir & 16 & 6 & 130 & 569 & 30 & $\begin{array}{l}\text { C-basalt, } \\
\text { U-marine, } \\
\text { U-organic }\end{array}$ & 8 & 2 & 3 & 5 & $\mathrm{X}$ & $\mathrm{X}$ \\
\hline $4 \mathrm{~B}$ & Doug Fir & 26 & 4 & 99 & 554 & 10 & $\begin{array}{l}\text { U-basalt, } \\
\text { U-organic }\end{array}$ & 4 & 5 & 7 & 10 & & \\
\hline $5 \mathrm{~A}$ & Alder & 14 & 2 & 257 & 1140 & 25 & $\begin{array}{l}\text { C-basalt, } \\
\text { U-basalt, } \\
\text { U-marine }\end{array}$ & 64 & 0 & 2 & 0 & $\mathrm{X}$ & $\mathrm{X}$ \\
\hline $5 \mathrm{~B}$ & $\begin{array}{l}\text { Alder/ } \\
\text { maple }\end{array}$ & 69 & 17 & 610 & 859 & 30 & $\begin{array}{l}\text { C-basalt, } \\
\text { U-basalt, } \\
\text { U-marine }\end{array}$ & 128 & 10 & 15 & 25 & $\mathrm{X}$ & \\
\hline $6 \mathrm{~A}$ & Alder & 21 & 14 & 183 & 244 & 35 & $\begin{array}{l}\text { C-basalt, } \\
\text { U-organic }\end{array}$ & 4 & 3 & 5 & 4 & $\mathrm{X}$ & $\mathrm{X}$ \\
\hline $6 \mathrm{~B}$ & Alder & 18 & 21 & 170 & 236 & 15 & $\begin{array}{l}\text { C-basalt, } \\
\text { U-organic }\end{array}$ & 8 & 5 & 10 & 40 & $\mathrm{X}$ & \\
\hline $7 \mathrm{~A}$ & Alder & 27 & 5 & 305 & 831 & 15 & $\begin{array}{l}\text { C-basalt, } \\
\text { U-basalt, } \\
\text { U-marine }\end{array}$ & 128 & 5 & 7 & 10 & $\mathrm{x}$ & $\mathrm{X}$ \\
\hline $7 \mathrm{~B}$ & Alder & 25 & 4 & 376 & 838 & 20 & $\begin{array}{l}\text { U-basalt, } \\
\text { U-marine }\end{array}$ & 128 & 3 & 5 & 2 & $\mathrm{X}$ & $\mathrm{X}$ \\
\hline
\end{tabular}




\begin{tabular}{|c|c|c|c|c|c|c|c|c|c|c|c|c|c|}
\hline $\begin{array}{l}\text { Sample } \\
\text { Reach }\end{array}$ & $\begin{array}{c}\text { Riparia } \\
\text { n Type }\end{array}$ & $\begin{array}{c}\text { Tree } \\
\text { Cover } \\
(\%)\end{array}$ & $\begin{array}{l}\text { Gradient } \\
\text { (degrees) }\end{array}$ & $\begin{array}{l}\text { Bank full } \\
\text { Width } \\
\text { (cm) }\end{array}$ & $\begin{array}{l}\text { Floodplain } \\
\text { Width } \\
\text { (cm) }\end{array}$ & $\begin{array}{l}\text { Pools } \\
(\%)\end{array}$ & Substrate & $\begin{array}{c}\text { Substrate } \\
\text { Size } \mathbf{D}_{50} \\
(\mathbf{m m})\end{array}$ & $\begin{array}{c}\begin{array}{c}\text { Small } \\
\text { LWD } \\
\text { Cover } \\
(\%)\end{array} \\
\end{array}$ & $\begin{array}{c}\text { Med } \\
\text { LWD } \\
\text { Cover } \\
(\%) \\
\end{array}$ & $\begin{array}{c}\text { Lrg } \\
\text { LWD } \\
\text { Cover } \\
(\%) \\
\end{array}$ & $\begin{array}{l}\text { Cray } \\
\text {-fish }\end{array}$ & Fish \\
\hline $8 \mathrm{~A}$ & Alder & 19 & 18 & 251 & 574 & 35 & $\begin{array}{l}\text { C-basalt, } \\
\text { U-basalt, } \\
\text { U-marine }\end{array}$ & 16 & 5 & 2 & 2 & $\mathrm{X}$ & $\mathrm{X}$ \\
\hline $8 \mathrm{~B}$ & Alder & 16 & 4 & 221 & 648 & 30 & $\begin{array}{l}\text { C-basalt, } \\
\text { U-basalt, } \\
\text { U-marine }\end{array}$ & 23 & 5 & 2 & 10 & $\mathrm{X}$ & $\mathrm{X}$ \\
\hline $9 \mathrm{~A}$ & Alder & 17 & 9 & 208 & 427 & 10 & $\begin{array}{l}\text { C-basalt, } \\
\text { U-basalt }\end{array}$ & 16 & 2 & 2 & 5 & $\mathrm{X}$ & \\
\hline 9B & Alder & 32 & 12 & 264 & 574 & 3 & $\begin{array}{l}\text { C-basalt, } \\
\text { U-basalt }\end{array}$ & 23 & 5 & 7 & 2 & $\mathrm{X}$ & \\
\hline $10 \mathrm{~A}$ & Alder & 21 & 14 & 130 & 716 & 15 & $\begin{array}{l}\text { C-basalt, } \\
\text { U-basalt, } \\
\text { U-marine }\end{array}$ & 22 & 4 & 5 & 7 & $\mathrm{X}$ & $\mathrm{X}$ \\
\hline 10B & Alder & 21 & 9 & 536 & 696 & 10 & $\begin{array}{l}\text { C-basalt, } \\
\text { U-basalt, } \\
\text { U-marine }\end{array}$ & 16 & 1 & 3 & 5 & $\mathrm{X}$ & \\
\hline $11 \mathrm{~A}$ & $\begin{array}{l}\text { Alder/ } \\
\text { maple }\end{array}$ & 18 & 9 & 107 & 635 & 15 & $\begin{array}{l}\text { U-basalt, } \\
\text { U-marine, } \\
\text { U-organic }\end{array}$ & 180 & 5 & 5 & 15 & $\mathrm{X}$ & $\mathrm{X}$ \\
\hline 11B & $\begin{array}{l}\text { Alder/ } \\
\text { maple }\end{array}$ & 16 & 9 & 109 & 480 & 15 & $\begin{array}{l}\text { U-basalt, } \\
\text { U-marine, } \\
\text { U-organic }\end{array}$ & 64 & 10 & 7 & 15 & $\mathrm{X}$ & $\mathrm{X}$ \\
\hline $12 \mathrm{~A}$ & Alder & 14 & 9 & 178 & 348 & 5 & $\begin{array}{l}\text { U-basalt, } \\
\text { U-marine, } \\
\text { U-organic }\end{array}$ & 32 & 5 & 10 & 10 & $\mathrm{X}$ & $\mathrm{X}$ \\
\hline $12 \mathrm{~B}$ & Alder & 15 & 11 & 262 & 472 & 5 & $\begin{array}{l}\text { U-basalt, } \\
\text { U-marine, } \\
\text { U-organic }\end{array}$ & 45 & 20 & 15 & 20 & $\mathrm{X}$ & $\mathrm{X}$ \\
\hline $13 \mathrm{~A}$ & Alder & 35 & 8 & 160 & 384 & 20 & $\begin{array}{l}\text { U-basalt, } \\
\text { U-marine, } \\
\text { U-organic }\end{array}$ & 64 & 2 & 1 & 2 & & \\
\hline $13 \mathrm{~B}$ & Alder & 27 & 8 & 69 & 536 & 3 & $\begin{array}{l}\text { U-basalt, } \\
\text { U-marine, } \\
\text { U-organic }\end{array}$ & 45 & 2 & 4 & 1 & & \\
\hline
\end{tabular}




\begin{tabular}{|c|c|c|c|c|c|c|c|c|c|c|c|c|c|}
\hline $\begin{array}{c}\text { Sample } \\
\text { Reach }\end{array}$ & $\begin{array}{l}\text { Riparia } \\
\text { n Type }\end{array}$ & $\begin{array}{c}\text { Tree } \\
\text { Cover } \\
(\%)\end{array}$ & $\begin{array}{l}\text { Gradient } \\
\text { (degrees) }\end{array}$ & $\begin{array}{c}\text { Bank full } \\
\text { Width } \\
\text { (cm) }\end{array}$ & $\begin{array}{l}\text { Floodplain } \\
\text { Width } \\
\text { (cm) }\end{array}$ & $\begin{array}{c}\text { Pools } \\
(\%)\end{array}$ & Substrate & $\begin{array}{c}\text { Substrate } \\
\text { Size } D_{50} \\
(\mathbf{m m})\end{array}$ & $\begin{array}{c}\text { Small } \\
\text { LWD } \\
\text { Cover } \\
(\%)\end{array}$ & $\begin{array}{c}\text { Med } \\
\text { LWD } \\
\text { Cover } \\
(\%)\end{array}$ & $\begin{array}{c}\text { Lrg } \\
\text { LWD } \\
\text { Cover } \\
(\%)\end{array}$ & $\begin{array}{l}\text { Cray } \\
\text {-fish }\end{array}$ & Fish \\
\hline $14 \mathrm{~A}$ & Doug Fir & 19 & 19 & 180 & 592 & 20 & $\begin{array}{l}\text { C-basalt, } \\
\text { U-basalt, } \\
\text { U-organic }\end{array}$ & 180 & 5 & 5 & 7 & & \\
\hline 14B & Doug Fir & 22 & 4 & 170 & 208 & 15 & $\begin{array}{l}\text { C-basalt, } \\
\text { U-basalt, } \\
\text { U-organic }\end{array}$ & 22 & 5 & 10 & 10 & & \\
\hline
\end{tabular}


Table B-1 (cont.). Summary of habitat characteristics expected to affect amphibian occupancy by sample reaches

\begin{tabular}{|l|c|c|c|c|}
\hline $\begin{array}{c}\text { Sample } \\
\text { Reach }\end{array}$ & TDS (g/L) & Sal (ppt) & DO $(\boldsymbol{\%})$ & $\mathbf{p H}$ \\
\hline 1A & 0.114 & 0.08 & 117.4 & 6.95 \\
\hline 1B & 0.114 & 0.08 & 116.5 & 6.95 \\
\hline 2A & 0.052 & 0.04 & 96.3 & 7.75 \\
\hline 2B & 0.053 & 0.04 & 107.1 & 7.75 \\
\hline 3A & 0.058 & 0.04 & 157.1 & 7.13 \\
\hline 3B & 0.06 & 0.04 & 147.9 & 6.84 \\
\hline 4A & 0.076 & 0.05 & 122.2 & 7.55 \\
\hline 4B & 0.08 & 0.06 & 122.9 & 7.62 \\
\hline 5A & 0.081 & 0.06 & 141.3 & 7.43 \\
\hline 5B & 0.079 & 0.06 & 159.3 & 7.28 \\
\hline 6A & 0.056 & 0.04 & 141.6 & 7.05 \\
\hline 6B & 0.055 & 0.04 & 146.1 & 6.97 \\
\hline 7A & 0.082 & 0.06 & 151.2 & 7.04 \\
\hline 7B & 0.082 & 0.06 & 142.5 & 7.15 \\
\hline 8A & 0.124 & 0.09 & 119.8 & 6.99 \\
\hline 8B & 0.082 & 0.06 & 121.6 & 7.04 \\
\hline 9A & 0.087 & 0.06 & 127.9 & 6.92 \\
\hline 9B & 0.086 & 0.06 & 122.2 & 7.16 \\
\hline 10A & 0.081 & 0.06 & 144.8 & 7.28 \\
\hline 10B & 0.081 & 0.06 & 144.8 & 7.28 \\
\hline 11A & 0.082 & 0.06 & 121.6 & 6.92 \\
\hline 11B & 0.082 & 0.06 & 118.3 & 6.97 \\
\hline 12A & 0.113 & 0.08 & 135.1 & 7.06 \\
\hline 12B & 0.115 & 0.08 & 142.3 & 7.18 \\
\hline 13A & 0.108 & 0.08 & 140.1 & 7.22 \\
\hline 13B & 0.108 & 0.08 & 138.3 & 7.42 \\
\hline 14A & 0.054 & 0.04 & 140.9 & 7.62 \\
\hline 14B & 0.056 & 0.04 & 146.1 & 7.61 \\
\hline & & & & \\
\hline
\end{tabular}




\section{$\underline{\text { Site } 1}$}

Site 1 is a steel beam footbridge over an unnamed tributary to Jones Creek, located on an off-road vehicle path east of Ben Smith Creek Road at latitude 45.584, longitude 123.381. Site 1 is 3,642 feet $(1,110$ meters) southeast of the Wilson River with an elevation of 680 feet (207 meters) above sea level. National Wetlands Inventory (NWI) data for the area depict a riverine, upper perennial, unconsolidated bottom, semipermanently flooded (R3UBF) wetland feature in the area of the site. The footbridge at Site 1 is 576 inches $(1,463 \mathrm{~cm})$ across and 48 inches $(122 \mathrm{~cm})$ wide. The stream reach downstream of the footbridge (Site 1A) is a shallow, slow moving stream consisting of glide habitat with gently sloping banks. Just downstream of the study area, there is a steep rocky drop off where the tributary joined Jones Creek. The stream reach upstream of the footbridge (Site 1B) is a small, quickly flowing stream, dominated by riffle and run habitat, surrounded by dense vegetation. Site 1 was surveyed on three separate occasions in both 2010 and 2011.

\section{$\underline{\text { Site } 2}$}

Site 2 is a steel culvert that transports an unnamed tributary to the Devils Lake Fork Wilson River, east of Beaver Dam Road at latitude 45.617, longitude -123.345. Site 2 is located 1,444 feet (440 meters) east of the Wilson River with an elevation of 1,671 feet (509 meters) above sea level. NWI data for the area depict a riverine, intermittent, streambed, seasonally flooded (R4SBC) wetland feature in the area of the site. The culvert at Site 2 is 480 inches $(1,219 \mathrm{~cm})$ long and 43 inches $(109 \mathrm{~cm})$ in diameter. The stream reach downstream of the culvert (Site 2A) consists of a shallow, narrow stream that varies from steeper deeply incised areas to more open valleys with low gradient 
mostly vegetated banks. Stream habitat is mostly made up of slow moving glides. The stream reach upstream of the culvert (Site $2 \mathrm{~b}$ ) is a slow moving stream that varies from a narrow bedrock-lined channel to a flat vegetated marsh. Stream habitat varies from steppool to riffle/glide. Site 2 was surveyed on three separate occasions in both 2010 and 2011.

$\underline{\text { Site } 3}$

Site 3 is a steel culvert that transports an unnamed tributary to the South Fork Wilson River under Lyda Road. Site 3 is 12,139 feet (3,700 meters) east of the Wilson River at latitude 45.573 , longitude -123.455 . The elevation of Site 2 is 1,880 feet ( 573 meters) above sea level. NWI data for the area depict a riverine, upper perennial, unconsolidated bottom, semipermanently flooded (R3UBF) wetland feature in the area of the site. The culvert at Site 3 is 860 inches $(2,184 \mathrm{~cm})$ long and 89 inches $(226 \mathrm{~cm})$ in diameter. The stream reach downstream of the culvert (Site 3A) consists of a cascading stream flowing through a vegetated ravine. The study reach was mostly flat with rocky banks. The stream reach upstream of the culvert (Site 3B) is a narrow quickly flowing stream with steep vegetated banks. Stream habitat is a mix of step-pool and riffle. An area 640 feet (195 meters) to the east of Site 3B had been logged shortly before surveys occurred in 2010 and had no tree cover. Site 3 was surveyed on three separate occasions in both 2010 and 2011.

\section{Site 4}

Site 4 is a plastic culvert that transports an unnamed tributary to Elliot Creek under an unnamed road at latitude 45.585 longitude -123.375 . Site 4 is 16,732 feet $(5,100$ meters $)$ 
southeast of the Wilson River with an elevation of 1,841 feet (561 meters) above sea level. NWI data for the area depict a riverine, intermittent, streambed, seasonally flooded (R4SBC) wetland feature in the area of the site. The culvert at Site 430 is 612 inches (16 meters) long and 39 inches $(99 \mathrm{~cm})$ in diameter. The stream reach downstream of the culvert (Site 4A) consists of a heavily silted marshy area with flat grassy areas on both sides of the stream. The stream reach upstream of the culvert (Site 4B) is a slow riffle stream that flows through a narrow, heavily vegetated channel 200 feet (67 meters) from a logged area. Site 4 was surveyed on three separate occasions in both 2010 and 2011.

\section{$\underline{\text { Site } 5}$}

Site 5 is a steel culvert that transports an unnamed tributary to the North Fork Wilson River under an N. Fork Wilson River Road at latitude 45.616, longitude -123.55. Site 5 is 9,843 feet (3,000 meters) north of the Wilson River with an elevation of 818 feet (250 meters) above sea level. NWI data for the area depict a riverine, upper perennial, unconsolidated streambed, semipermanently flooded (R3UBF) wetland feature in the area of the site. The culvert at Site 5 is 655 inches $(1,664 \mathrm{~cm})$ long and 42 inches $(107 \mathrm{~cm})$ in diameter. The downstream reach (Site 5A) drops approximately 8 feet (2.4 meters) from the culvert to a plunge pool and then continues across a shallow gravel bar until it reaches the North Fork Wilson River. Stream habitat was a mix of pool and low gradient riffle. During the dry months, the stream flows underground for approximately 5 feet (1.5 meters) before resurfacing and joining the North Fork Wilson River. The stream reach upstream of the culvert (Site 5B) consists of a cascading stream with several deep pools that becomes flat and wide it approaches the culvert. Site 5 was surveyed on three separate occasions in both 2010 and 2011. 
$\underline{\text { Site } 6}$

Site 6 is a steel culvert that transports an unnamed tributary to the Little North Fork Wilson River under Coast Range Road at latitude 45.498, longitude -123.627. Site 6 is 1,542 feet (470 meters) north of the Wilson River with an elevation of 397 feet (121 meters) above sea level. NWI data for the area depict a riverine, intermittent, streambed, seasonally flooded (R4SBC) wetland feature in the area of the site. The culvert at Site 6 is 1,020 inches $(2,591 \mathrm{~cm})$ long and 36 inches $(92 \mathrm{~cm})$ in diameter. The downstream reach (Site 6A) drops approximately 6 feet (1.8 meters) from the culvert to a plunge pool and then continues through a densely vegetated ravine, adjacent to the road. Stream habitat is a mix of pools, glides, and slow moving riffles. The stream reach upstream of the culvert (Site 6B) is a low flow stream which drops over a high gradient bedrock channel into a heavily sedimented pool and then continues through a series of step-pools created by rocks and LWD and then becomes a riffle through a narrow and heavily vegetated channel. Site 6 was surveyed on three separate occasions in both 2010 and 2011.

\section{$\underline{\text { Site } 7}$}

Site 7 is a wood beam bridge that transports Jones Creek, a tributary to the Wilson River under Jones Creek Road at latitude 45.591, longitude -123.561. Site 7 is 1,384 feet (425 meters) north of the Wilson River with an elevation of 617 feet (188 meters) above sea level. NWI data for the area depict a riverine, intermittent, streambed, seasonally flooded (R4SBC) wetland feature in the area of the site. The culvert at Site 7 is 672 inches $(1,707$ $\mathrm{cm})$ long and 204 inches $(518 \mathrm{~cm})$ in diameter. The downstream reach (Site 7A) is a wide stream with medium-gradient cobble banks and several large pieces of LWD criss- 
crossing the site. The stream habitat is mostly riffle with some deep pools. The stream reach upstream of the bridge (Site 7B) is a wide shallow stream with mostly flat grassy banks and some areas of steep clay-soil cliffs. Stream habitat is a mix of riffle and glide. Site 7 was surveyed on three separate occasions in both 2010 and 2011.

\section{Site 8}

Site 8 is a wood beam bridge that transports an unnamed tributary to Jordan Creek under Jordan Creek Road at latitude 45.537 , longitude -123.565 . Site 8 is 11,483 feet $(3,500$ meters) east of the Wilson River with an elevation of 568 feet (179 meters) above sea level. NWI data for the area depict a riverine, upper perennial, unconsolidated bottom (R3UBH) wetland feature in the area of the site. The bridge at Site 8 is 168 inches (427 $\mathrm{cm})$ long and 672 inches $(1,797 \mathrm{~cm})$ in diameter. The downstream reach (Site $8 \mathrm{~A})$ is a rocky stream that flows in a heavily vegetated depression with steep banks. Downstream of the site, the stream drops off steeply into Jordan Creek. Stream habitat is high gradient riffle. The stream reach upstream of the bridge (Site $8 \mathrm{~B}$ ) is a wide gravel and cobble stream with densely vegetated medium gradient banks. Stream habitat is riffle and glide. Site 8 was surveyed on three separate occasions in both 2010 and 2011. In early fall the Oregon Department of Fish and Wildlife (ODFW) deposits fish carcasses in the stream at Site 8 to supplement the stream with nutrients.

\section{$\underline{\text { Site } 9}$}

Site 9 is a steel culvert that transports an unnamed tributary to Jordan Creek under Jordan Creek Road at latitude 45.536, longitude -123.559 . Site 9 is 12,795 feet (3,900 meters) east of the Wilson River with an elevation of 594 feet (181 meters) above sea level. NWI 
data for the area depict a riverine, upper perennial, unconsolidated bottom, permanently flooded (R3UBH) wetland feature in the area of the site. The culvert at Site 9 is 504 inches $(1,280 \mathrm{~cm})$ long and 48 inches $(147 \mathrm{~cm})$ in diameter. The downstream reach of the site (Site 9A) drops approximately 4 feet from the culvert into a wide plunge pool before continuing down a steep gradient, and steeply dropping off over a bedrock streambed into Jordan Creek. The stream reach upstream of the culvert (Site 9B) is a series of quickly flowing cascade step pools with medium gradient banks. Site 9 was surveyed on three separate occasions in both 2010 and 2011. An area 312 feet (95 meters) west of the site was logged in early 2011, substantially increasing the level of disturbance in the vicinity.

\section{$\underline{\text { Site } 10}$}

Site 10 is a steel culvert that transports an unnamed tributary to Fall Creek under Kansas Creek Road at latitude 45.481 , longitude -123.645 . Site 10 is 2,428 feet (740 meters) south of the Wilson River with an elevation of 404 feet (123 meters) above sea level. NWI data for the area depict a riverine, upper perennial, unconsolidated bottom, semipermanently flooded (R3UBF) wetland feature in the area of the site. The culvert at Site 10 is 852 inches $(2,164 \mathrm{~cm})$ long and 66 inches $(168 \mathrm{~cm})$ in diameter. The downstream reach (Site 10A) is a quickly flowing riffle stream with steep, vegetated banks, and several steep cascades. The stream reach upstream of the culvert (Site 10B) consisted of a wide shallow stream with heavily vegetated flat banks progressing to steeper hillsides. Stream habitat was a mix of riffles and pools. Several embedded pieces of large woody debris defined the stream's flow patterns. Site 10 was surveyed on three separate occasions in both 2010 and 2011. 


\section{$\underline{\text { Site } 11}$}

Site 11 is a concrete bridge that transports an unnamed tributary to Ben Smith Creek Forest Road 1-7-10.1 at latitude 45.577 , longitude -123.522 . Site 11 is 4,396 feet $(1,340$ meters) south of the Wilson River with an elevation of 912 feet (278 meters) above sea level. NWI data for the area depict a riverine, upper perennial, unconsolidated bottom, permanently flooded $(\mathrm{R} 3 \mathrm{UBH})$ wetland feature in the area of the site. The bridge at Site 11 is 194 inches $(493 \mathrm{~cm})$ long and 474 inches $(1,203 \mathrm{~cm})$ in diameter. The downstream reach (Site 11A) is a low gradient stream with a sandy cobbley bottom and flat vegetated banks progressing to steep shrubby hillsides. Stream habitat was mostly riffle with some deep pools. The stream reach upstream of the bridge (Site 11B) consists of a flat rocky stream with wide, vegetated banks and some bedrock outcroppings. Stream habitat was made up of riffles with slow moving edewater. Site 11 was surveyed on three separate occasions in 2011.

\section{$\underline{\text { Site } 12}$}

Site 12 is a steel culvert that transports Ryan Creek, a tributary to the Wilson River, under Wolf Creek Road at latitude 45.555, longitude -123.606. Site 12 is 394 feet (120 meters) east of the Wilson River with an elevation of 417 feet (127 meters) above sea level. NWI data for the area depict a riverine, upper perennial, unconsolidated bottom, permanently flooded (R3UBH) wetland feature in the area of the site. The culvert at Site 12 is 552 inches $(1,402 \mathrm{~cm})$ long and 30 inches $(76 \mathrm{~cm})$ in diameter. The downstream reach (Site 12A) is a low flow riffle, heavily silted stream with densely vegetated banks. The stream

reach upstream of the culvert (Site 12B) consists of a flat low flow stream with a series of 
pools surrounded by small trees and wide flat grassy banks. Site 12 was surveyed on three separate occasions in 2011.

\section{$\underline{\text { Site } 13}$}

Site 13 is a concrete bridge that transports Keenig Creek, a tributary to the Wilson River, under Wolf Creek Road at latitude 45.543, longitude -123.613. Site 13 is 492 feet (150 meters) west of the Wilson River with an elevation of 486 feet (148 meters) above sea level. NWI data for the area depict a riverine, upper perennial, unconsolidated bottom, permanently flooded (R3UBH) wetland feature in the area of the site. The bridge at Site 13 is 192 inches $(488 \mathrm{~cm})$ long and 696 inches $(1,768 \mathrm{~cm})$ in diameter. The downstream reach (Site 13A) is a narrow, quickly flowing stream that meanders through rocky banks with minimal overhanging vegetation. The stream reach upstream of the bridge (Site 13B) consists of a densely vegetated, quickly flowing, riffle stream with several midstream bars and large pieces of LWD that split the stream channel. Site 13 was surveyed on three separate occasions in 2011.

\section{$\underline{\text { Site } 14}$}

Site 14 is an aluminum culvert that transports an unnamed tributary to Elliot Creek, under Beaver Dam Road at latitude 45.578, longitude -123.385. Site 14 is 16,404 feet $(5,000$ meters) southeast of the Wilson River with an elevation of 1,975 feet (602 meters) above sea level. NWI data for the area depict a riverine, intermediate, streambed, seasonally flooded (R4SBC) wetland feature in the area of the site. The culvert at Site 14 is 636 inches $(1,615 \mathrm{~cm})$ long and 30 inches $(76.2 \mathrm{~cm})$ in diameter. The downstream reach (Site $14 \mathrm{~A})$ is a high gradient series of step pools broken up by mid-stream bars and large 
woody debris with grassy banks. The stream reach upstream of the culvert (Site 14B) consisted of a highly silted low flow riffle stream with incised banks surrounded by wide grassy areas. Site 14 was surveyed on three separate occasions in 2011. 

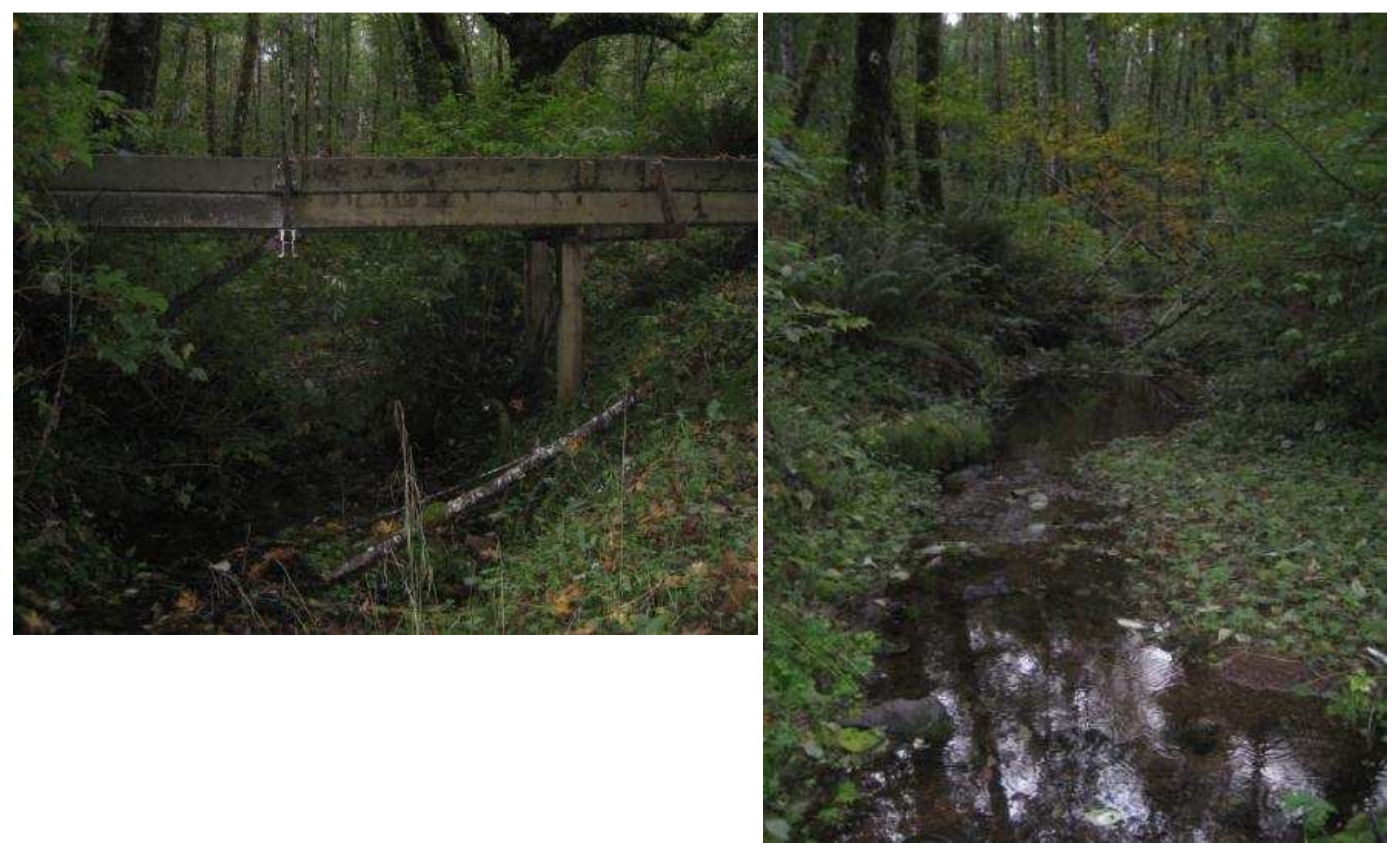

Site 1A Looking Upstream

Site 1A Looking Downstream
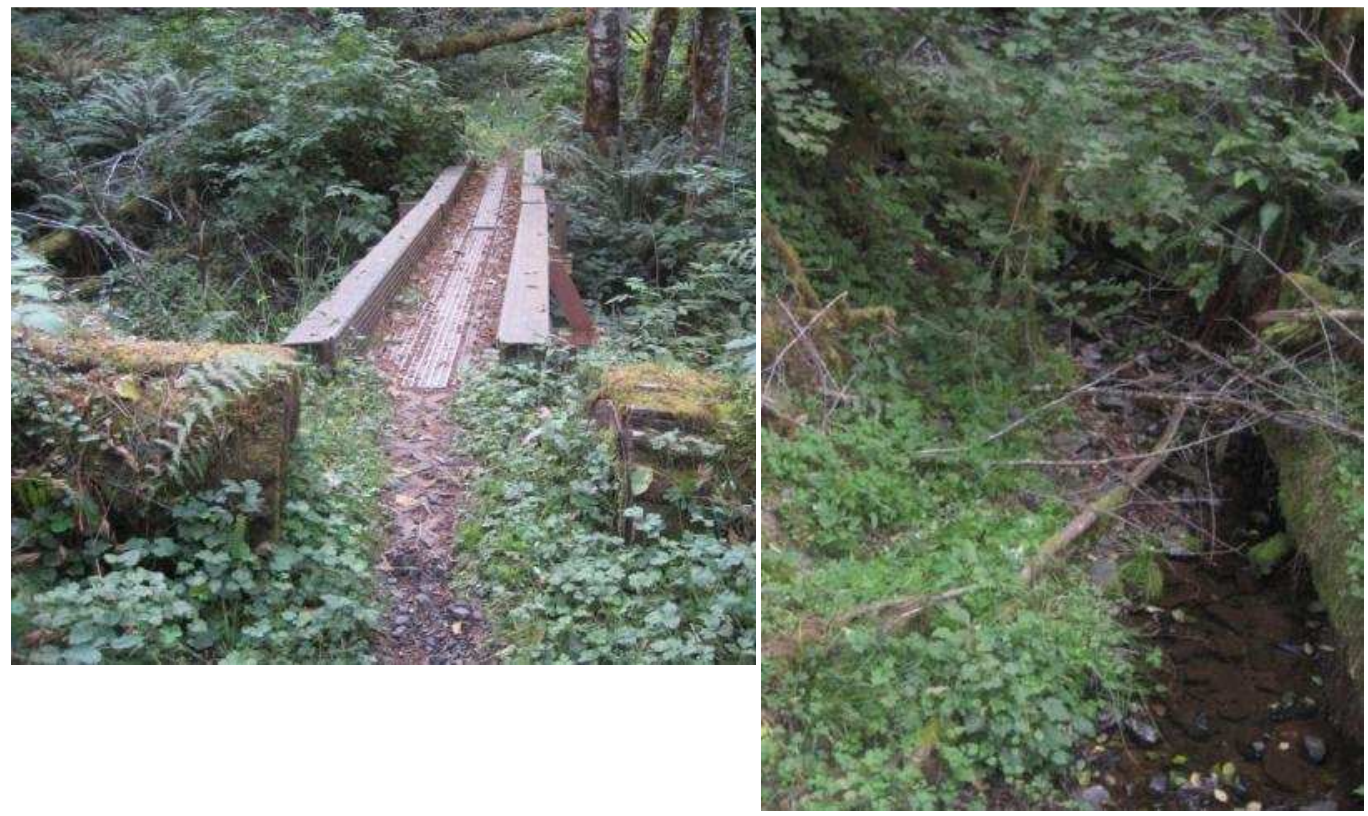

Footbridge at Site 1

Site 1B Looking Upstream 


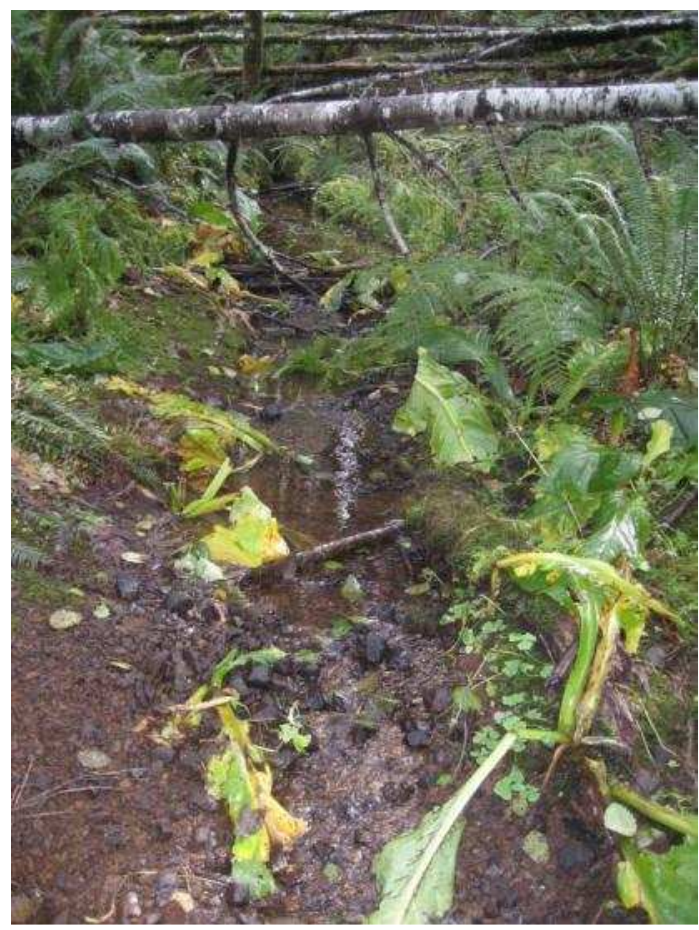

Site 2A Looking Upstream

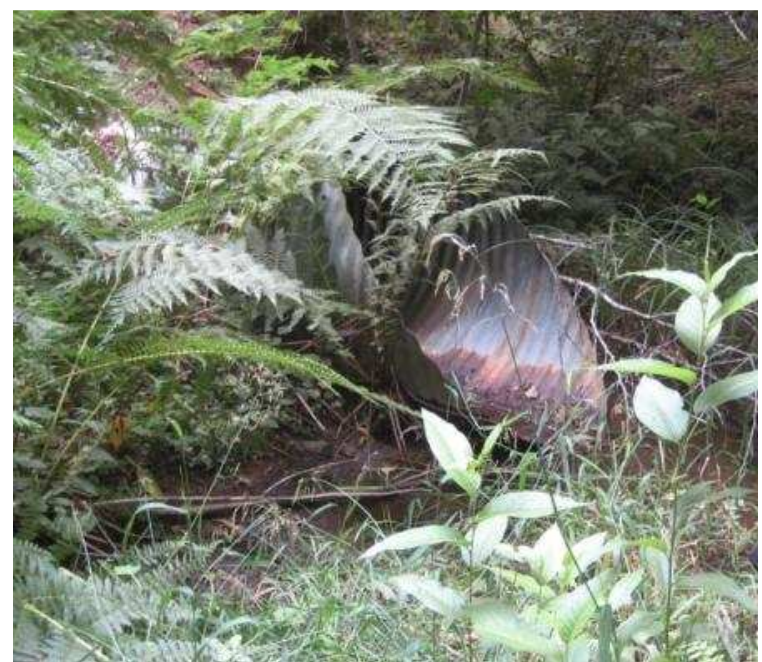

Site 2B Culvert

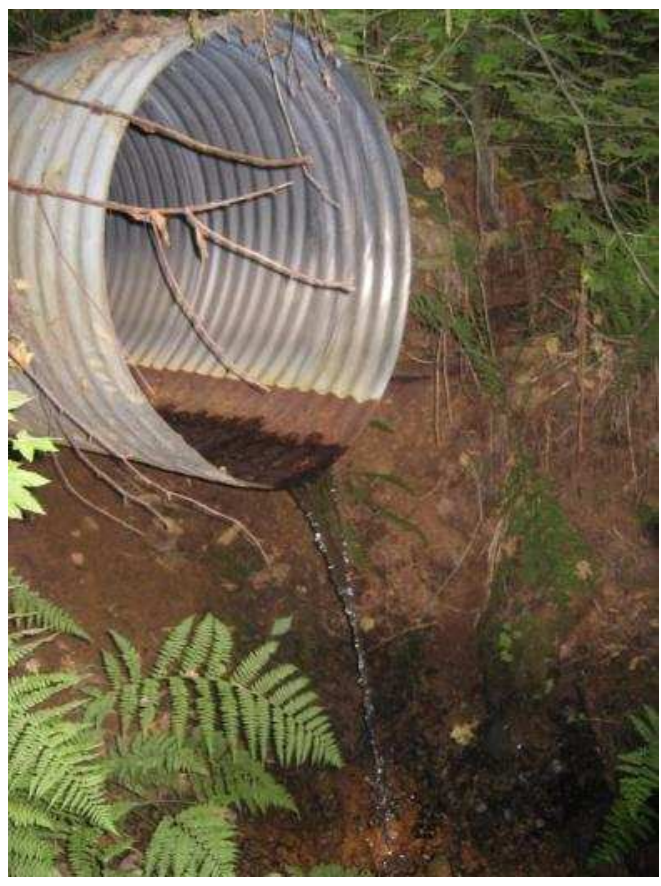

Site 2A Culvert

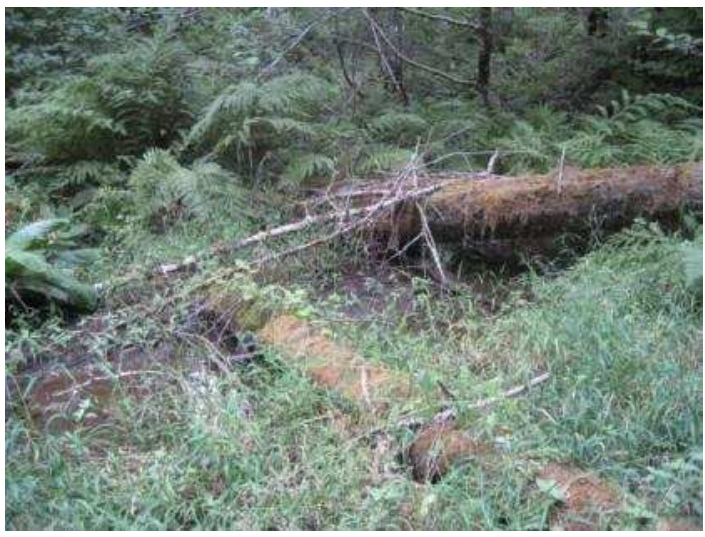

Site 2B Looking Upstream 

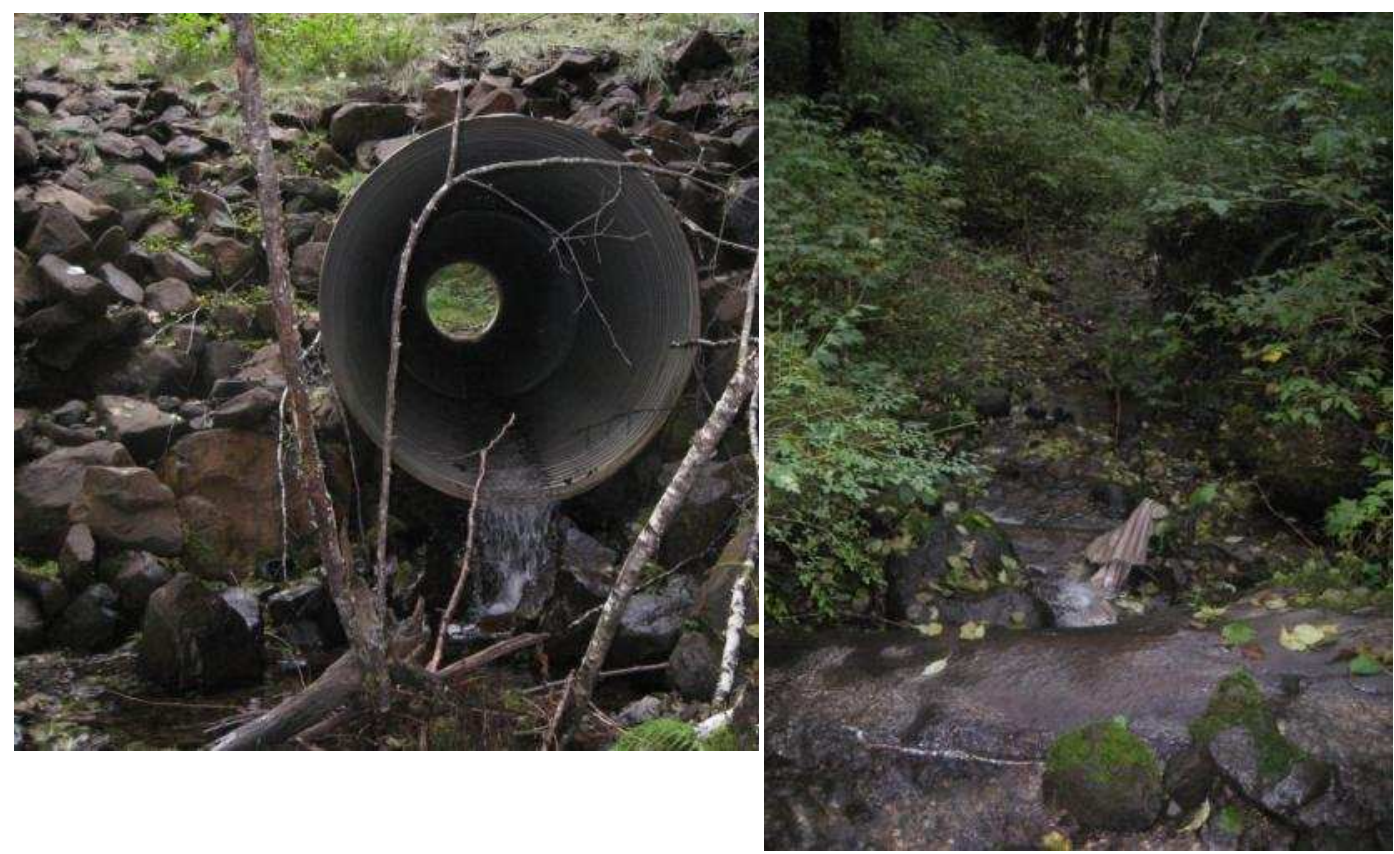

Site 3A Looking Upstream

Site 3A looking downstream
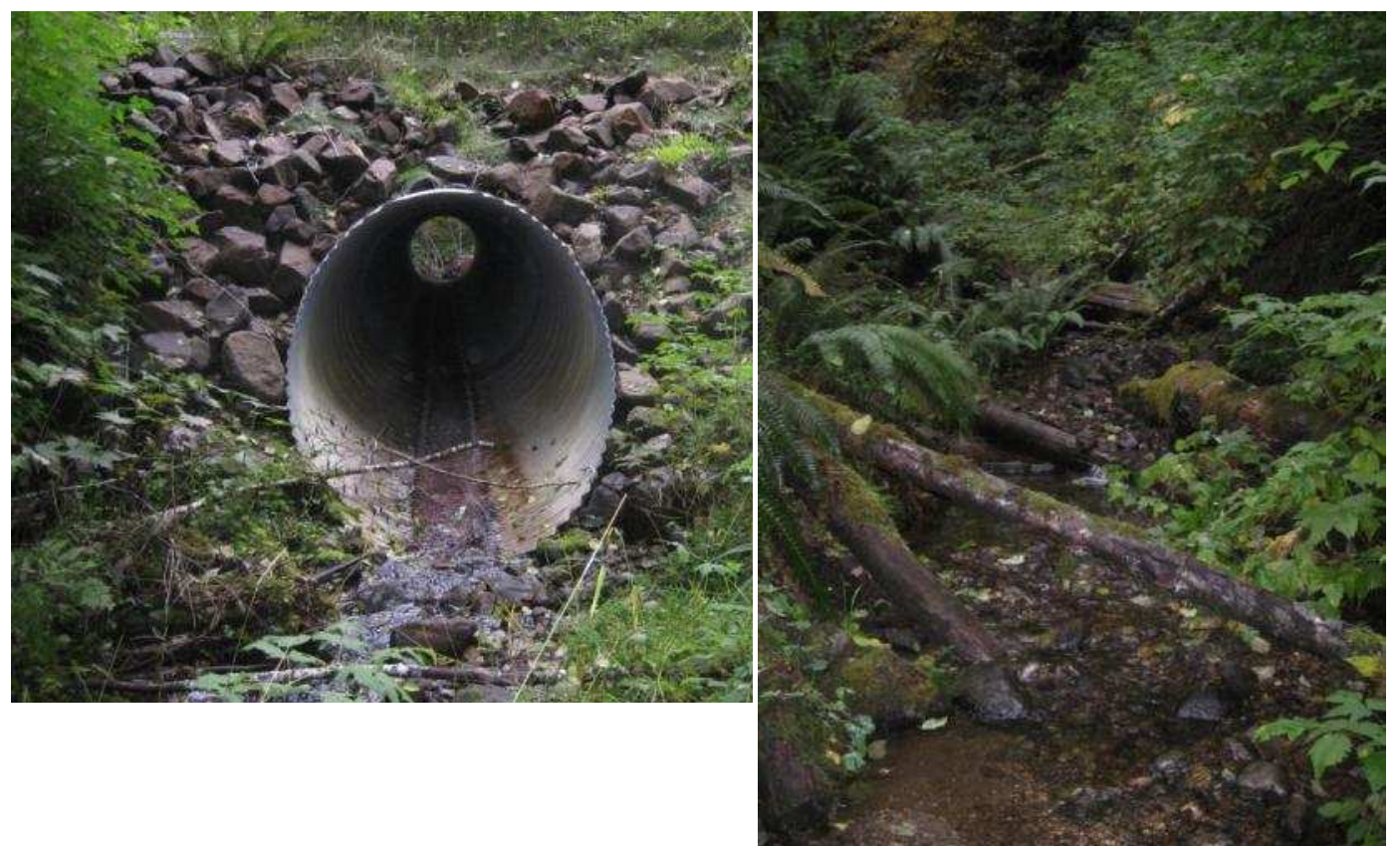

Site 3B Looking Downstream

Site 3B Looking Upstream 

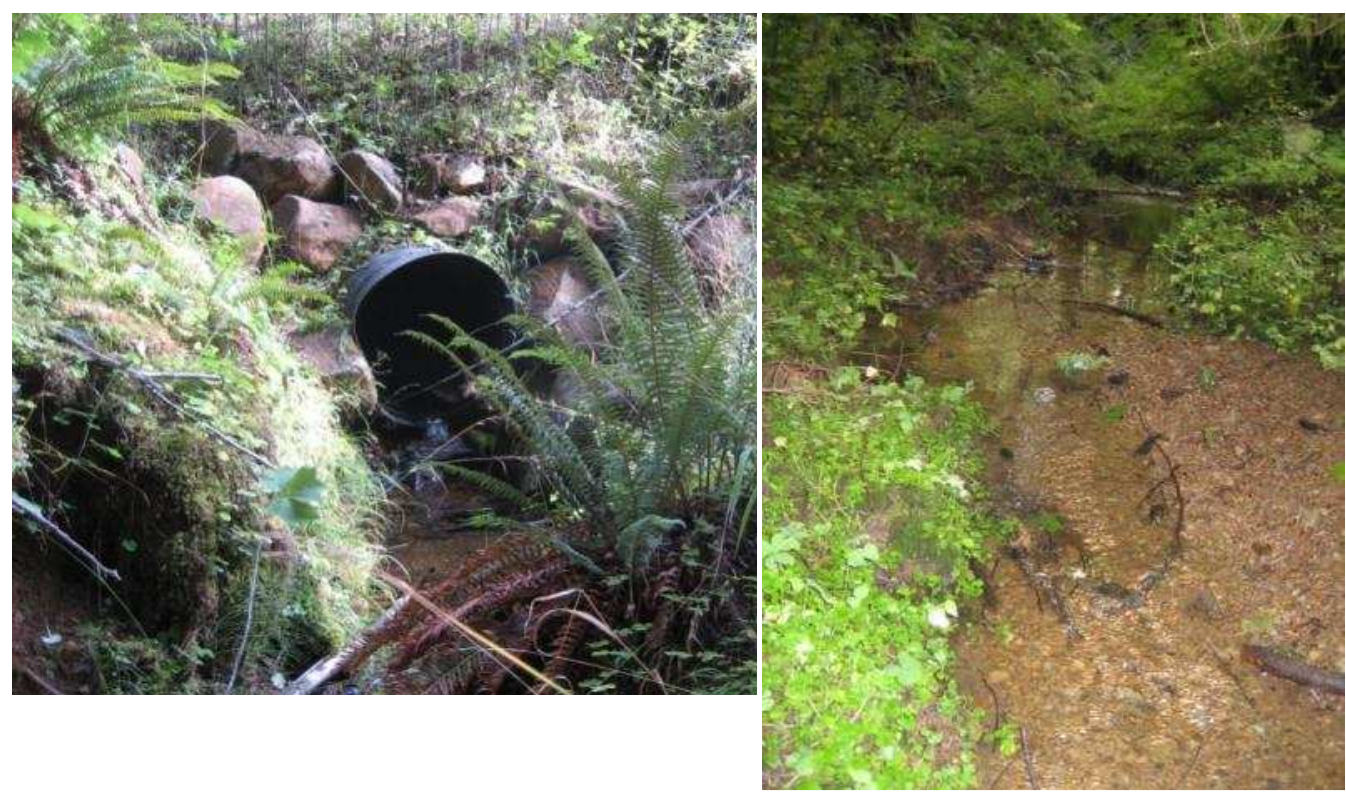

Site 4A Looking Upstream

Site 4B Looking Downstream

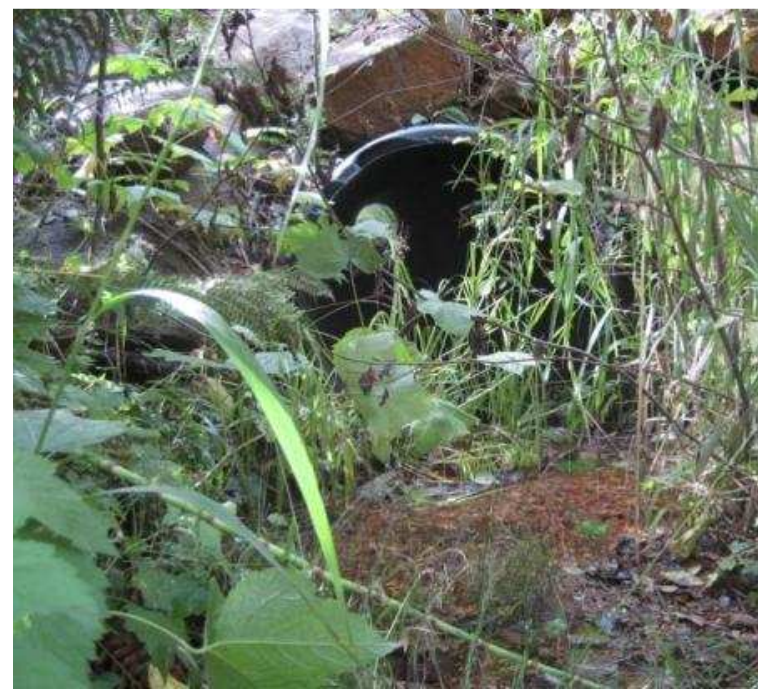

Site 4B Looking Downstream

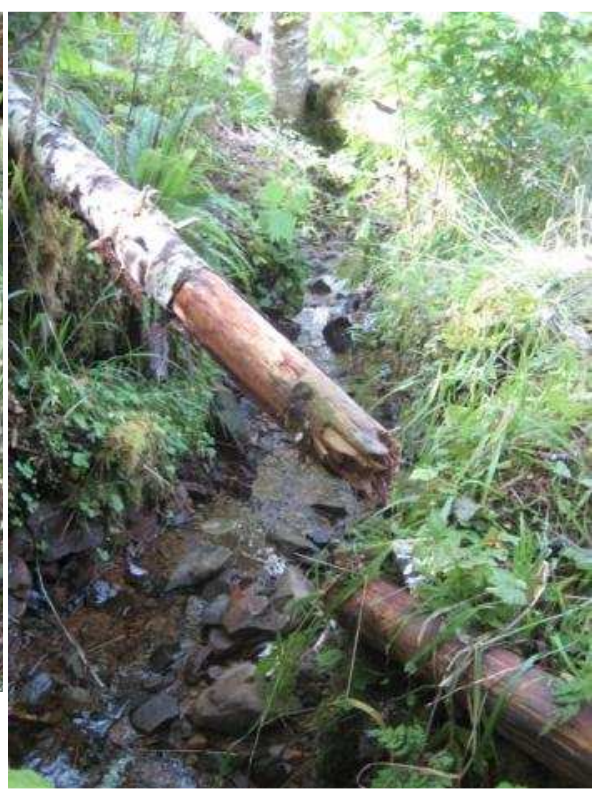

Site 4B Looking Upstream 


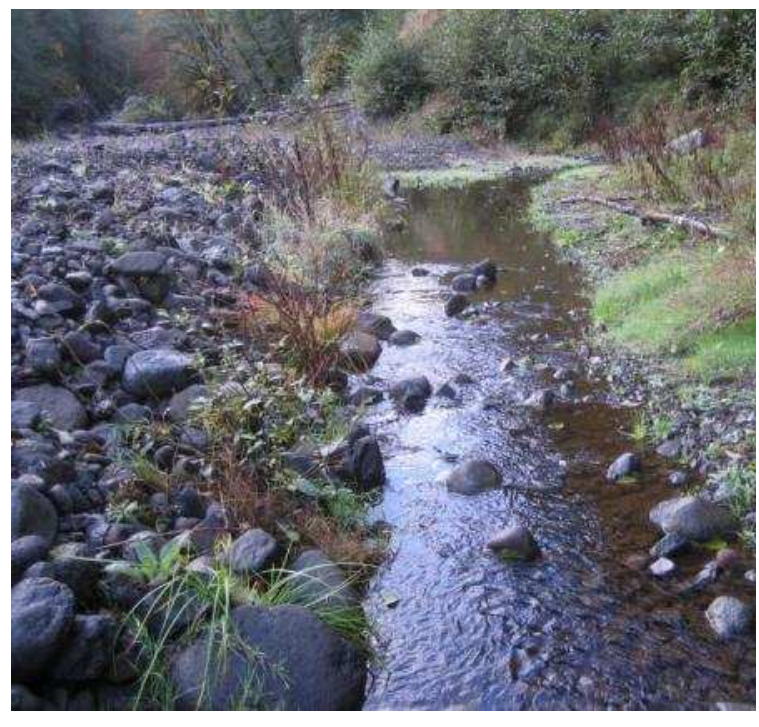

Site 5A Looking Downstream

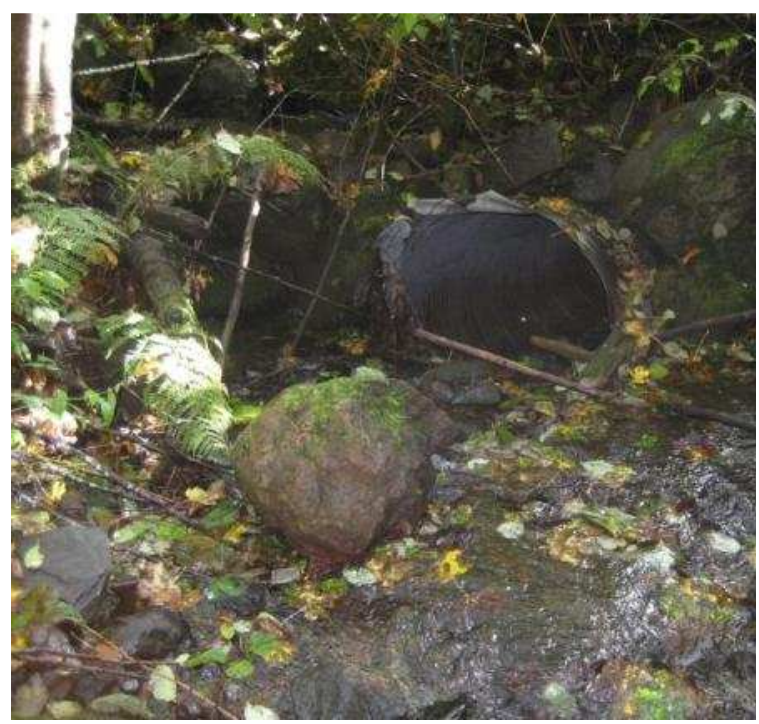

Site 5B Looking Downstream

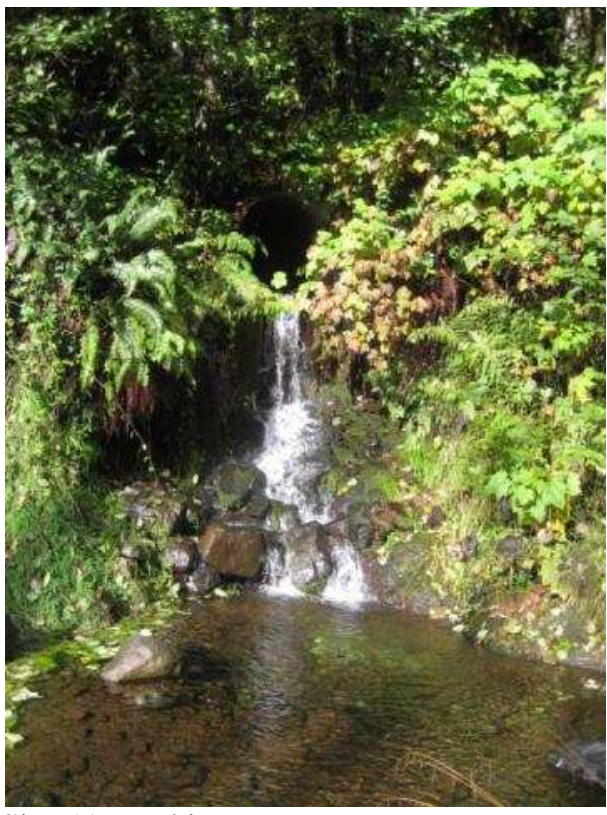

Site 5A Looking Upstream

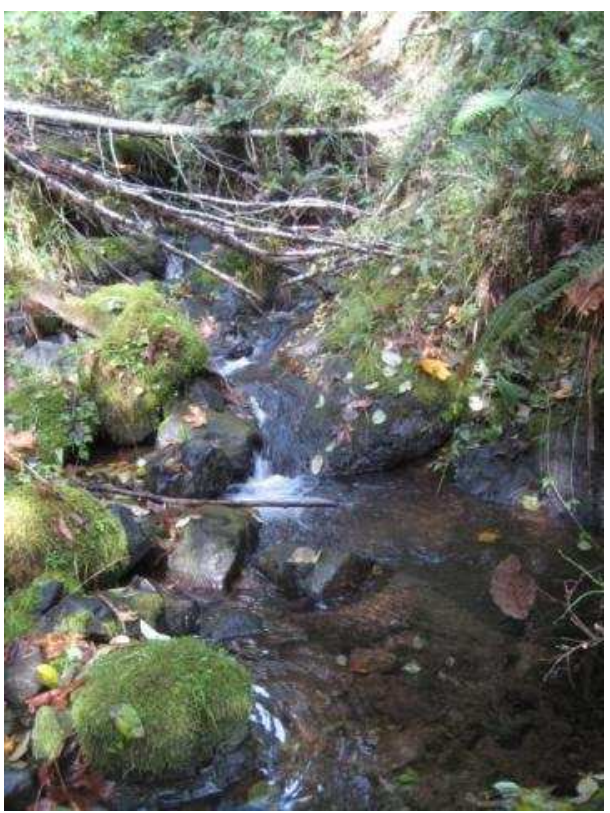

Site 5B Looking Upstream 

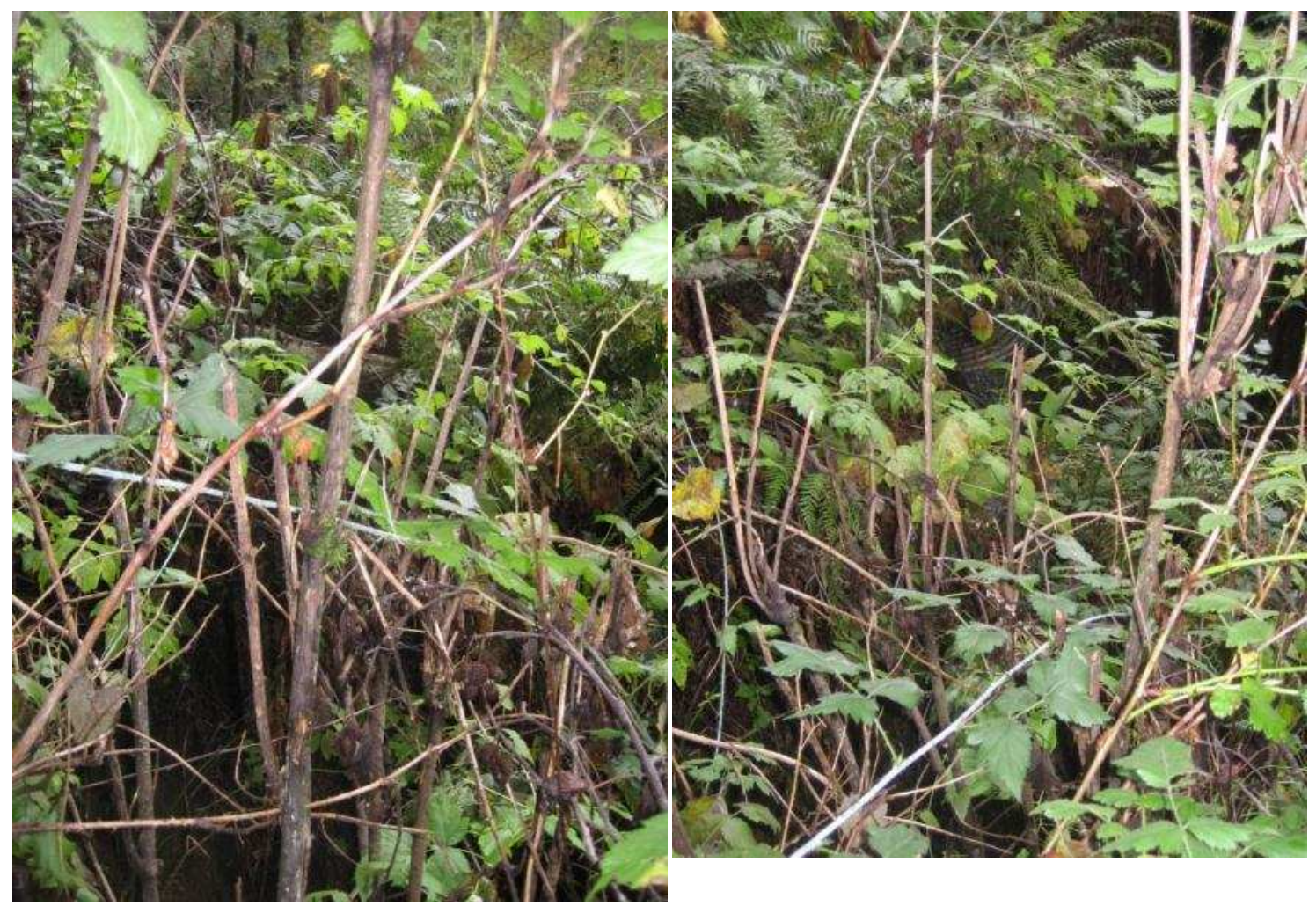

Site 6A Looking Downstream

Site 6A Looking Upstream
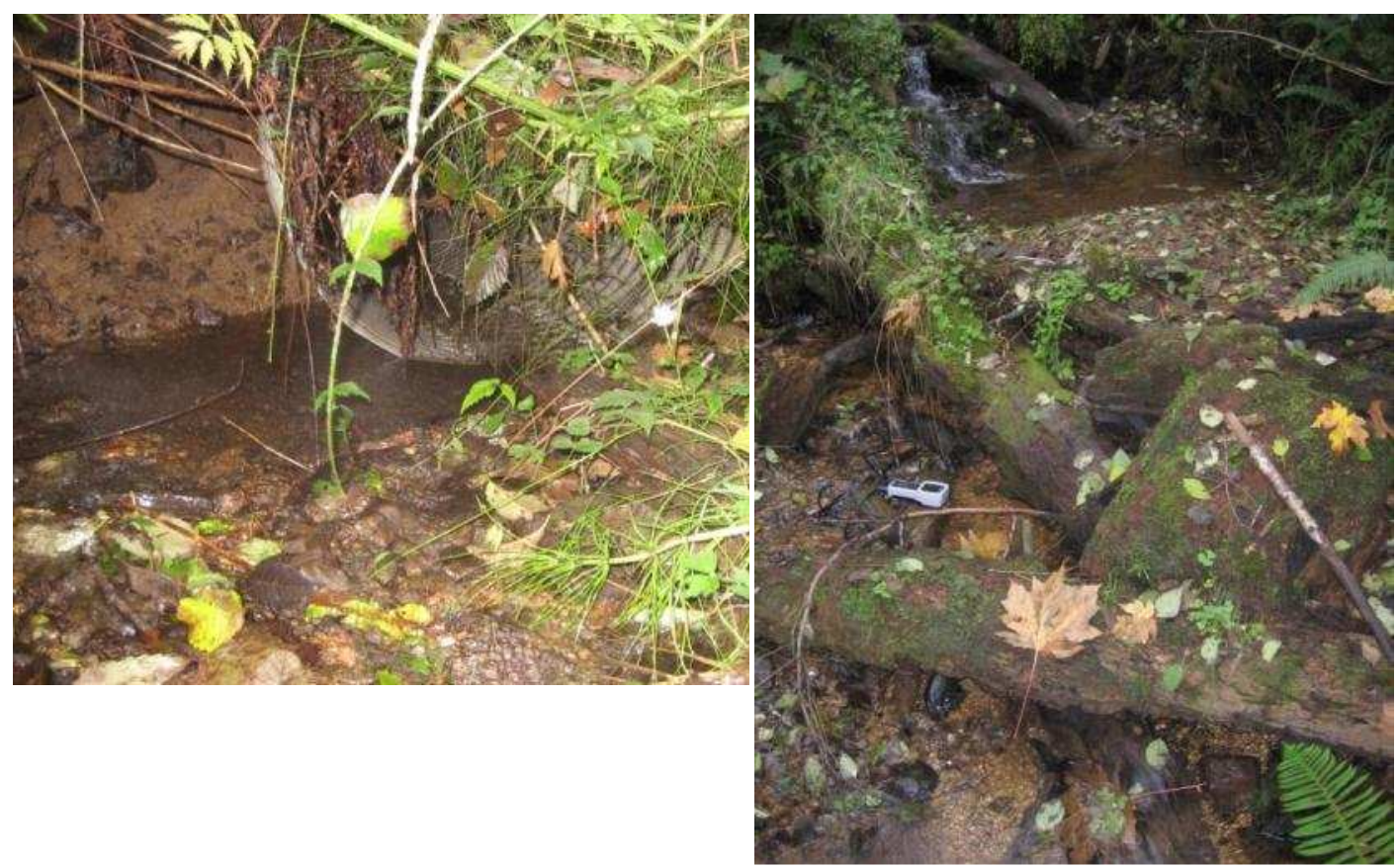

Site 6B Looking Downstream

Site 6B Looking Upstream 


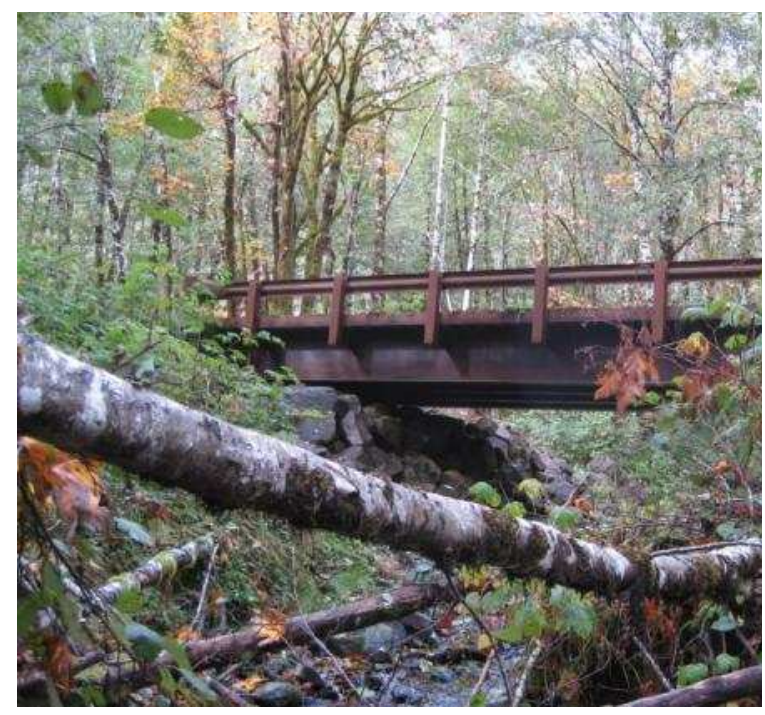

Site 7A Looking Upstream

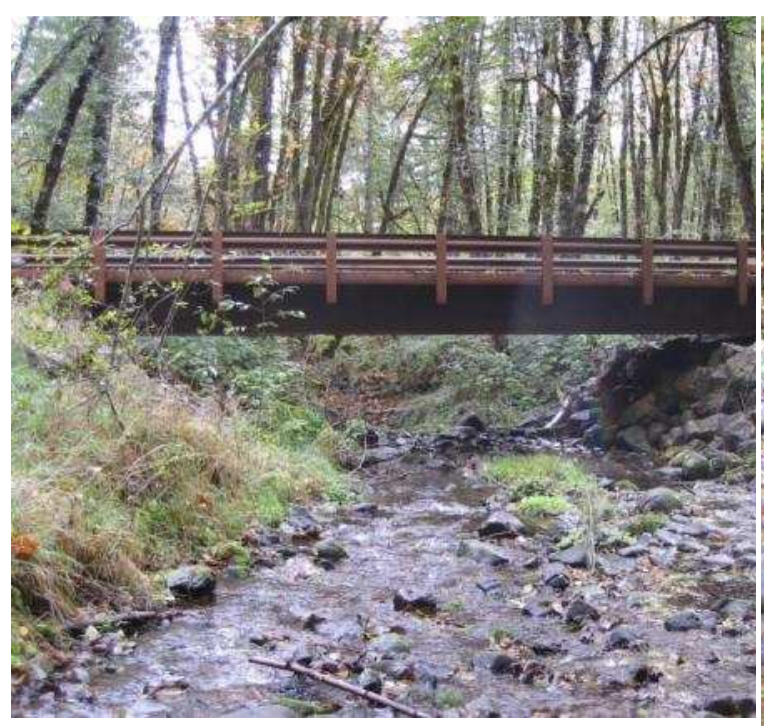

Site 7B Looking Downstream

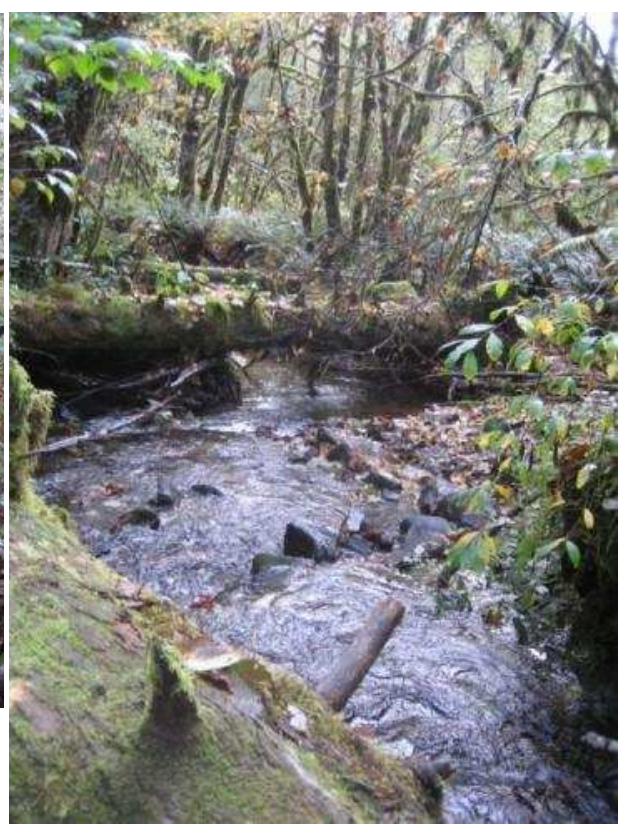

Site 7A Looking Downstream

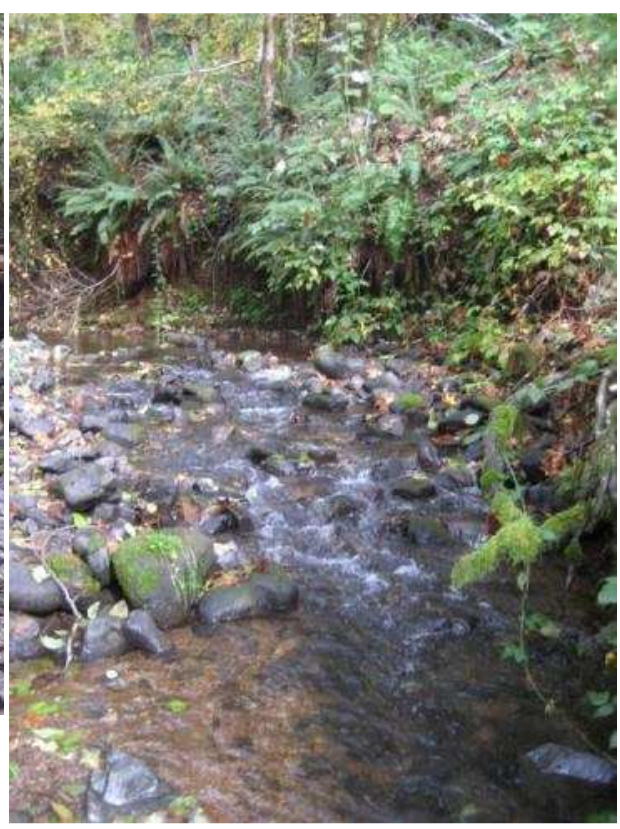

Site 7B Looking Upstream 

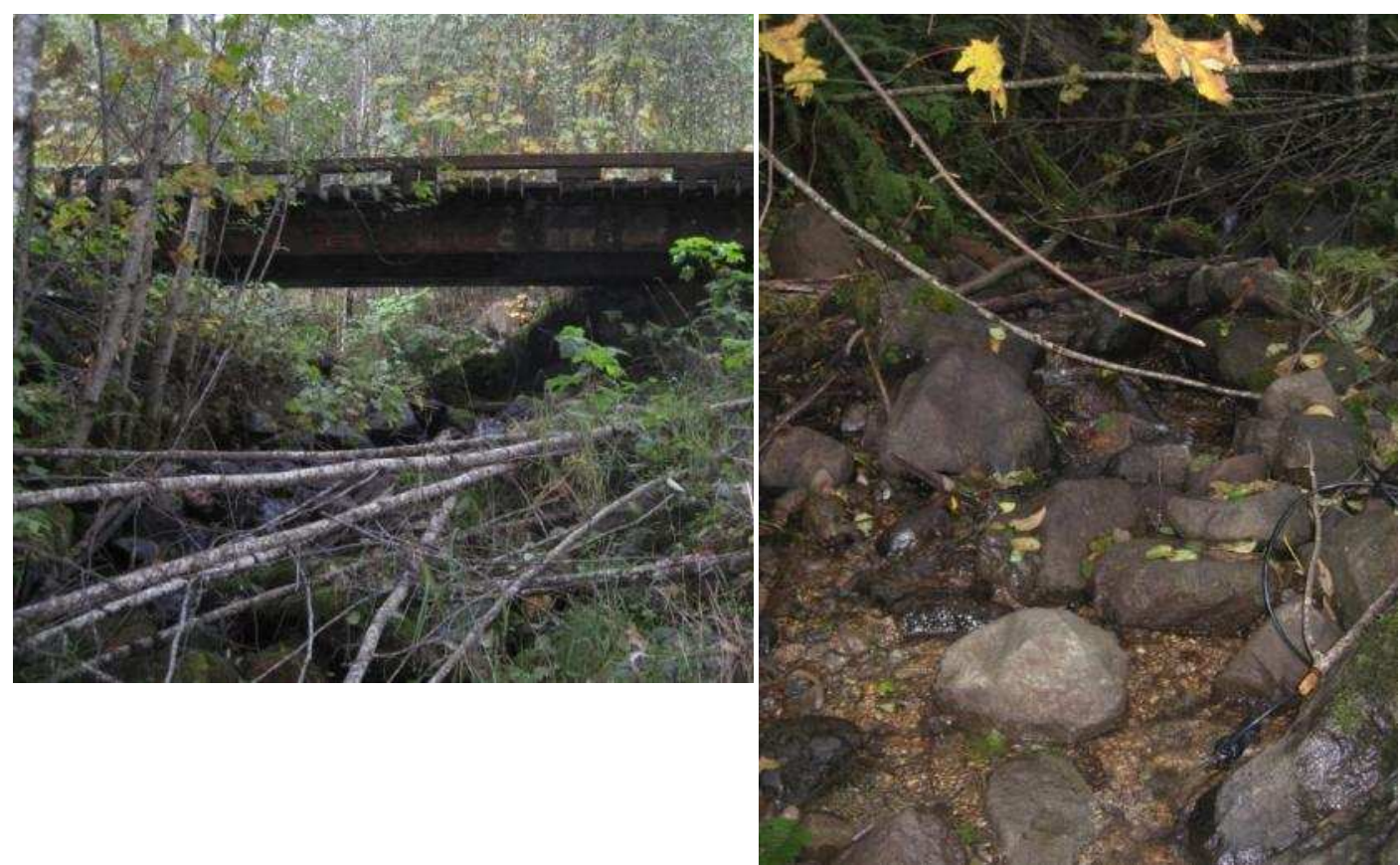

Site 8A Looking Upstream

Site 8A Looking Downstream
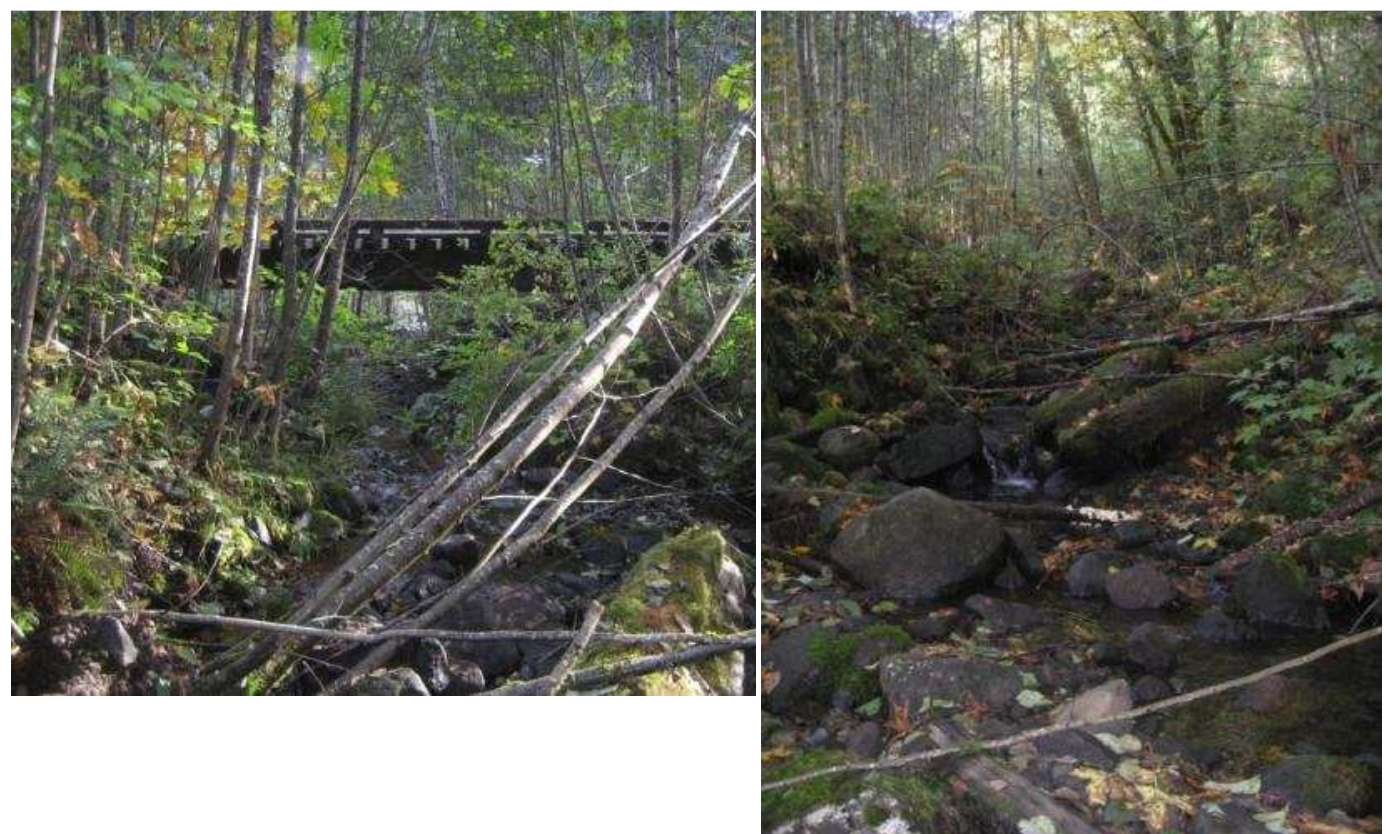

Site 8B Looking Downstream

Site 8B Looking Upstream 

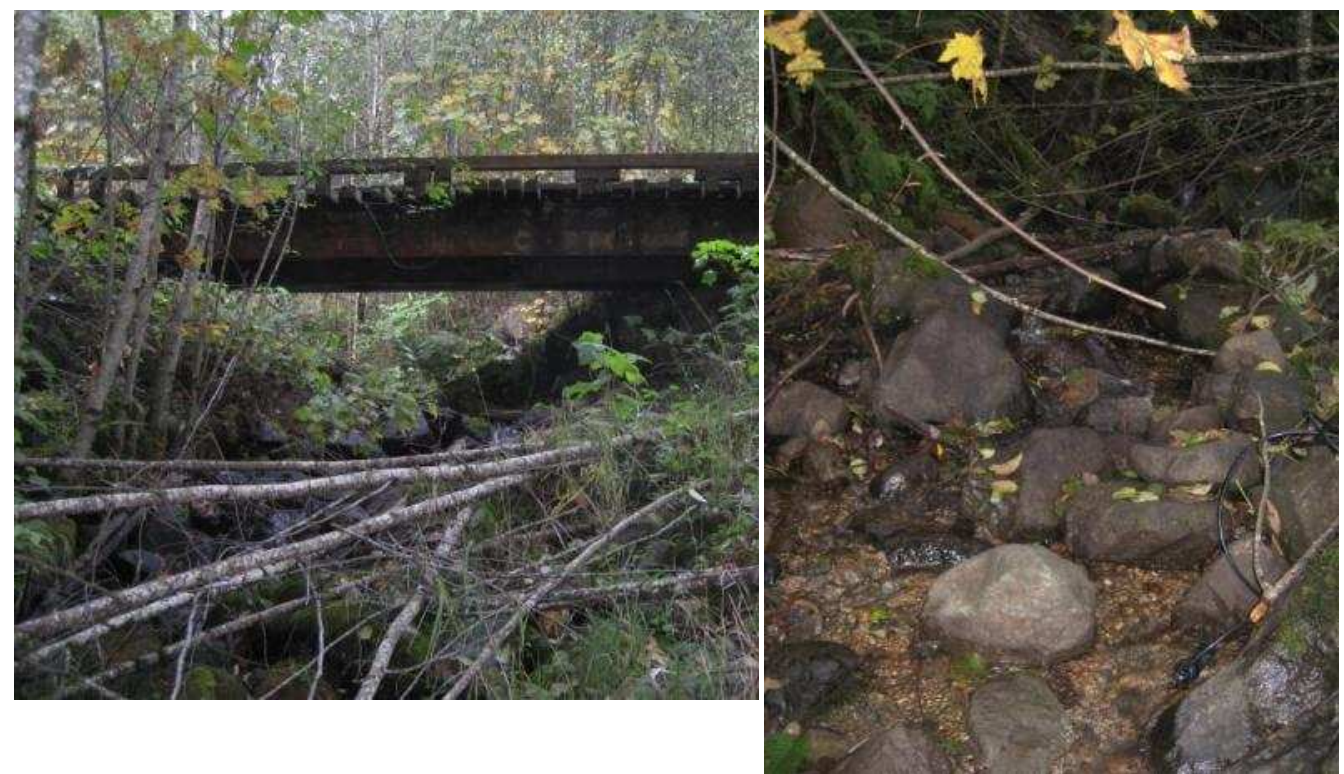

Site 8A Looking Upstream

Site 8A Looking Downstream
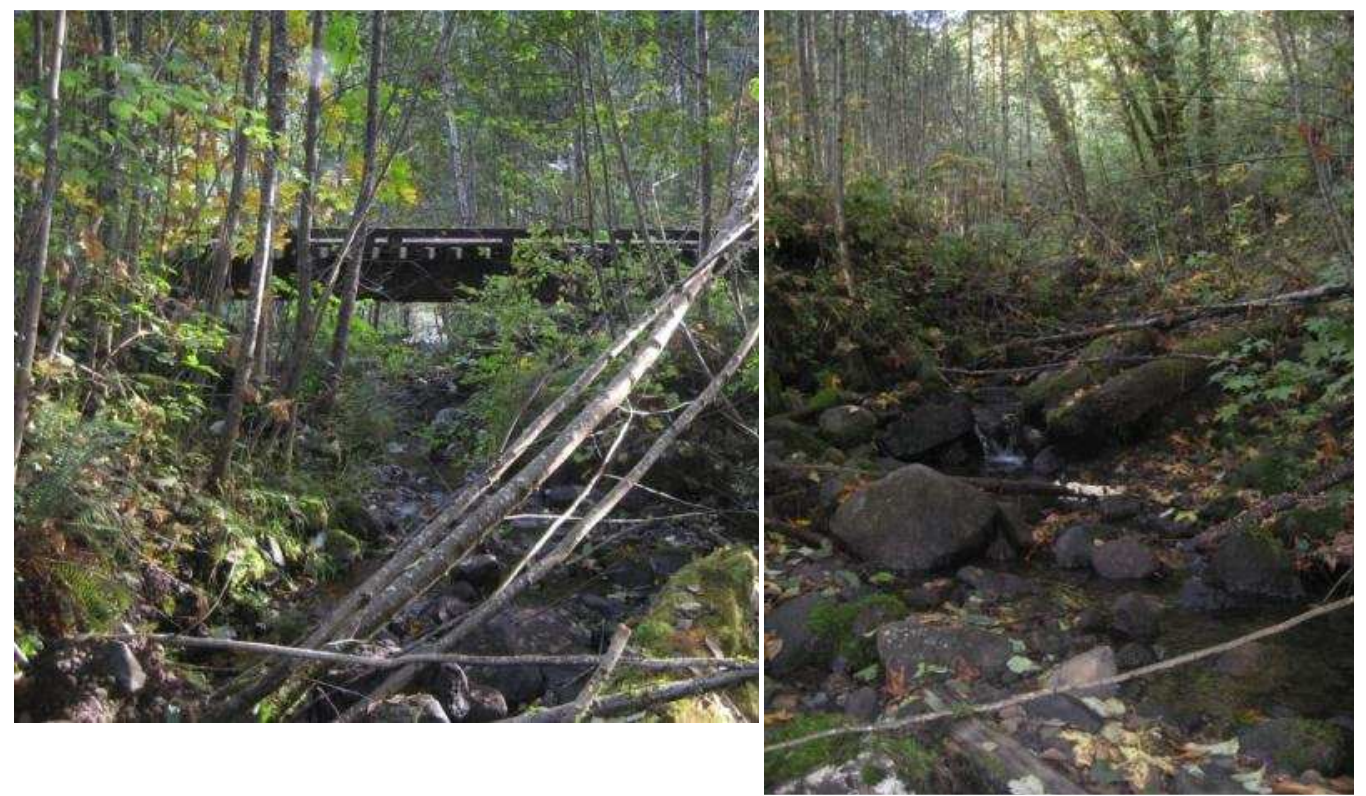

Site 8B Looking Downstream

Site 8B Looking Upstream 

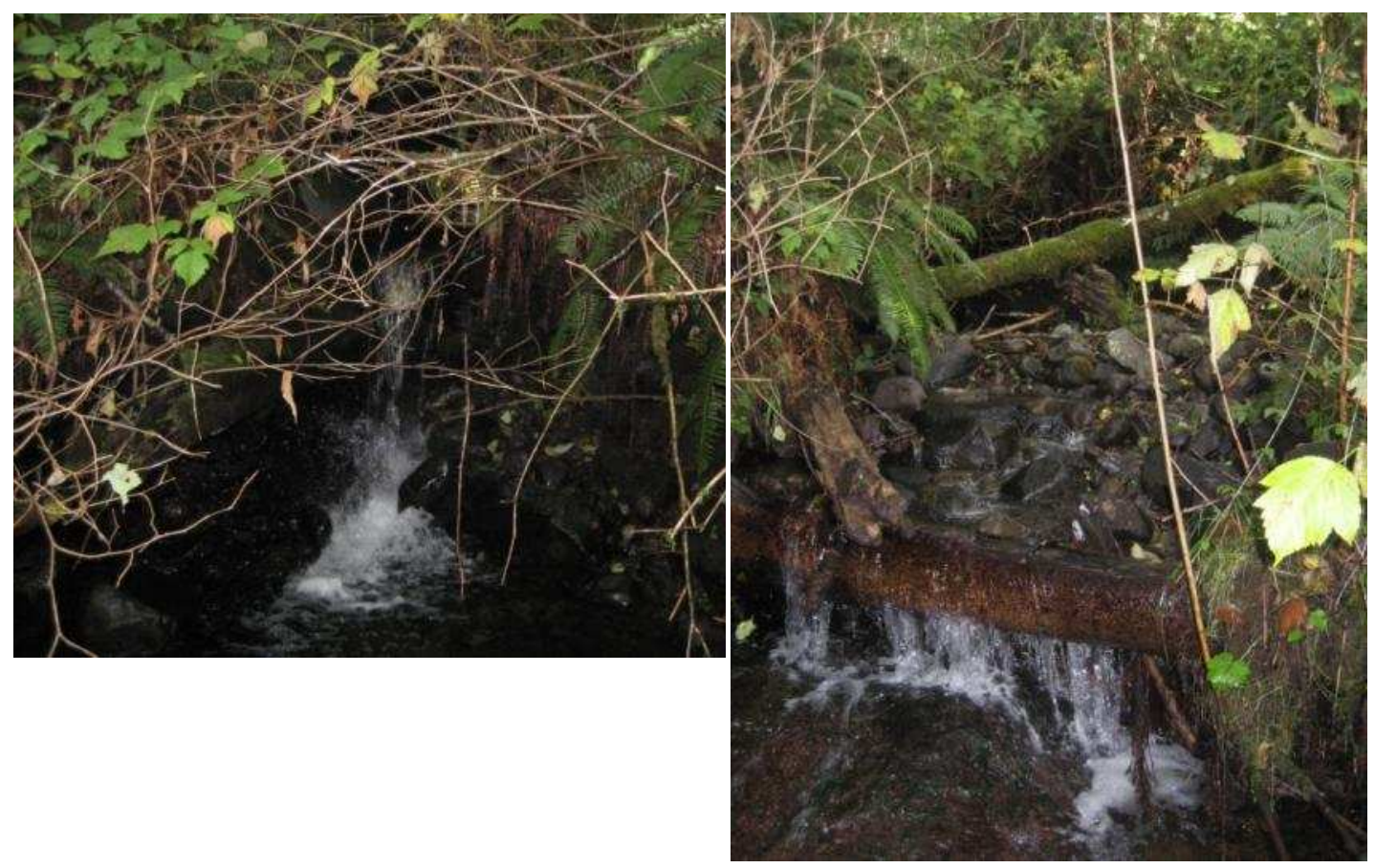

Site 9A Looking Upstream

Site 9A Looking Upstream
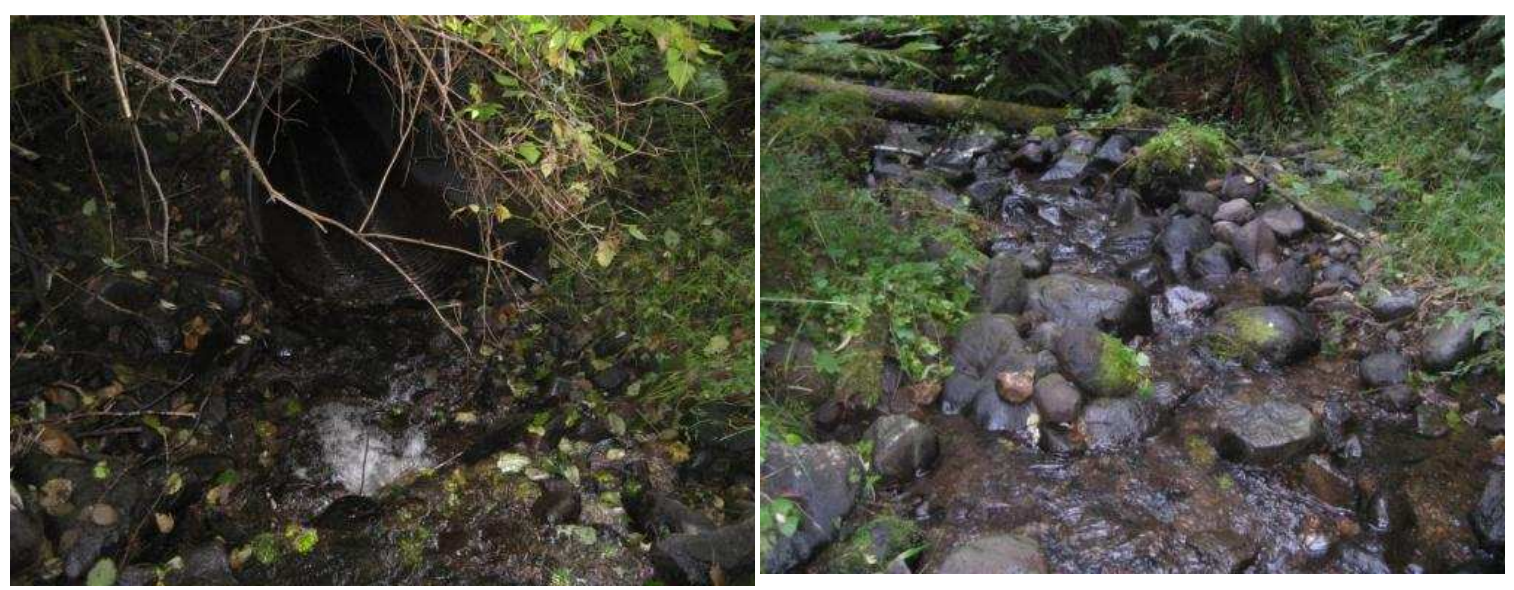

Site 9B Looking Downstream

Site 9B Looking Upstream 

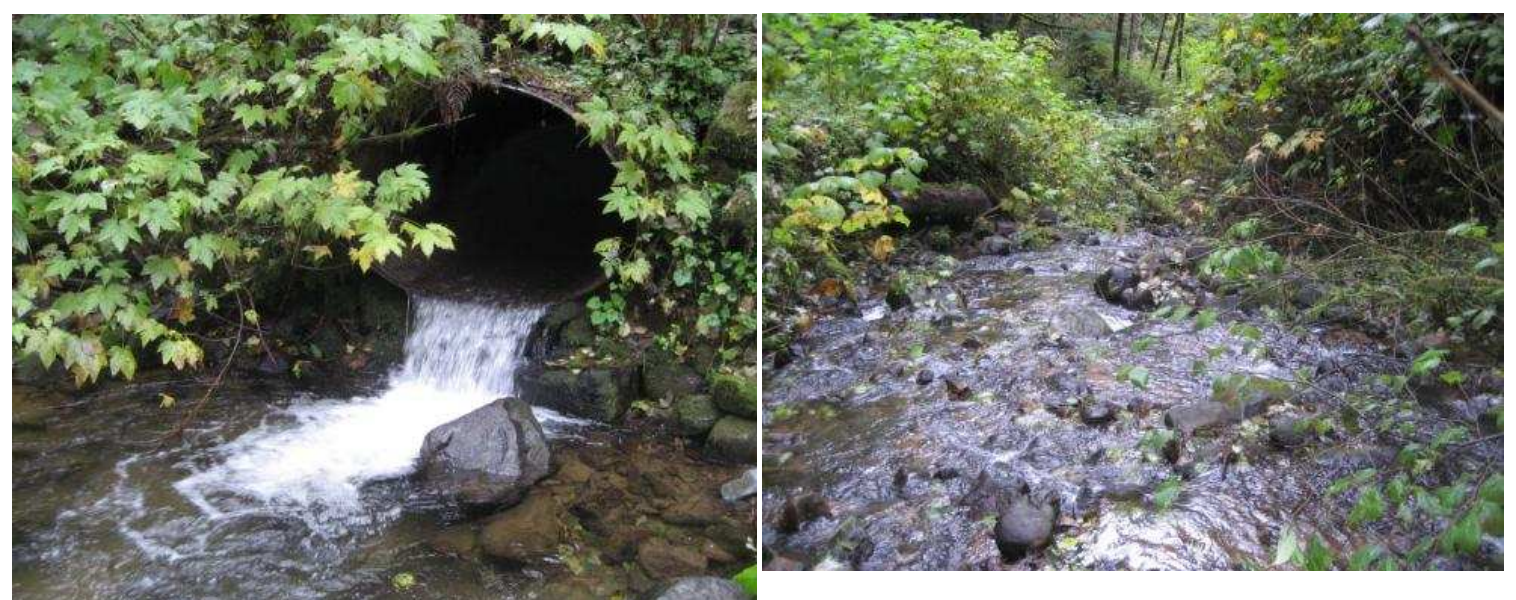

Site 10A Looking Upstream

Site 10A Looking Downstream
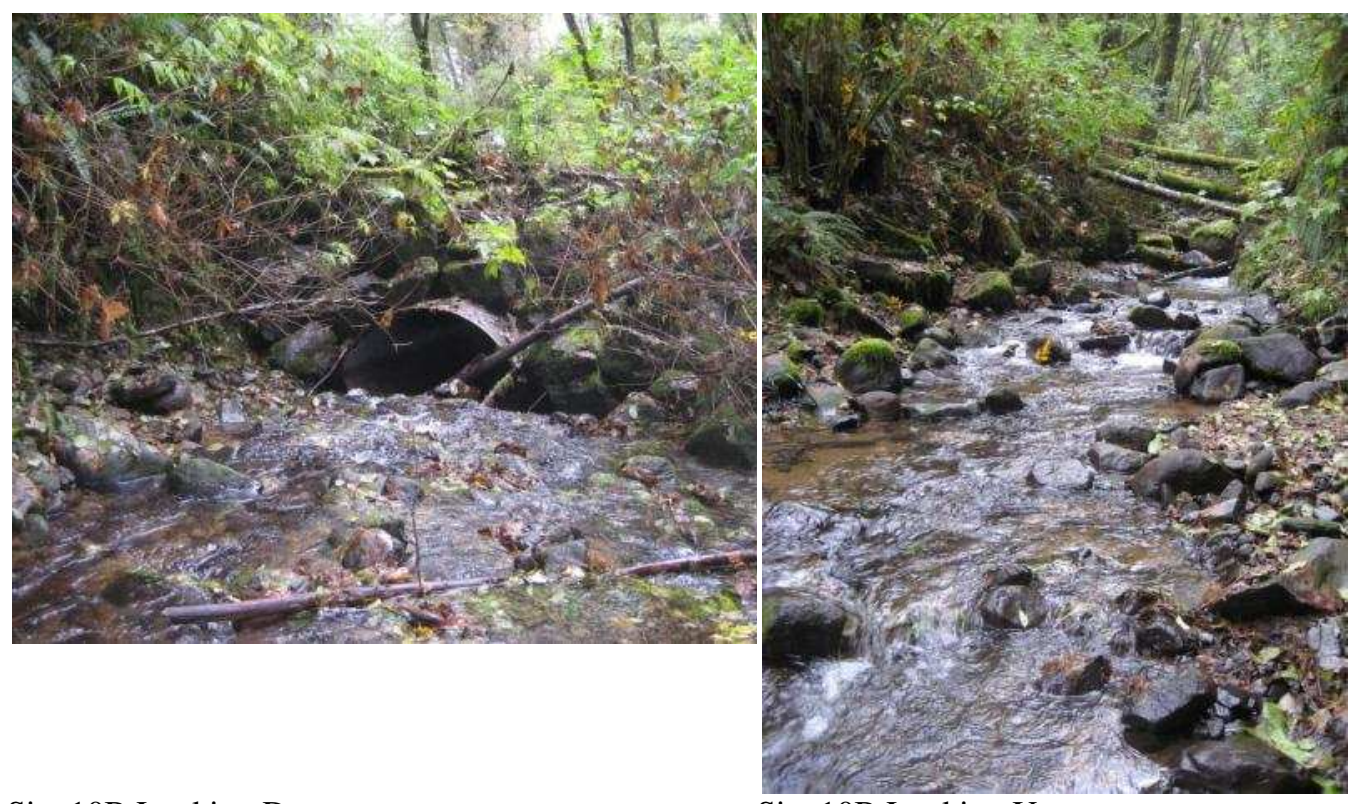

Site 10B Looking Downstream

Site 10B Looking Upstream 

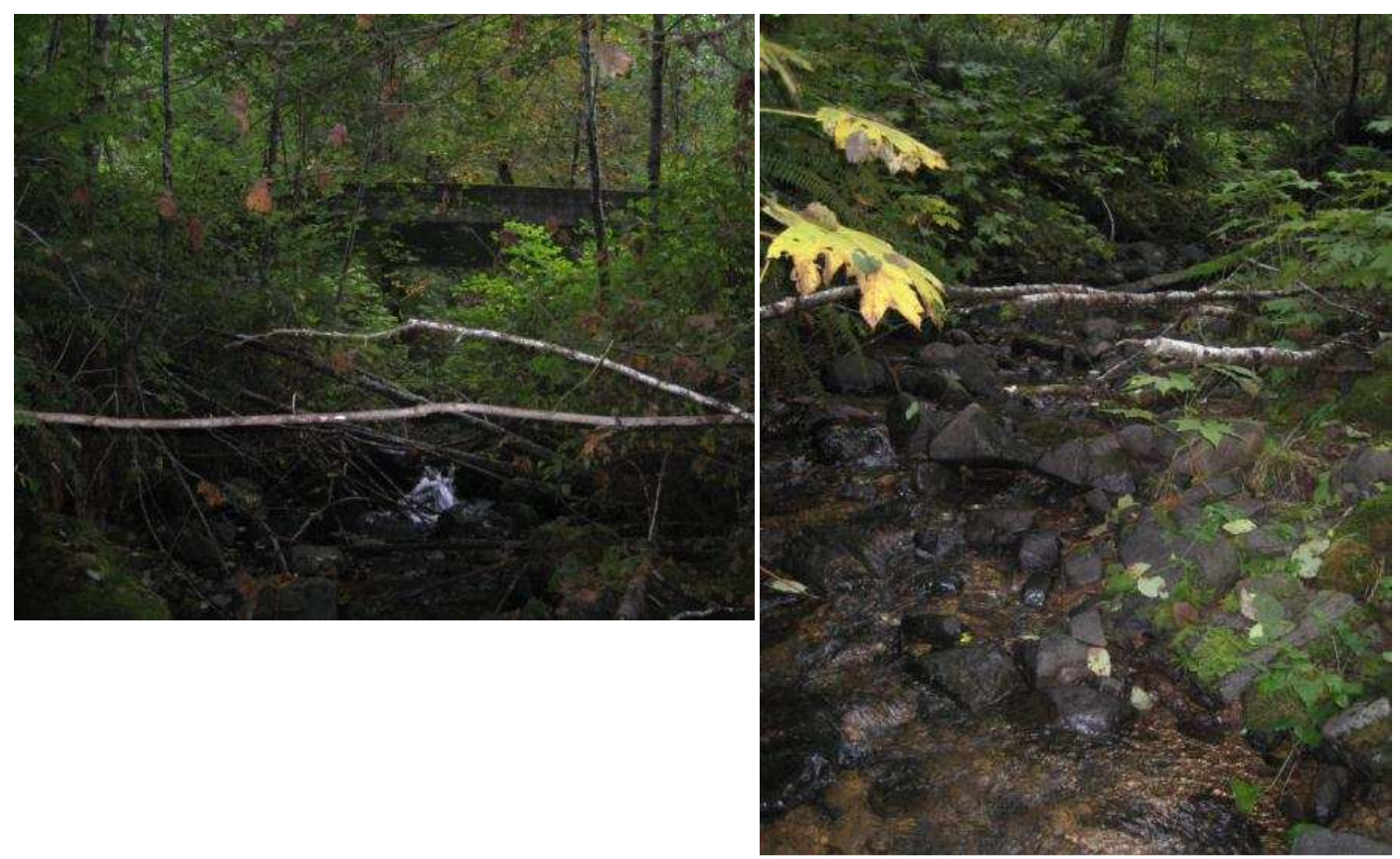

Site 11A Looking Upstream

Site 11A looking Upstream

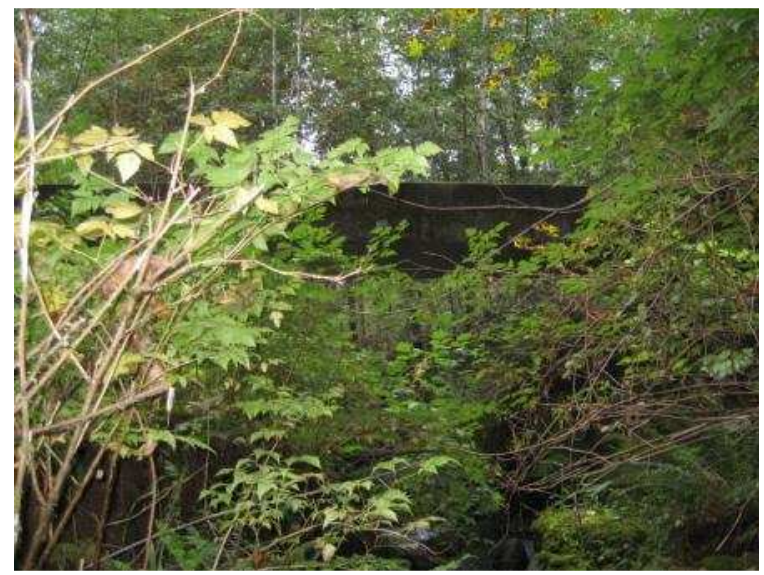

Site 11B Looking Downstream

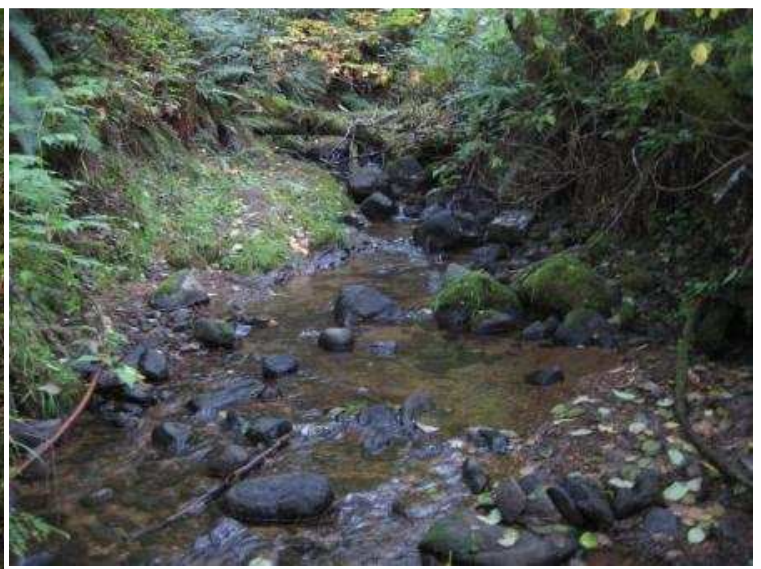

Site 11B Looking Upstream 

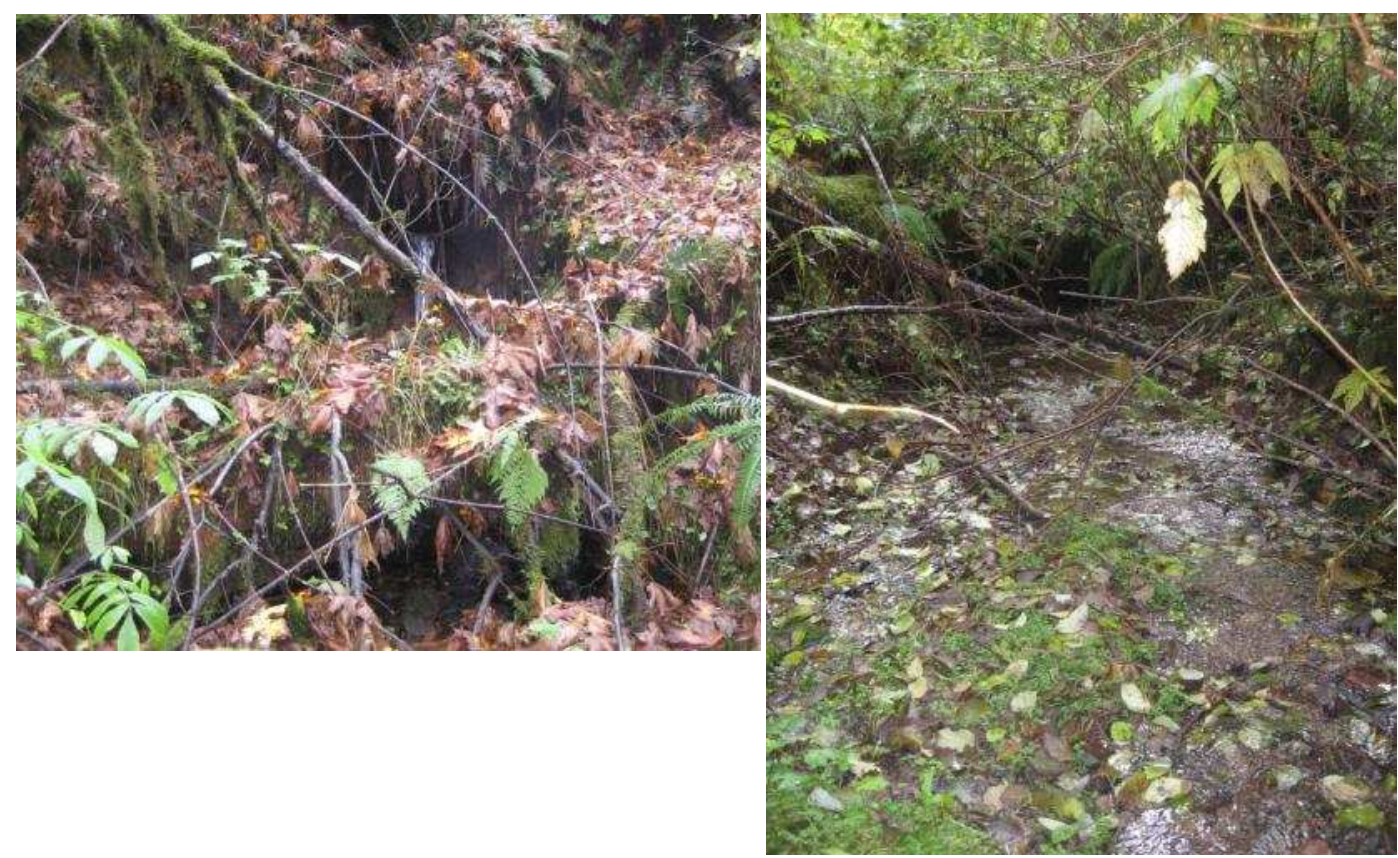

Site 12A Looking Upstream

Site 12A Looking Downstream

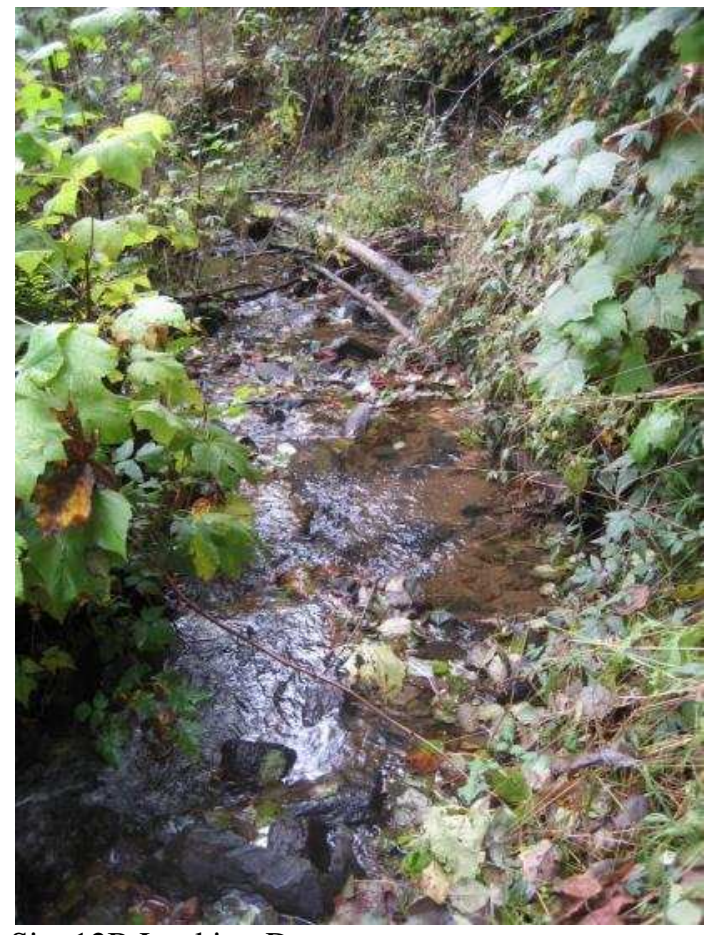

Site 12B Looking Downstream

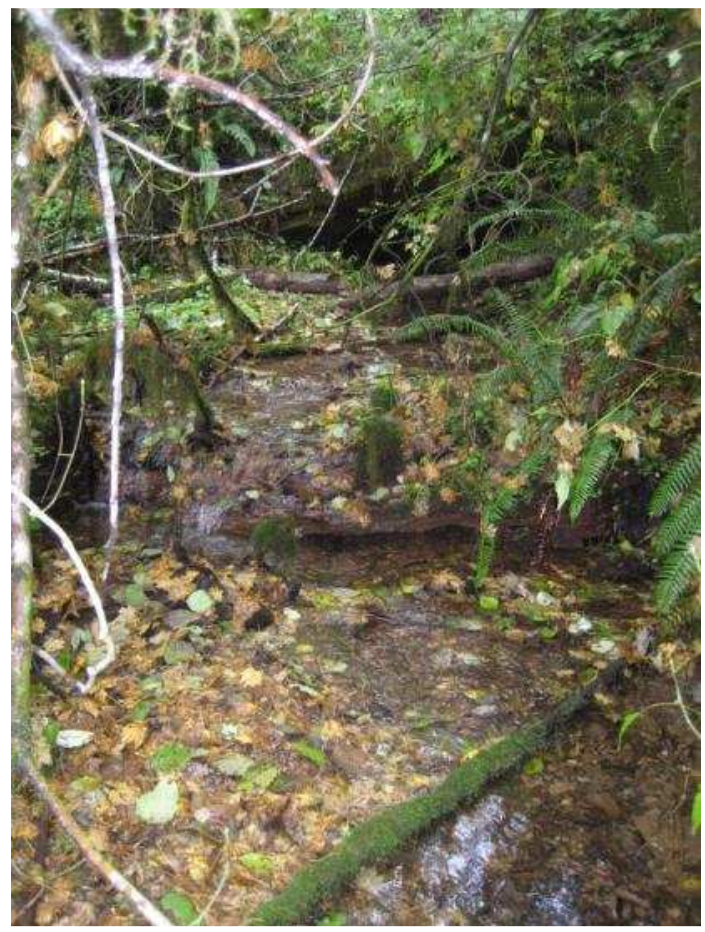

Site 12B Looking Upstream 

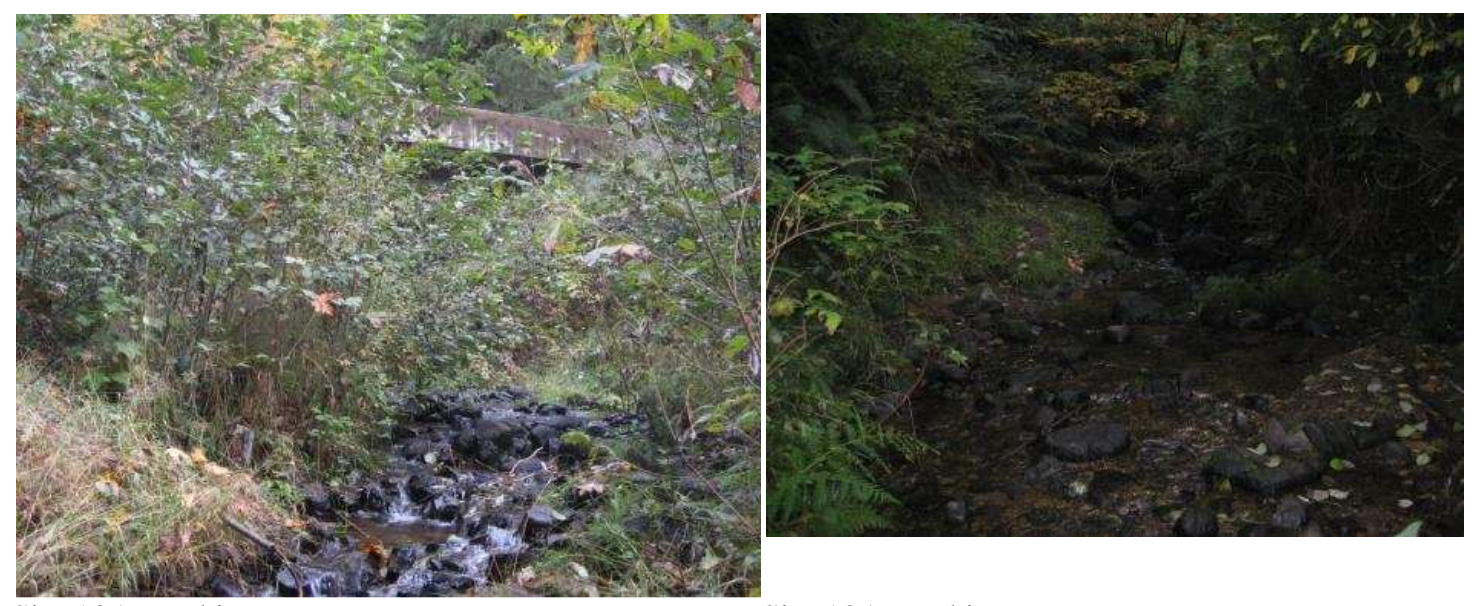

Site 13A Looking Upstream

Site 13A Looking Downstream

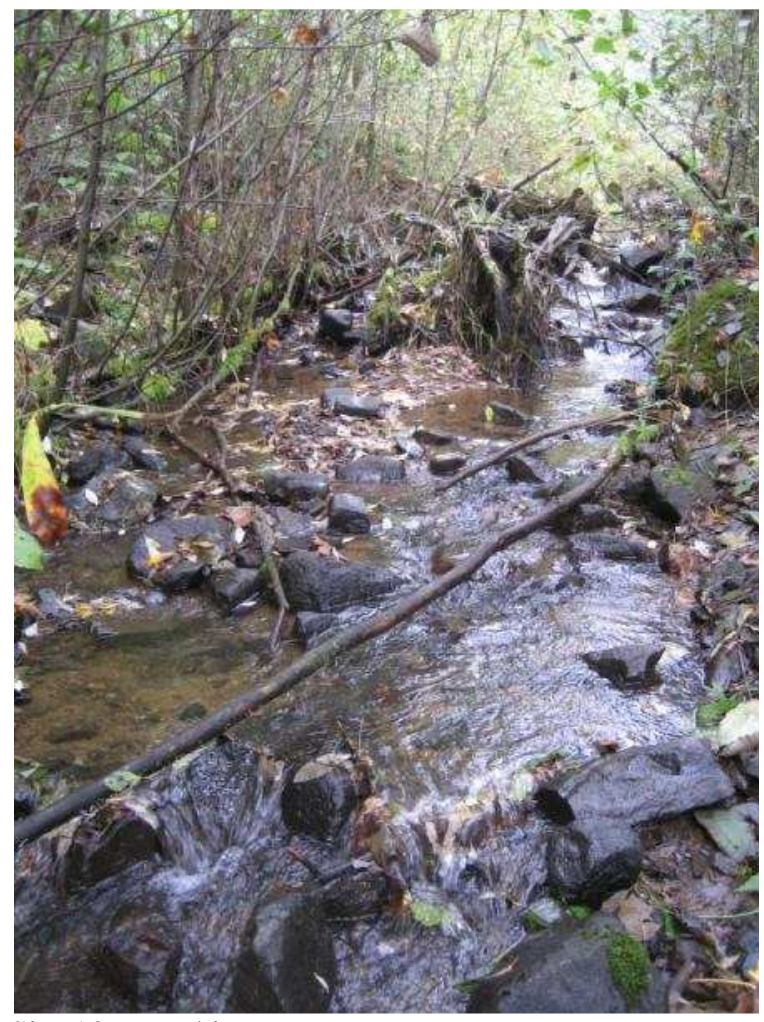

Site 13B Looking Upstream 

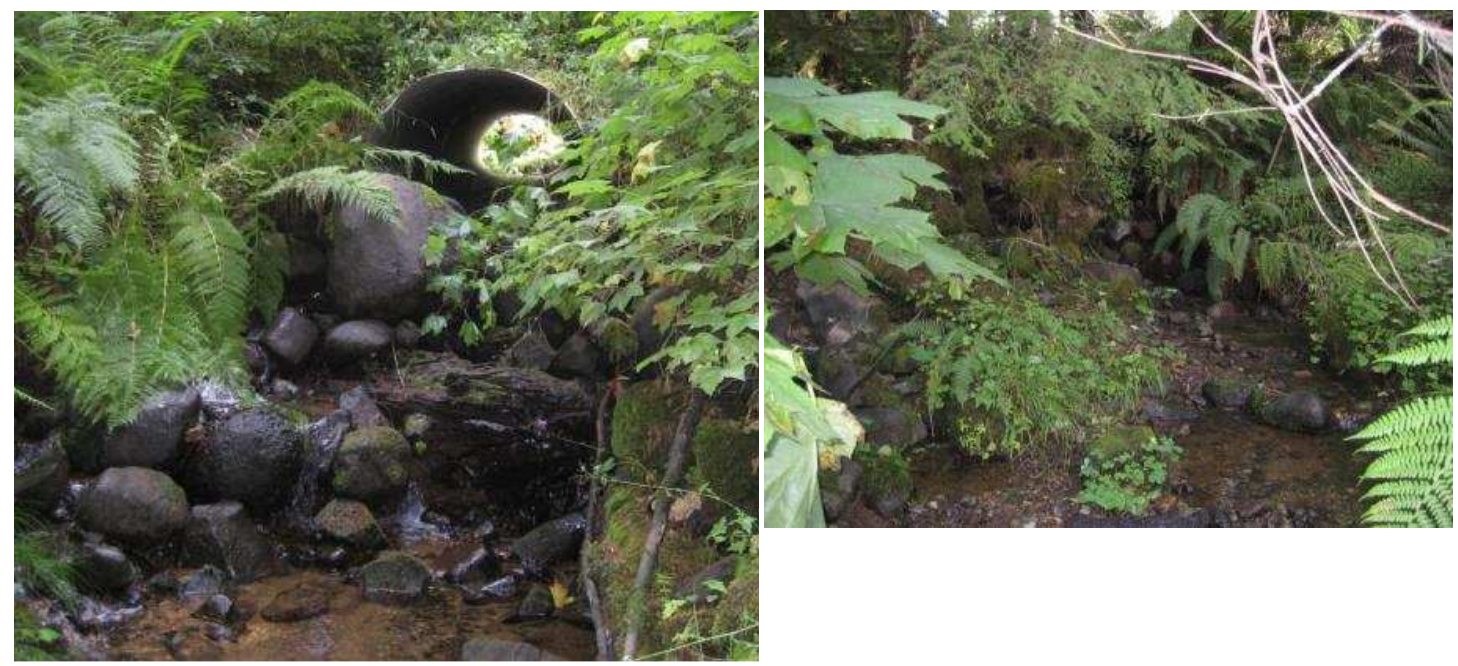

Site 14A Looking Upstream

Site 14A Looking Upstream

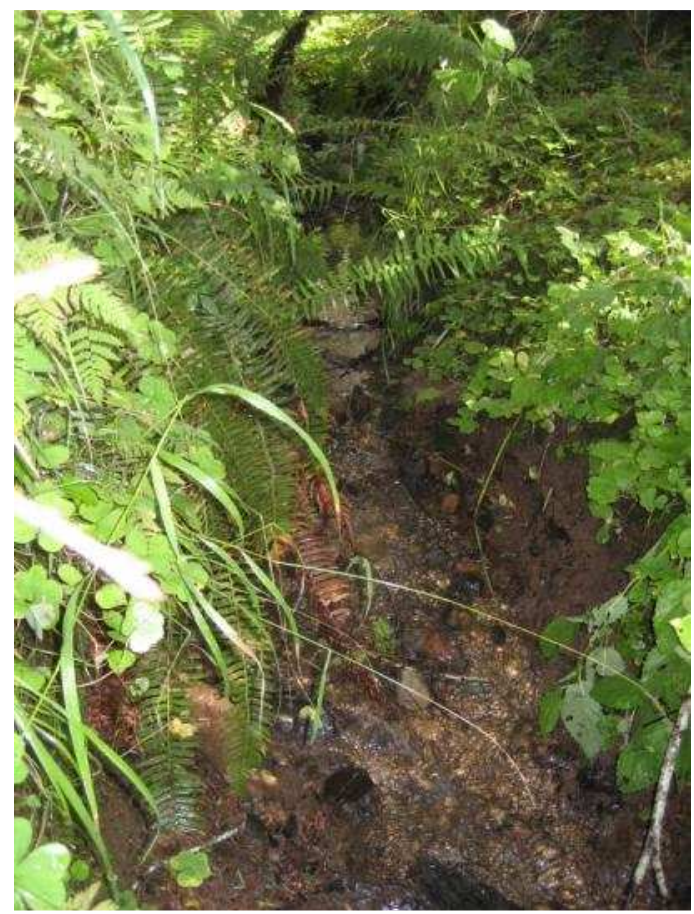

Site 14B Looking Upstream 
Appendix C. Detection results for each study species at sample reaches in the study area including abundance of individuals detected during each survey.

\begin{tabular}{|l|c|c|c|c|c|c|c|}
\hline \multicolumn{7}{|c|}{ Pacific Giant Salamander } \\
\hline $\begin{array}{c}\text { Sample } \\
\text { Reach }\end{array}$ & Survey 1 & Survey 2 & Survey 3 & Survey 4 & Survey 5 & Survey 6 & Total \\
\hline 1A & 0 & 0 & 0 & 1 & 11 & 4 & 16 \\
\hline 1B & 0 & 0 & 1 & 0 & 5 & 6 & 12 \\
\hline 2A & 2 & 0 & 0 & 0 & 0 & 0 & 2 \\
\hline 2B & 1 & 1 & 0 & 1 & 0 & 0 & 3 \\
\hline 3A & 3 & 0 & 6 & 9 & - & - & 18 \\
\hline 3B & 7 & 2 & 7 & 10 & 28 & - & 54 \\
\hline 4A & 0 & 1 & 0 & 1 & 1 & 0 & 3 \\
\hline 4B & 2 & 0 & 2 & 4 & 5 & 0 & 13 \\
\hline 5A & 0 & 0 & 0 & 0 & 1 & 11 & 12 \\
\hline 5B & 1 & 0 & 0 & 1 & 2 & 8 & 12 \\
\hline 6A & 3 & 2 & 0 & 4 & 10 & 7 & 26 \\
\hline 6B & 1 & 1 & 0 & 5 & 7 & 8 & 22 \\
\hline 7A & 2 & 0 & 0 & 0 & 0 & 0 & 2 \\
\hline 7B & 0 & 0 & 0 & 1 & 2 & 1 & 4 \\
\hline 8A & 0 & 0 & 0 & $1^{*}$ & 0 & 2 & 3 \\
\hline 8B & 0 & 0 & 0 & $3^{*}$ & 1 & $2^{*}$ & 6 \\
\hline 9A & 0 & 1 & 0 & 0 & 3 & 7 & 11 \\
\hline 9B & 1 & $2 *$ & 0 & $1^{*}$ & 3 & 4 & 11 \\
\hline 10A & 2 & 1 & 0 & 3 & 11 & 10 & 27 \\
\hline 10B & 2 & 0 & 1 & 6 & 12 & 0 & 21 \\
\hline 11A & - & - & - & 1 & 0 & 1 & 2 \\
\hline 11B & - & - & - & 0 & 1 & 1 & 2 \\
\hline 12A & - & - & - & 0 & 1 & 3 & 4 \\
\hline 12B & - & - & - & 0 & 6 & $7 *$ & 13 \\
\hline 13A & - & - & - & 4 & 0 & 0 & 4 \\
\hline 13B & - & - & - & 4 & 0 & 0 & 4 \\
\hline 14A & - & - & - & 3 & 7 & 0 & 10 \\
\hline 14B & - & - & - & 0 & 0 & 0 & 0 \\
\hline Strat & - & 0 & 0 & 0 & 0 & \\
\hline
\end{tabular}

*Stream reaches where at least one neotenic salamander was detected during the survey. 


\begin{tabular}{|l|c|c|c|c|c|c|c|}
\hline \multicolumn{7}{|l|}{ Coastal Tailed Frog } \\
\hline $\begin{array}{l}\text { Stream } \\
\text { Reach }\end{array}$ & Survey 1 & Survey 2 & Survey 3 & Survey 4 & Survey 5 & Survey 6 & Total \\
\hline 1A & 0 & 0 & 0 & 0 & 0 & 0 & 0 \\
\hline 1B & 0 & 0 & 0 & 0 & 2 & 0 & 2 \\
\hline 2A & 0 & 0 & 0 & 0 & 0 & 0 & 0 \\
\hline 2B & 0 & 0 & 0 & 0 & 0 & 0 & 0 \\
\hline 3A & 17 & 2 & 2 & 15 & - & - & 36 \\
\hline 3B & 2 & 0 & 0 & 3 & 15 & - & 20 \\
\hline 4A & 0 & 0 & 0 & 0 & 0 & 0 & 0 \\
\hline 4B & 0 & 0 & 0 & 0 & 0 & 0 & 0 \\
\hline 5A & 0 & 1 & 0 & 0 & 2 & 0 & 3 \\
\hline 5B & 1 & 1 & 0 & 0 & 3 & 2 & 7 \\
\hline 6A & 0 & 0 & 0 & 2 & 4 & 0 & 6 \\
\hline 6B & 0 & 0 & 0 & 1 & 1 & 0 & 2 \\
\hline 7A & 0 & 0 & 0 & 0 & 1 & 0 & 1 \\
\hline 7B & 0 & 0 & 0 & 0 & 0 & 0 & 0 \\
\hline 8A & 0 & 0 & 0 & 2 & 0 & 0 & 2 \\
\hline 8B & 0 & 0 & 0 & 0 & 0 & 0 & 0 \\
\hline 9A & 0 & 0 & 0 & 0 & 0 & 0 & 0 \\
\hline 9B & 0 & 0 & 0 & 0 & 1 & 0 & 1 \\
\hline 10A & 0 & 0 & 0 & 10 & 0 & 1 & 11 \\
\hline 10B & 0 & 1 & 0 & 10 & 0 & 2 & 13 \\
\hline 11A & - & - & - & 1 & 1 & 1 & 3 \\
\hline 11B & - & - & - & 2 & 1 & 0 & 3 \\
\hline 12A & - & - & - & 2 & 0 & 0 & 2 \\
\hline 12B & - & - & - & 0 & 0 & 0 & 0 \\
\hline 13A & - & - & - & 0 & 1 & 0 & 1 \\
\hline 13B & - & - & - & 0 & 1 & 0 & 1 \\
\hline 14A & - & - & - & 7 & 1 & 0 & 8 \\
\hline 14B & - & - & - & 10 & 2 & 0 & 12 \\
\hline
\end{tabular}




\begin{tabular}{|c|c|c|c|c|c|c|c|}
\hline \multicolumn{7}{|c|}{ Columbia Torrent Salamander } \\
\hline Site & Survey 1 & Survey 2 & Survey 3 & Survey 4 & Survey 5 & Survey 6 & Total \\
\hline 1A & 0 & 0 & 0 & 0 & 0 & 0 & 0 \\
\hline 1B & 0 & 0 & 0 & 0 & 0 & 0 & 0 \\
\hline 2A & 0 & 0 & 0 & 0 & 0 & 0 & 0 \\
\hline 2B & 0 & 0 & 0 & 0 & 0 & 0 & 0 \\
\hline 3A & 0 & 0 & 0 & 1 & - & - & 1 \\
\hline 3B & 0 & 0 & 1 & 0 & 1 & - & 2 \\
\hline 4A & 0 & 0 & 0 & 0 & 0 & 0 & 0 \\
\hline 4B & 0 & 0 & 0 & 0 & 0 & 0 & 0 \\
\hline 5A & 0 & 0 & 0 & 0 & 0 & 0 & 0 \\
\hline 5B & 0 & 0 & 0 & 0 & 0 & 0 & 0 \\
\hline 6A & 0 & 0 & 0 & 0 & 0 & 0 & 0 \\
\hline 6B & 0 & 0 & 0 & 0 & 0 & 0 & 0 \\
\hline 7A & 0 & 0 & 0 & 0 & 0 & 0 & 0 \\
\hline 7B & 0 & 0 & 0 & 0 & 0 & 0 & 0 \\
\hline 8A & 0 & 0 & 0 & 0 & 0 & 0 & 0 \\
\hline 8B & 0 & 0 & 0 & 0 & 0 & 0 & 0 \\
\hline 9A & 0 & 0 & 0 & 0 & 0 & 0 & 0 \\
\hline 9B & 0 & 0 & 0 & 0 & 0 & 0 & 0 \\
\hline 10A & 0 & 0 & 0 & 0 & 0 & 0 & 0 \\
\hline 10B & 0 & 0 & 0 & 0 & 0 & 0 & 0 \\
\hline 11A & - & - & - & 0 & 0 & 0 & 0 \\
\hline 11B & - & - & - & 0 & 0 & 0 & 0 \\
\hline 12A & - & - & - & 0 & 0 & 0 & 0 \\
\hline 12B & - & - & - & 0 & 0 & 0 & 0 \\
\hline 13A & - & - & - & 0 & 0 & 0 & 0 \\
\hline 13B & - & - & - & 0 & 0 & 0 & 0 \\
\hline 14A & - & - & - & 0 & 0 & 0 & 0 \\
\hline 14B & - & - & - & 0 & 0 & 0 & 0 \\
\hline
\end{tabular}


Appendix D: Covariance Matrices for habitat and sampling parameters. Covariance was determined to be positive when values were greater than 0.5 and negative when values were less than $\mathbf{- 0 . 5}$. Values of all non-binomial covariates have been transformed using z-scores prior to evaluation for covariance.

\begin{tabular}{|l|l|l|l|l|l|l|l|l|l|l|l|l|l|l|l|l|}
\hline & Crayfish & Fish & Long & Lat & Elev & Type & $\begin{array}{c}\text { Mat- } \\
\text { erial }\end{array}$ & Diam & Length & $\begin{array}{c}\text { Rip- } \\
\text { arian }\end{array}$ & $\begin{array}{c}\text { Tree } \\
\text { Cover }\end{array}$ & $\begin{array}{c}\text { Grad } \\
\text {-ient }\end{array}$ & $\begin{array}{c}\text { Bank full } \\
\text { Width }\end{array}$ & $\begin{array}{c}\text { Flood- } \\
\text { plain } \\
\text { Width }\end{array}$ & \begin{tabular}{c} 
Confine \\
\hline Crayfish
\end{tabular} \\
\hline
\end{tabular}




\begin{tabular}{|c|c|c|c|c|c|c|c|c|c|c|c|c|c|c|}
\hline \multicolumn{15}{|c|}{ Habitat Covariates (cont.) } \\
\hline & Pools & Substrate & $\begin{array}{l}\text { Pebble } \\
\text { Count }\end{array}$ & $\begin{array}{l}\text { Small } \\
\text { LWD }\end{array}$ & $\begin{array}{l}\text { Med } \\
\text { LWD }\end{array}$ & $\begin{array}{c}\text { Lrg } \\
\text { LWD }\end{array}$ & TDS & Sal & DO & pH & Disturb & $\begin{array}{c}\text { Up/ } \\
\text { Down }\end{array}$ & $\begin{array}{c}\text { Fish } \\
\text { Passage }\end{array}$ & Constriction \\
\hline Crayfish & & + & & & & & & & & - & & & & \\
\hline Fish & & & & & & & & & & & & & & \\
\hline Long & & - & & & & & & & & & & & & \\
\hline Lat & & & & & & & & & & & & & & \\
\hline Elev & & - & & & & & - & - & & + & & & & \\
\hline Type & & + & & & & & & & & & & & & \\
\hline Material & & & & & & & + & + & & & & & & - \\
\hline Diam & & & & & & & & + & & & & & & - \\
\hline Length & & & & & & & & & & & & & & \\
\hline Riparian & & & & & & & & & & & & & & \\
\hline Tree Cover & & & & & & & & & & & & & & \\
\hline Gradient & & & & & & & & & & & & & & \\
\hline $\begin{array}{l}\text { Bank full } \\
\text { Width }\end{array}$ & & & & & & & & & + & & & & & \\
\hline $\begin{array}{l}\text { Floodplain } \\
\text { Width } \\
\end{array}$ & & & & & & & & & & & & & & \\
\hline Confine & + & & & & & & & & + & & & & & \\
\hline Pools & + & & & & & & & & & & & & & \\
\hline Substrate & & + & & & & & & & & & & & & \\
\hline $\begin{array}{l}\text { Pebble } \\
\text { Count }\end{array}$ & & & + & & & & & & & & & & & \\
\hline Small LWD & & & & + & & & & & & & & & & \\
\hline Med LWD & & & & & + & & & & & & & & & \\
\hline Lrg LWD & & & & & + & + & & & & & & & & \\
\hline TDS & & & & & & & + & + & & & & & & - \\
\hline$\underline{\text { Sal }}$ & & & & & & & + & + & & & & & & - \\
\hline DO & & & & & & & & & + & & & & & \\
\hline $\mathrm{pH}$ & & & & & & & & & & + & & & & \\
\hline Disturbance & & & & & & & & & & & + & & & \\
\hline Up/ Down & & & & & & & & & & & & + & & \\
\hline Fish Pass & & & & & & & & & & & & & + & \\
\hline Constriction & & & & & & & - & - & & & & & & + \\
\hline
\end{tabular}




\begin{tabular}{|l|c|c|c|c|c|}
\hline \multicolumn{7}{|c|}{ Sampling Covariates } \\
\hline & Julian Date & Weather & Stream Flow & Air Temp & Stream Temp \\
\hline Julian1 & + & & & & \\
\hline Weather & & + & & & \\
\hline $\begin{array}{l}\text { Stream } \\
\text { Flow }\end{array}$ & & & + & & \\
\hline Air Temp & & & & + & \\
\hline $\begin{array}{l}\text { Stream } \\
\text { Temp }\end{array}$ & & & & & + \\
\hline
\end{tabular}




\section{Appendix E. Highest weighted models for the Pacific giant salamander 2011 dataset.}

Rankings of top ranked models a using Akaike's Information Criterion (AIC) with a small sample size correction (AICc) in program PRESENCE to explain the proportion of sites occupied $(\psi)$ by Pacific giant salamanders during the 2011 sampling season. QuasiAICc (AICc corrected with a variance inflation factor), the relative differences in QAICc ( $\triangle$ QAICc), QAICc model weights $\left(\mathrm{w}_{\mathrm{i}}\right)$, model likelihood, and number of parameters $(\mathrm{K})$ are given for each model.

\begin{tabular}{lcccc}
\hline \multicolumn{1}{c}{ Model } & QAICc & $\Delta$ QAICc & $\mathrm{w}_{\mathrm{i}}$ & $\mathrm{K}$ \\
\hline$\psi($ CFPres), $\mathrm{p}()$. & 95.35 & 0.3785 & 0.3785 & 2 \\
$\psi($ CFPres, FPres(.) & 96.04 & 0.2681 & 0.2681 & 3 \\
$\psi($ CFPres, Fpres, Constriction), $\mathrm{p}()$. & 97.19 & 0.1508 & 0.1508 & 4 \\
$\psi($ CFPres, Constriction), $\mathrm{p}()$. & 97.3 & 0.1428 & 0.1428 & 3 \\
\hline
\end{tabular}




\section{Appendix F. Highest weighted models for the coastal tailed frog 2010/2011 dataset.}

Rankings of top ranked models a using Akaike's Information Criterion (AIC) with a small sample size correction (AICc) in program PRESENCE to explain the proportion of sites occupied $(\psi)$ by coastal tailed frogs during the 2010 and 2011 sampling seasons.

Quasi-AICc (AICc corrected with a variance inflation factor), the relative differences in QAICc ( $\triangle$ QAICc), QAICc model weights $\left(\mathrm{w}_{\mathrm{i}}\right)$, model likelihood, and number of parameters (K) are given for each model.

\begin{tabular}{|c|c|c|c|c|}
\hline Model & QAICc & $\triangle \mathrm{QAICc}$ & $\mathrm{w}_{\mathrm{i}}$ & $\mathrm{K}$ \\
\hline$\psi(\mathrm{DO}), \mathrm{p}($ Weather, StreamTemp) & 106.76 & 0 & 0.2406 & 3 \\
\hline $\begin{array}{l}\psi(\text { Confinement }), \mathrm{p}(\text { Weather, } \\
\text { StreamTemp) }\end{array}$ & 107.71 & 0.95 & 0.1496 & 3 \\
\hline $\begin{array}{l}\psi \text { (Long, Confinement), } \mathrm{p} \text { (Weather, } \\
\text { StreamTemp) }\end{array}$ & 108.15 & 1.26 & 0.1282 & 4 \\
\hline $\begin{array}{l}\psi(\text { Long, DO), } \mathrm{p}(\text { Weather, } \\
\text { StreamTemp) }\end{array}$ & 108.48 & 1.59 & 0.1087 & 4 \\
\hline
\end{tabular}




\section{Appendix G. Highest weighted models for the coastal tailed frog 2011 dataset.}

Rankings of top ranked models a using Akaike's Information Criterion (AIC) with a small sample size correction (AICc) in program PRESENCE to explain the proportion of sites occupied $(\psi)$ by coastal tailed frogs during the 2011 sampling season. AICc, the relative differences in AICc $(\triangle \mathrm{AICc})$, AICc model weights $\left(\mathrm{w}_{\mathrm{i}}\right)$, model likelihood, and number of parameters $(\mathrm{K})$ are given for each model.

\begin{tabular}{lcccc}
\multicolumn{1}{c}{ Model } & AICc & $\Delta$ AICc & $\mathrm{w}_{\mathrm{i}}$ & $\mathrm{K}$ \\
\hline$\psi($ CFPres, DO),p(JDate) & 102.63 & 0 & 0.3814 & 3 \\
$\psi($ CFPRes, DO),p(JDate, & 103.65 & 1.02 & 0.229 & 3 \\
$\begin{array}{l}\text { StreamTemp) } \\
\psi(\text { CFPres, DO),p(Jdate, }\end{array}$ & 104.87 & 2.24 & 0.1244 & 4 \\
\begin{tabular}{l} 
StreamTemp) \\
\hline
\end{tabular} & & & & \\
\hline
\end{tabular}




\section{Appendix H. Highest weighted models for the Columbia torrent salamander 2010/2011 dataset.}

Rankings of top ranked models a using Akaike's Information Criterion (AIC) with a small sample size correction (AICc) in program PRESENCE to explain the proportion of sites occupied $(\psi)$ by Columbia torrent salamanders during the 2010 and 2011 sampling seasons. AICc, the relative differences in AICc $(\triangle \mathrm{AICc}), \mathrm{AICc}$ model weights $\left(\mathrm{w}_{\mathrm{i}}\right)$, model likelihood, and number of parameters $(\mathrm{K})$ are given for each model.

\begin{tabular}{lcccc}
\multicolumn{1}{c}{ Model } & AICc & $\Delta$ AICc & $\mathrm{w}_{\mathrm{i}}$ & $\mathrm{K}$ \\
\hline$\psi$ (FPres, FishPass),p(JDate) & 26.23 & 0 & 0.1399 & 3 \\
$\psi$ (CFPres, FPres),p(JDate) & 26.24 & 0.01 & 0.1392 & 3 \\
$\psi$ (FPres), (JDate) & 26.39 & 0.16 & 0.1291 & 2 \\
$\psi$ (CFPres, FishPass),p(JDate) & 26.75 & 0.52 & 0.1078 & 3 \\
$\psi($ CFPres),p(JDate) & 27.13 & 0.9 & 0.0892 & 2 \\
$\psi$ (CFPres, FPres, FishPass),p(JDate) & 27.33 & 1.1 & 0.0807 & 4 \\
\hline
\end{tabular}




\section{Appendix I. Linear regression analysis results for habitat covariates presumably linked to percent dissolved oxygen concentration in streams.}
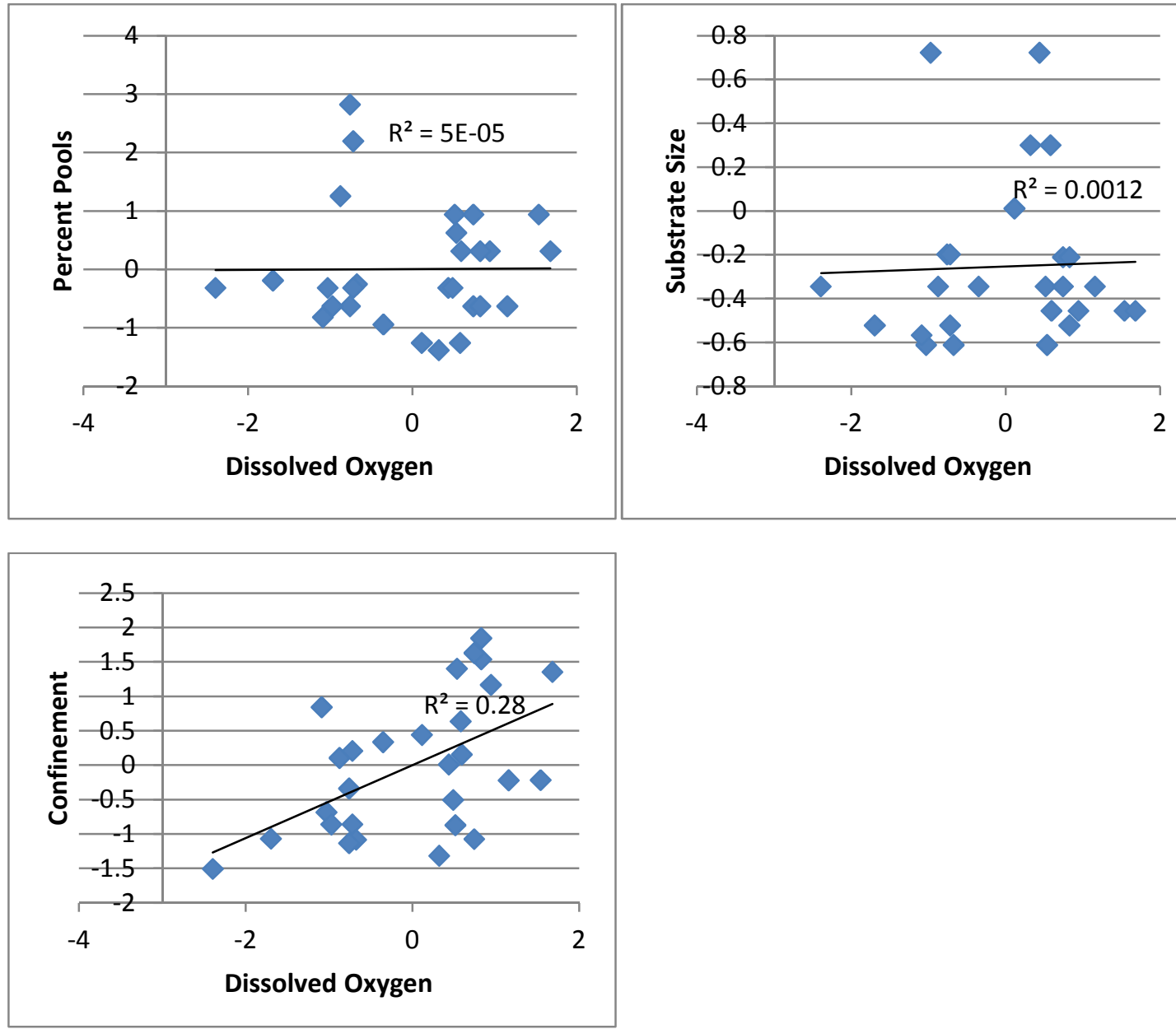

Figure I-1. Linear regression plots for dissolved oxygen concentrations compared to percent pools, substrate size, and channel confinement associated with in-stream habitat. Values for dissolved oxygen, percent pools, substrate size, and confinement have all been transformed using z-scores.

Table I-1. Linear regression analysis results evaluating dissolved oxygen relative to percent pools, substrate size, and confinement. Only the relationship between dissolved oxygen and confinement was higher than that corresponding to the $95 \%$ significance level, and thus provides enough evidence to reject the null hypothesis that the variables are independent of each other. Values for dissolved oxygen, percent pools, substrate size, and confinement have all been transformed using z-scores

\begin{tabular}{|l|l|l|l|}
\hline & $\begin{array}{l}\text { Multiple R- } \\
\text { squared }\end{array}$ & $\begin{array}{l}\text { Adjusted R- } \\
\text { squared }\end{array}$ & p-value \\
\hline Dissolved Oxygen & 0.0001 & -0.0384 & $\mathbf{0 . 9 5 8 8}$ \\
\hline \% Pools & 0.0006 & -0.0379 & $\mathbf{0 . 9 0 3}$ \\
\hline Substrate Size & 0.2781 & 0.2504 & $\mathbf{0 . 0 0 4} *$ \\
\hline Confinement & 0.271 &
\end{tabular}

